\title{
Functional correlates of the a-adducin polymorphism
}

Citation for published version (APA):

Beeks, E. (2007). Functional correlates of the a-adducin polymorphism. [Doctoral Thesis, Maastricht University]. Datawyse / Universitaire Pers Maastricht. https://doi.org/10.26481/dis.20070706eb

Document status and date:

Published: 01/01/2007

DOI:

10.26481/dis.20070706eb

Document Version:

Publisher's PDF, also known as Version of record

\section{Please check the document version of this publication:}

- A submitted manuscript is the version of the article upon submission and before peer-review. There can be important differences between the submitted version and the official published version of record.

People interested in the research are advised to contact the author for the final version of the publication, or visit the DOI to the publisher's website.

- The final author version and the galley proof are versions of the publication after peer review.

- The final published version features the final layout of the paper including the volume, issue and page numbers.

Link to publication

\footnotetext{
General rights rights.

- You may freely distribute the URL identifying the publication in the public portal. please follow below link for the End User Agreement:

www.umlib.nl/taverne-license

Take down policy

If you believe that this document breaches copyright please contact us at:

repository@maastrichtuniversity.nl

providing details and we will investigate your claim.
}

Copyright and moral rights for the publications made accessible in the public portal are retained by the authors and/or other copyright owners and it is a condition of accessing publications that users recognise and abide by the legal requirements associated with these

- Users may download and print one copy of any publication from the public portal for the purpose of private study or research.

- You may not further distribute the material or use it for any profit-making activity or commercial gain

If the publication is distributed under the terms of Article $25 \mathrm{fa}$ of the Dutch Copyright Act, indicated by the "Taverne" license above, 
Functional correlates of the $\alpha$-adducin polymorphism

Esther Beeks 
(c) E. Beeks, Maastricht 2007

ISBN: 978.90 .5278 .635 .3

Layout: Tiny Wouters

Cover: Dik Versteeg

Production: Datawyse / Universitaire Pers Maastricht

Printing of this thesis was financially supported by sanofi-aventis Netherlands B.V. and sigma-tau B.V. 


\title{
Functional correlates of the $\alpha$-adducin polymorphism
}

\author{
Proefschrift
}

ter verkrijging van de graad van doctor aan de Universiteit Maastricht,

op gezag van de Rector Magnificus, Prof. mr. G.P.M.F. Mols, volgens het besluit van het College van Decanen,

in het openbaar te verdedigen

op vrijdag 6 juli 2007 om 14.00 uur

door

Esther Beeks

UMi 


\section{Promotor}

Prof. dr. P.W. de Leeuw

\section{Copromotores}

Dr. M.M. van der Klauw

Dr. A.A. Kroon

\section{Beoordelingscommissie}

Prof. dr. M. Daeman, voorzitter

Prof. di. G. Eianchi, Ospedale San Raffaele, Mian, Italy

Prof. dr. A. de Boer, Universiteit Utrecht

Prof. dr. M. van Dielien-Visser

Prof. dr. Y. Pinto

Financial support by the Netherlands Heart Foundation for the publication of this thesis is gratefully acknowledged. The study described in this thesis was supported by a grant of the Netherlands Heart Foundation (NHF-2002B205). 


\section{Contents}

$\begin{array}{lll}\text { Chapter } 1 & \text { Introduction } & 7\end{array}$

Chapter 2 Genetic predisposition to salt-sensitive hypertension.

A systematic review

Chapter 3 Long-term follow-up of renal hemodynamics in essential hypertension

Chapter 4 Association between the $\alpha$-adducin Gly460Trp polymorphism 47 and systolic blood pressure in familial combined hyperlipidemia

Chapter $5 \alpha$-Adducin Gly460Trp polymorphism and renal hemodynamics

59 in essential hypertension

Chapter 6 Comparison of two sodium loading techniques in hypertensive and normotensive subjects

Chapter 7 Exaggerated natriuresis following hypertonic saline loading in subjects with the Trp460Trp variant of the $\alpha$-adducin gene

Chapter 8 Response to dietary sodium loading in subjects with variants of the $\alpha$-adducin Gly460Trp polymorphism

Chapter 9 General discussion

Summary

Samenvatting

Dankwoord

Curriculum vitae 


\section{Chapter 1}

Introduction

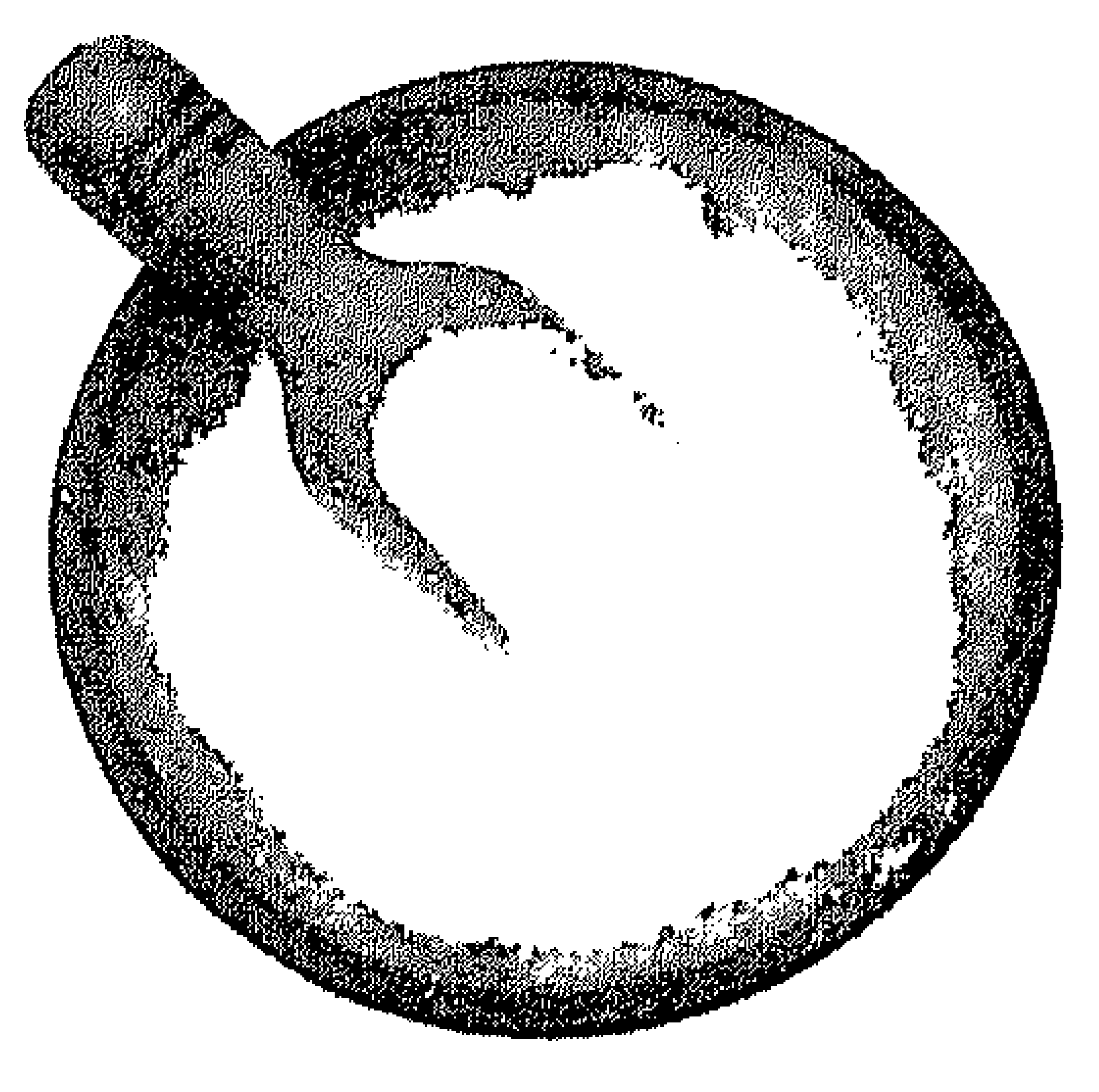




\section{Introduction}

Essential hypertension refers to a lasting increase in blood pressure with heterogeneous genetic and environmental causes. Among the latter, dietary sodium has been generally accepted as an important contributor to hypertension. However, blood pressure responses to a high salt intake, or in other words the degree of salt sensitivity, varies considerably between individuals ${ }^{1,2}$, and it has been estimated that about $50 \%$ of hypertensive subjects are more or less sodium-sensitive ${ }^{1}$. Blood pressure of sodiumsensitive individuals rises and falls with increased and decreased sodium consumption respectively, whereas sodium-resistant individuals show little or no change in blood pressure or sometimes even a reversed response pattern. About 20 to 25 years ago the first studies were published on salt sensitivity ${ }^{3-6}$. To this very day, considerable heterogeneity exists in methods of salt sensitivity testing. Protocols vary in amount of salt administered, route of administration (oral or intravenous), duration of the intervention, and in the case of oral administration the order of the sodium diets. While in some studies salt sensitivity was treated as a dichotomous trait, others focused on blood pressure as a continuous variable. Despite these differences in definitions and protocols, several findings were consistently observed: hypertensive patients are more frequently salt-sensitive than normal individuals ${ }^{1}$, the prevalence of salt sensitivity is increased in older individuals ${ }^{7}$, black population ${ }^{8}$, and patients with low-renin hypertension such as diabetics ${ }^{6}$.

Both enhanced sodium reabsorption and altered activity of neurohormonal systems are thought to play a part in the process of salt sensitivity. During salt loading, neural and endocrine systems show adaptive responses to maintain homeostasis of body fluid volumes and blood pressure. These adaptive responses include suppression of the renin-angiotensin-aldosterone axis $^{3,4,9}$, and stimulation of natriuretic peptides ${ }^{10}$.

\section{Genetics of (sodium-sensitive) hypertension}

In the past, it has become clear that hypertension is a disorder that is found in families. In the last years, monogenic forms of hypertension such as Liddle syndrome and glucocorticoid-remediable aldosteronism have been discovered ${ }^{11-13}$. In both disorders, an increased tubular sodium reabsorption by the distal nephron has been documented, leading to a salt-sensitive form of hypertension and confirming the importance of an altered renal sodium handling in the development of hypertension.

Nowadays, many genes are now thought to play a part in the development of hypertension, possibly in combination with environmental factors (Figure $1.1)^{14-16}$. In the literature, variants of genes of the renin-angiotensin system ${ }^{17,18}$ 
and mutations in the so-called 'sodium-sensitive' genes like $\alpha$-adducin and $G$ protein $\beta 3$ subunit are associated with hypertension ${ }^{19,20}$. Despite all these association studies, with the exception of $\alpha$-adducin, results have not been consistent.

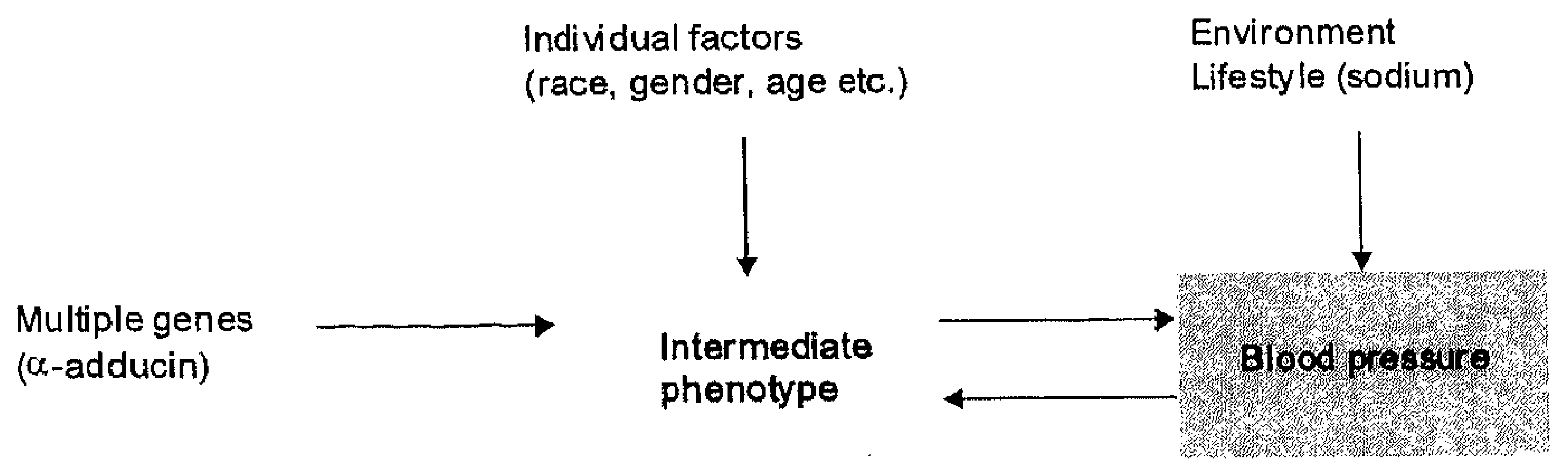

Figure 1.1 Schematic representation of blood pressure as a complex multigenic trait, affected by individual and environmental factors.

\section{a-Adducin Gly460Trp polymorphism}

Adducin is a cytoskeleton protein, which is thought to regulate cell-signal transduction through changes in the actin cytoskeleton ${ }^{21}$. Point mutations in rat adducin are involved in a form of primary hypertension which is associated with faster tubular ion transport ${ }^{22}$. Given the high degree of homology between rat and human adducin, it is not unreasonable to assume that the protein is also of importance in human hypertension. Indeed, saline infusion studies in man have shown that the mutated 460Trp allele is associated with a sodium-sensitive form of hypertension ${ }^{19,23}$. When hypertensives were subjected to chronic diuretic treatment, patients with the 460Trp variant displayed a greater decrease in mean arterial pressure ${ }^{24,25}$. Besides these functional studies, many research groups have tried to demonstrate an association between variants of the $\alpha$-adducin Gly460Trp polymorphism and blood pressure or hypertension. Results of these studies have not been consistent and it is difficult to draw an overall conclusion out of these studies, probably due to heterogeneity of the study population.

\section{Renal hemodynamics and glomerular filtration}

The kidney plays a central role in the pathophysiology of essential hypertension. In most hypertensives, renal hemodynamics are impaired, at 
least to a certain degree. Renal blood flow (RBF) and glomerular filtration rate (GFR) is lower while renal vascular resistance (RVR) is higher in hypertensives. In salt-resistant hypertensive patients, a high sodium intake induces an increase in RBF and GFR leading to no change or a slight decrease in filtration fraction (FF). In contrast, the renal hemodynamic response to salt loading in salt-sensitive patients or subjects is characterized by a decrease in RBF and no change in GFR. Hence FF, an indirect marker of intra-glomerular pressure, increases. This particular response of salt-sensitive subjects suggests an increase in pre- and post-glomerular vasoconstriction and has been attributed to an inadequate regulation of the renin-angiotensin system ${ }^{26-28}$.

RBF and GFR fall with increasing age and a rise in blood pressure. Structural changes in the resistance vessels may develop as an adaptation to the increase in pressure, but at the time contribute to a further rise in resistance and pressure. In this way, we are dealing with an ever-perpetuating mechanism to increase in blood pressure and reduce renal flow ${ }^{29,30}$. Eventually, structural alterations may lead to arteriolar nephrosclerosis ${ }^{31}$. Undoubtedly, this has consequences for the activity of the renin-angiotensin system and other, volume-regulating hormonal systems. 


\section{Outline of the thesis}

The main goal of the present thesis is to increase knowledge regarding the $\alpha$-adducin Gly460Trp polymorphism and factors related to sodium-sensitive hypertension. For this purpose, a number of clinical studies have been performed to address these research questions. These included a comparison of protocols that investigate sodium sensitivity and the assessment of long-term changes in renal hemodynamics.

Chapter 2 of this thesis provides a review of the literature on genetic polymorphisms related to sodium-sensitive blood pressure and in Chapter 3 we describe the long-term follow-up of renal hemodynamics in uncomplicated essential hypertension. In Chapter 4 we report on the association between the 460Trp allele of the $\alpha$-adducin Gly460Trp polymorphism and blood pressure in patients with familial combined hyperlipidemia. In Chapter 5 the impact of the 460Trp allele on renal hemodynamics in hypertensive patients during different sodium diets is studied. Chapter 6 describes the comparison between a rapid (hypertonic saline infusion) and a slow (dietary sodium intervention) protocol to assess sodium sensitivity of blood pressure. In Chapter 7 we present our data with respect to exaggerated natriuresis after hypertonic saline loading in subjects with the Trp460Trp variant of the $\alpha$-adducin gene. Chapter 8 focuses on the responses of blood pressure and neurohormones to dietary sodium loading in relation to the variants of the $\alpha$-adducin Gly460Trp polymorphism in essential hypertension. Finally in Chapter 9 (general discussion) the findings described in this thesis are put in perspective in the light of current and future research interests. 
Introduction

\section{References}

1. Weinberger MH. Salt sensitive human hypertension. Endocr Res 1991;17(1-2):43-51.

2. Luft FC, Weinberger MH. Heterogeneous responses to changes in dietary salt intake: the salt- sensitivity paradigm. Am J Clin Nutr 1997;65(2 Suppl):612S-617S.

3. Kawasaki T, Delea CS, Bartter FC, Smith H. The effect of high-sodium and low-sodium intakes on blood pressure and other related variables in human subjects with idiopathic hypertension. Am J Med 1978;64(2):193-198.

4. Fujita T, Henry WL, Bartter FC, Lake CR, Delea CS. Factors influencing blood pressure in salt-sensitive patients with hypertension. Am J Med 1980;69(3):334-344.

5. Miller JZ, Daugherty SA, Weinberger MH, Grim CE, Christian JC, Lang CL. Blood pressure response to dietary sodium restriction in normotensive adults. Hypertension 1983;5(5): 790-795.

6. Weinberger MH, Miller JZ, Luft FC, Grim CE, Fineberg NS. Definitions and characteristics of sodium sensitivity and blood pressure resistance. Hypertension 1986;8(6 Pt 2):I1127-134.

7. Overlack A, Ruppert M, Kolloch R, Gobel B, Kraft K, Diehl J, Schmitt W, Stumpe KO. Divergent hemodynamic and hormonal responses to varying salt intake in normotensive subjects. Hypertension 1993; 22(3):331-338.

8. Sulfivan JM. Salt sensitivity. Definition, conception, methodology, and long-term issues. Hypertension 1991;17(1 Suppl):161-168.

9. Krekels MM, Schaper NC, de Leeuw PW. Sensitivity of blood pressure and renin activation during sodium restriction. Hypertension 1997;30(5):1216-1222.

10. Kohno $M$, Yasunari $K$, Murakawa $K$, Kanayama $Y$, Matsuura T, Takeda T. Effects of highsodium and low-sodium intake on circulating atrial natriuretic peptides in salt-sensitive patients with systemic hypertension. Am J Cardiol 1987;59(12):1212-1213.

11. Hansson JH, Nelson-Williams $C$, Suzuki H, Schild L, Shimkets R, Lu Y, Canessa C, Iwasaki $T$, Rossier B, Lifton RP. Hypertension caused by a truncated epithelial sodium channel gamma subunit: genetic heterogeneity of Liddle syndrome. Nat Genet 1995;11(1):76-82.

12. Lifton RP, Dluhy RG, Powers M, Rich GM, Cook S, Ulick S, Lalouel JM. A chimaeric 11 betahydroxylase/aldosterone synthase gene causes glucocorticoid-remediable aldosteronism and human hypertension. Nature 1992;355(6357):262-265.

13. Luft FC. Molecular genetics of salt-sensitivity and hypertension. Drug Metab Dispos 2001; 29(4 Pt 2):500-504.

14. Luft FC. Molecular genetics of human hypertension. J Hypertens 1998;16:1871-1878

15. Morris BJ. Genes for essential hypertension: The first decade of research. In: 2002043, editor. Progress in Hypertension; 1999:1-44.

16. Gavras I, Manolis A, Gavras H. Genetic epidemiology of essential hypertension. J Hum Hypertens 1999;13(4):225-229.

17. Poch E, Gonzalez D, Giner V, Bragulat E, Coca A, de La Sierra A. Molecular basis of salt sensitivity in human hypertension. Evaluation of renin-angiotensin-aldosterone system gene polymorphisms. Hypertension 2001;38(5):1204-1209.

18. Hunt SC, Geleijnse JM, Wu LL, Witteman JC, Williams RR, Grobbee DE. Enhanced blood pressure response to mild sodium reduction in subjects with the $235 T$ variant of the angiotensinogen gene. Am J Hypertens 1999;12(5):460-466.

19. Cusi D, Barlassina C, Azzani T, Casari G, Citterio L, Devoto M, Glorioso N, Lanzani C, Manunta P, Righetti M, Rivera R, Stella P, Troffa C, Zagato L, Bianchi G. Polymorphisms of alpha-adducin and salt sensitivity in patients with essential hypertension. Lancet 1997;349: 1353-1357.

20. Siffert W, Rosskopf D, Siffert G, Busch S, Moritz A, Erbel R, Sharma AM, Ritz E, Wichmann $\mathrm{HE}$, Jakobs $\mathrm{KH}$, Horsthemke $B$. Association of a human $\mathrm{G}$-protein beta3 subunit variant with hypertension. Nat Genet 1998;18(1):45-48.

21. Hughes $C A$, Bennett $V$. Adducin: a physical model with implications for function in assembly of spectrin-actin complexes. J Biol Chem 1995;270(32):18990-18996. 
Chapter 1

22. Tripodi G, Valtorta F, Torielli L, Chieregatti E, Salardi S, Trusolino L, Menegon A, Ferrari $P$, Marchisio PC, Bianchi G. Hypertension-associated point mutations in the adducin alpha and beta subunits affect actin cytoskeleton and ion transport. J Clin Invest 1996;97:2815-2822.

23. Manunta $P$, Cusi $D$, Barlassina $C$, Righetti $M$, Lanzani $C, D^{\prime}$ Amico $M$, Buzzi $L$, Citterio $L$ Stella $P$. Rivera R, Bianchi G.. Alpha-adducin polymorphisms and renal sodium handling in essential hypertensive patients. Kidney Int 1998;53:1471-1478.

24. Glorioso N, Manunta P, Filigheddu F, Troffa C, Stella P, Barlassina C, Lombardi C, Soro A, Dettori F, Parpaglia PP, Alibrandi MT, Cusi D, Bianchi G. The role of alpha-adducin polymorphism in blood pressure and sodium handling regulation may not be excluded by a negative association study. Hypertension 1999;34(4 Pt 1):649-654.

25. Sciarrone MT, Stella P, Barlassina C, Manunta P, Lanzani C, Bianchi G, Cusi D. ACE and alpha-adducin polymorphism as markers of individual response to diuretic therapy. Hypertension 2003;41(3):398-403.

26. Williams GH, Holtenberg NK. Non-modulating hypertension. A subset of sodium-sensitive hypertension. Hypertension 1991;17(1 Suppl):181-185.

27. van Paassen $P$, de Zeeuw $D$, Navis $G$, de Jong $P E$. Does the renin-angiotensin system determine the renal and systemic hemodynamic response to sodium in patients with essential hypertension? Hypertension 1996;27(2):202-208.

28. Campese VM, Parise M, Karubian F. Bigazzi R. Abnormal renal hemodynamics in black saltsensitive patients with hypertension. Hypertension 1991;18(6):805-812.

29. Julius $S$. The blood pressure seeking properties of the central nervous system. J Hypertens 1988;6(3):177-185.

30. Mulvany MJ, Aalkjaer C. Structure and function of small arteries. Physiol Rev 1990;70(4): 921-961.

31. Folkow B. In: Harington M, editor. Hypotensive drugs. London: Pergamon; 1956:163-174. 


\section{Chapter 2}

Genetic predisposition to salt-sensitivity A systematic review

E Beeks, AGH Kessels, AA Kroon, MM van der Klauw, PW de Leeuw 


\section{Chapter 2}

\section{Abstract}

\section{Background}

The present study was designed to assess the role of genetic polymorphisms in salt sensitivity of blood pressure.

\section{Data identification}

We conducted a systematic review by searching the Medline literature from March 1993 to June 2003. Each paper was scrutinized and data concerning study population, method of salt sensitivity testing, blood pressure measurement, definition of salt sensitivity, and effects were extracted.

\section{Study selection and data extraction}

A total of 23 studies met the inclusion criteria. There was considerable heterogeneity in the method of salt sensitivity testing among the studies. Due to these differences, it was impossible to perform pooled analyses by genetic variants. Detailed investigation was done on the $\alpha$-adducin Gly460Trp, ACE $1 / D$, angiotensinogen M235T, $G$ protein $\beta 3$ C825T, aldosterone synthase gene and $11 \beta$-hydroxysteroid dehydrogenase type $2 \mathrm{G} 534 \mathrm{~A}$ polymorphism.

\section{Results}

Our analysis shows that the 460Trp variant of the $\alpha$-adducin polymorphism is probably associated with a sodium-sensitive form of hypertension, while the polymorphisms of the angiotensin II type 1 receptor gene and the $-344 \mathrm{C} / \mathrm{T}$ variant of the aldosterone synthase gene are not associated with phenotype.

\section{Conclusion}

in view of the lack of standardization in salt sensitivity testing, we propose uniformity in study design in these types of studies. 


\section{Introduction}

High blood pressure arises from the combined action of genetic and environmental factors. Among the latter, dietary sodium has been generally accepted as an important contributor to hypertension. However, blood pressure responses to a high salt intake, or in other words, the degree of salt sensitivity, varies considerably between individuals ${ }^{1,2}$. Both enhanced sodium reabsorption and altered activity of neurohormonal systems are thought to play a part in this process. As a corollary, several genes that are associated with these mechanisms, have been implicated as well. An extreme example of this is the gain-of-function mutation in the gene encoding the epithelial sodium channel which mediates net renal sodium reabsorption in the distal tubule and causes Liddle's syndrome, a rare autosomal dominant form of severe human saltsensitive hypertension ${ }^{3}$. On a less extreme account, the Gly460Trp variant of the $\alpha$-adducin gene is associated with enhanced renal tubular sodium reabsorption and a salt-sensitive rise in blood pressure ${ }^{4,5}$. Another example concerns a variant of the gene encoding the $\beta 3$ subunit of heterotrimeric $G$ proteins which enhance $G$ protein activation and increase the activity of the sodium-proton exchanger ${ }^{6,7}$. A polymorphism in this gene may modify the response of blood pressure to salt.

Renin-angiotensin-aldosterone system (RAAS) polymorphisms are also of interest, as suppressed or relatively fixed renin levels may be associated with a greater blood pressure response to sodium ${ }^{8}$. Moreover, sodium-sensitive individuals exhibit a blunted rise of renin and aldosterone when switching from a low to a high salt $\operatorname{diet}^{9}$. Therefore, polymorphisms that could increase the formation of angiotensin II (ACE I/D, angiotensinogen M235T and G-6A) or promote sodium retention through an action of this peptide (AT1R A1166C and CYP11B2) are also relevant in the context of sodium sensitivity. Finally, atrial natriuretic peptide and some steroid hormones are able to modulate renal sodium retention. In this respect, the activity of the 11/-hydroxysteroid dehydrogenase type 2 (11ßHSD2) may be impaired in sodium-sensitive subjects ${ }^{10}$. Polymorphisms in the gene encoding this steroid could play a role in increased sensitivity of blood pressure to sodium intake.

Several association studies have been performed to identify genetic factors responsible for hypertension, but so far results have not been consistent. One of the reasons for the apparent discrepancies may be the definition of the phenotype under study. This is particularly relevant when it comes to the association between genetic factors and salt sensitivity of blood pressure. The aim of the present review is to summarize the literature on genetic polymorphisms that have been linked to salt sensitivity of blood pressure. 


\section{Methods}

\section{Literature search}

Papers examining genetic factors associated with salt sensitivity were identified from MEDLINE (March 1993-June 2003) using the topic-related key words 'salt' or 'sodium sensitivity' and 'gene' or 'polymorphism' (and their abbreviations). Also, the following genetic polymorphisms were searched for: $\alpha$-adducin Gly460Trp (ADD1), G protein $\beta 3$ (GNB3 C825T), angiotensin II type 1 receptor (AT1R A1166C), angiotensinogen (AGT Met235Thr), angiotensin converting enzyme (ACE I/D), aldosterone synthase (CYP11B2 C-344T and intron 2

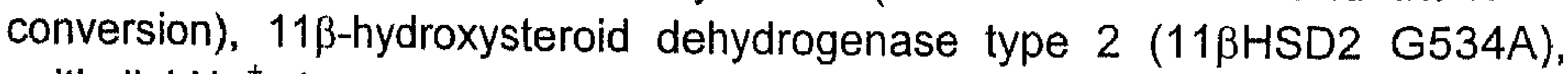
epithelial $\mathrm{Na}^{+}$channel $(649 \gamma \mathrm{ENaC})$ and atrial natriuretic peptide (ANP Hpa II). Animal studies, case reports and papers in a language other than English were excluded from this review. References used in papers were also selected. Each paper was scrutinized and data concerning study population, method of salt sensitivity testing, blood pressure measurement, definition of salt sensitivity, and effects were extracted. Only when these items were described with sufficient details to copy the study, papers were selected for analysis. In case several reports were available from the same study population, only the most recent and complete data were used.

\section{Analysis and presentation of the data}

In general, blood pressure responses to sodium were measured either during changes in dietary salt intake or after acute salt loading (infusion) and after diuretic treatment. Data have been presented in terms of systolic (SBP), diastolic (DBP) and mean blood pressure (MAP). However, due to heterogeneity in methods of salt sensitivity testing, it was impossible to perform pooled analyses by genotype.

\section{Results}

\section{Identification and selection of studies}

From a total of 28 potentially relevant papers, 23 studies met the prespecified criteria. They comprised the following genetic variants: the $\alpha$-adducin Gly460Trp ${ }^{45.11-15}, G$ protein $\beta 3$ (GNB3 C825T) ${ }^{16-18}$, angiotensin converting enzyme (ACE I/D) ${ }^{13,15,18-23}$, angiotensinogen (AGT M235T) ) $22-26^{26}$ angiotensin conversion ${ }^{18.22}$, epithelial $\mathrm{Na}^{+}$aldosterone synthase $\mathrm{C}-344 \mathrm{~T}^{18,22,27}$ and intron 2 and atrial natriuretic peptide polymorphism (ANP ${ }^{28}, 11 \beta \mathrm{HSD} 2 \mathrm{G} 534 \mathrm{~A}^{22,29,30}$ excluded because of lack of salt senstivity (ANP Hpa II) ${ }^{31}$. Four studies were 
extended sample of patients and genetic polymorphisms of an earlier study, in which the population was smaller with less genetic polymorphisms studied. ${ }^{32}$ Therefore, the extended study was chosen for this review ${ }^{22}$. For six genetic polymorphisms more than two papers were available, i.e. $\alpha$-adducin (seven studies), ACE (eight studies), AGT (five studies), 11ßHSD2 (three studies), G protein $\beta 3$ (three studies) and aldosterone synthase (three studies). The main findings of these studies have been listed in Tables 2.1 to 2.6, while Table 2.7 summarizes the remaining polymorphisms that have been studied in relation to salt sensitivity.

Two types of studies are included in this review. On the one hand, studies investigating the response of blood pressure to either dietary or intravenous administration of sodium and on the other hand studies examining the effect of diuretics on blood pressure.

Table $2.1 \quad \alpha$-adducin Gly460Trp polymorphism.

$\begin{array}{lrcccl}\text { Reference } & \text { N } & \text { Population } & \text { Mean age (years) } & \text { Association } & \text { Allele } \\ \text { Cusi }^{4} & 90 & \text { HT } & 43 & + & 460 \text { Trp } \\ \text { Manunta }^{11} & 108 & \text { HT } & 43 & + & 460 T \text { Trp } \\ \text { Glorioso }^{5} & 143 & \text { HT } & 46 & + & 460 T r p \\ \text { Grant }^{12} & 279 & \text { HT } & 48 & + & \text { Trp460Trp } \\ \text { Ciechanowicz }^{14} & 68 & \text { HT } & 35 & - & - \\ \text { Barlassina }^{13} & 145 & \text { HT } & 44 & + & 460 T_{\mathrm{rp}}+\mathrm{DD}^{\mathrm{a}} \\ \text { Sciarrone }^{15} & 87 & \text { HT } & 43 & + & 460 \mathrm{Trp}+\mathrm{I}^{\mathrm{a}}\end{array}$

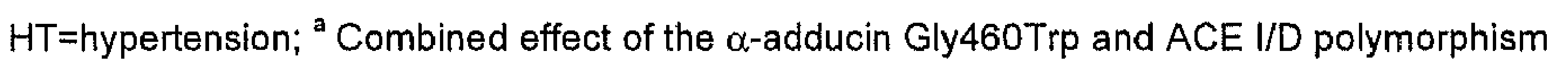

Table 2.2 ACE I/D polymorphism.

$\begin{array}{lrlccc}\text { Reference } & \text { N } & \text { Population } & \text { Mean age (years) } & \text { Association } & \text { Allele } \\ \text { Kojima }^{19} & 104 & \text { HT (Japanese) } & 53 & - & - \\ \text { Hiraga }^{20} & 66 & \text { HT (Japanese) } & 52 & + & \text { II } \\ \text { Dengel }^{21} & 35 & \text { HT } & 63 & + & \text { D } \\ \text { Poch }^{22} & 71 & \text { HT } & 47 & + & \text { I } \\ \text { Johnson }^{23} & 46 & \text { ISH, HT, NT } & 69 & - & - \\ \text { Pamies-Andreu }^{18} & 102 & \text { HT } & 37 & - & -\end{array}$

$H T=$ hypertension; $I S H=i$ solated systolic hypertension; $N T=$ normotension 
Chapter 2

Table 2.3 AGT M235T and G-6A polymorphism.

$\begin{array}{lrlccc}\text { Reference } & \text { N } & \text { Population } & \text { Mean age (years) } & \text { Association } & \text { Allele } \\ \text { Johnson }^{23} & 46 & \text { ISH, HT, NT } & 69 & + & \text { MM } \\ \text { Schorr }^{24} & 187 & \text { NT (white) } & 25 & - & - \\ \text { Hunt }^{25} & 100 & \text { HT } & 66 & + & \text { T } \\ \text { Poch }^{22} & 71 & \text { HT } & 47 & - & - \\ \text { Hunt }^{26} & 378 & \text { NT } & 43 & + & \text { AA }^{\text {a }}\end{array}$

ISH=isolated systolic hypertension; HT=hypertension; NT=normotension;

a ATT G-6A polymorphism

Table 2.4 11ßHSD2 G534A and CA-repeat polymorphism.

$\begin{array}{lrlccc}\text { Reference } & \text { N } & \text { Population } & \text { Mean age (years) } & \text { Association Allele } \\ \text { Poch }^{22} & 71 & \text { HT } & 47 & + & \text { GG } \\ \text { Lovati }^{30} & 149 & \text { NT (white) } & 25 & - & - \\ & & & & + & \text { Microsatellite marker } \\ \text { Agarwal }^{29} & 198 & \text { HT (white) } & 45 & + & \text { Shorter CA-repeat length } \\ & 153 & \text { NT (white) } & 25 & \end{array}$

HT=hypertension; NT=normotension; ${ }^{a}$ CA-repeat polymorphism in intron 1

Table 2.5 GNB3 C825T polymorphism.

$\begin{array}{lclccc}\text { Reference } & \text { N } & \text { Population } & \text { Mean age (years) } & \text { Association } & \text { Allele } \\ \text { Schorr }^{16} & 193 & \text { NT (white) } & 25 & - & - \\ \text { Turner }^{17} & 387 & \text { HT } & 48 & + & \text { TT } \\ \text { Pamies-Andreu }^{18} & 102 & \text { HT } & 37 & - & -\end{array}$

NT, normotension; HT, hypertension

Table 2.6 CYP11B2 C-344T polymorphism.

$\begin{array}{lrcccc}\text { Reference } & \text { N } & \text { Population } & \text { Mean age (years) } & \text { Association } & \text { Allele } \\ \text { Brand }^{27} & 163 & \text { NT } & 25 & - & - \\ \text { Poch }^{22} & 71 & \text { HT } & 47 & - & - \\ \text { Pamies-Andreu }^{18} & 102 & \text { HT } & 37 & - & \text { - }\end{array}$

NT, normotension; HT, hypertension 
Table 2.7 Other polymorphisms.

\begin{tabular}{|c|c|c|c|c|c|c|}
\hline Reference & Polymorphism & $N$ & Population & Mean age (years) & Association & Allele \\
\hline Poch $^{22}$ & $\begin{array}{l}\text { AT1R A1166C } \\
\text { CYP11B2 intron } 2 \\
\text { conversion }\end{array}$ & 71 & HT & 47 & - & - \\
\hline Pamies-Andreu ${ }^{18}$ & $\begin{array}{l}\text { AT1R A1166C } \\
\text { CYP11B2 intron } 2 \\
\text { conversion }\end{array}$ & 102 & $\mathrm{HT}$ & 37 & + & $\overline{\mathrm{W}}$ \\
\hline $\begin{array}{l}\text { Poch }^{28} \\
\text { Schorr }^{31}\end{array}$ & $\begin{array}{l}\gamma \mathrm{ENaC} \text { C649G } \\
\text { ANP Hpa II }\end{array}$ & $\begin{array}{r}48 \\
103\end{array}$ & $\begin{array}{l}\text { HT (white) } \\
\text { NT (white) }\end{array}$ & $\begin{array}{l}52 \\
25\end{array}$ & - & - \\
\hline
\end{tabular}

$H T$, hypertension; NT, normotension

\section{a-Adducin Gly460Trp polymorphism}

Seven studies addressed the role of the $\alpha$-adducin Gly460Trp polymorphism on salt sensitivity (Table 2.1$)^{4,5.11-15}$, of which five were performed by the same research group $4,5,11,13,15$. The paper by Cusi et al. ${ }^{4}$ consisted of two sub-studies: an acute salt loading test and a chronic diuretic treatment test. Since an extension of the chronic diuretic treatment was later published by Glorioso et $a / .^{5}$ only the acute salt sensitivity test from Cusi's paper was used for this review. This particular study showed that the decrease in mean arterial pressure (MAP), defined as the difference in blood pressure after saline infusion and after furosemide administration, was greater in the Gly460Trp than in the Gly460Gly variant $(-15.9 \pm 2.0 \mathrm{mmHg}$ versus $-7.4 \pm 1.3 \mathrm{mmHg}, \mathrm{p}=0.001)$. The study of Manunta et al. ${ }^{11}$ also showed that after acute salt loading (2 I of saline, $310 \mathrm{mmol} \mathrm{NaCl}$ in $2 \mathrm{~h}$ ) the increase in MAP was greater in Gly460Trp than in Gly460Gly $(8.0 \pm 1.2 \mathrm{mmHg}$ and $2.2 \pm 0.7 \mathrm{mmHg}$ respectively, $p=0.001)$. Glorioso et al..$^{5}$ studied the effect of chronic diuretic administration in relation to the $\alpha$-adducin Gly460Trp polymorphism. After treatment with hydrochlorothiazide for 2 months, MAP decreased, on average, more in patients with the 460Trp allele than in patients homozygous for the Gly460 allele $(F=13.57, p<0.001)$. This study was performed in two Italian populations ('Sassari' population, Gly460Gly versus 460Trp: 9.3 versus $15.9 \mathrm{mmHg}$, $p=0.004$, and 'Milano' population, Gly460Gly versus 460Trp: 6.4 versus $12.6 \mathrm{mmHg}, p=0.01)$. One study investigated the association between $\alpha$-adducin and sodium sensitivity using a high and low sodium $\operatorname{diet}^{12}$. The change in SBP from high to low sodium diet was significantly greater in patients with the Trp460Trp genotype compared to those with Gly460Trp or Gly460Gly. Finally, a Polish study failed to find a significant change in blood pressure (from low to high sodium diet) between the genotype groups ${ }^{14}$. 


\section{ACE I/D polymorphism}

Six studies investigated the relationship between variants of the ACE polymorphism and salt sensitivity (Table 2.2) ${ }^{18-23}$. Two of these showed association between the I allele and salt sensitivity ${ }^{20,22}$. While Hiraga et demonstrated that patients with the II genotype had a significantly gre blood pressure rise during high dietary salt intake than patients with the II DD genotype, Poch et $a / .^{22}$ found a significantly higher prevalence of : sensitive hypertension in II and ID patients as compared with hypertensives. One study showed an association between the $D$ allele enhanced blood pressure responses during a high salt diet ${ }^{21}$. Three studies not find an association between variants of the ACE I/D polymorphism and sensitivity ${ }^{18,19,23}$.

\section{$\alpha$-Adducin Gly460Trp and ACE I/D polymorphism}

Two studies addressed the combined effect of the $\alpha$-adducin and the $f$ genotype on sodium sensitivity of blood pressure (Table 2.1) ${ }^{13,15}$. Barlassin al. ${ }^{13}$ investigated the synergistic effect of the $\alpha$-adducin and the ACE gen $\epsilon$ blood pressure changes with body sodium and volume expansion. In this st a greater increase in MAP was found in patients carrying at least one $46 \mathrm{C}$ allele as compared with patients homozygous for the Gly460 allele (7.0versus $2.5 \pm 0.6 \mathrm{mmHg}, p=0.0001$ ). The ACE genotype alone was associated with any blood pressure change after acute salt loading. When effects of the $\alpha$-adducin and ACE polymorphism were combined, $f$ displayed a significant synergistic effect on the blood pressure increase $\varepsilon$ sodium loading and on the pressure-natriuresis relationship. A large pres effect of the ACE D allele was seen only in the presence of the 460Trp allel the $\alpha$-adducin polymorphism. Recently, Sciarrone et al. ${ }^{15}$ concluded that $\alpha$-adducin and ACE //D polymorphism can be useful in predicting interindividual degree of response to hydrochlorothiazide. Patients carryin! least one I allele of the ACE gene and one 460Trp allele of the $\alpha$-adducin g had the largest fall in mean blood pressure with treatment. These patients an odds ratio of almost 16 of being a responder to hydrochlorothia: compared with patients with DD+Gly 46 OGly.

\section{Angiotensinogen gene}

\section{M235T variant}

In four papers the relationship between the AGT M235T polymorphism and sensitivity has been studied (Table 2.3) ) $2-25^{2}$. Two of these (one normotensives and one in hypertensives) found no association betw 
variants of this polymorphism and salt sensitivity ${ }^{22,24}$. In the study of Johnson et $a l^{23}$, on the other hand, a significant association existed between the AGT M235T genotype and salt-related changes in DBP, but not in SBP. For sodium doses less than or equal to $200 \mathrm{mmol} /$ day, DBP among subjects with the TT genotype decreased, while DBP increased in subjects with the MM and MT genotypes. For sodium doses of $300 \mathrm{mmol} /$ day, DBP increased in all subjects, but this increase was greater in subjects with MM than in subjects with MT or TT. Hunt et $a / .^{25}$ performed a randomized, double blind, trial comparing blood pressure responses to low sodium mineral salt and common salt in the different genotype groups. They concluded that the $235 \mathrm{~T}$ allele was associated with greater blood pressure decreases after sodium reduction than the $235 \mathrm{M}$ allele.

\section{G-6A variant}

In their study on the effect of the G-6A variant of the angiotensinogen gene, Hunt et $a .^{26}$ found that this variant influenced the blood pressure responses to sodium. After 36 months of reduced sodium intake the decrease in DBP was greater in patients carrying the AA genotype compared to those with the GG
genotype.

\section{1ß-Hydroxysteroid dehydrogenase type 2 G534A polymorphism}

Two studies investigated the role of the $11 \beta \mathrm{HSD} 2$ G534A polymorphism on salt sensitivity of blood pressure (Table 2.4) ) $2,30^{\text {. Poch et al. }}{ }^{22}$ showed that hypertensive patients with the GG variant had a significantly greater increase in SBP on a high sodium diet than those with the GA variant. In normotensives, however, Lovati et $a l^{30}$ failed to find such a difference. On the other hand, the latter investigators also found a polymorphic microsatellite marker of the gene which was associated with reduced $11 \beta \mathrm{HSD} 2$ activity and salt sensitivity, suggesting that certain functional variants of the $11 \beta \mathrm{HSD} 2$ gene may contribute to enhanced blood pressure responses to salt in humans. Similarly, Agarwal et $a l^{29}$ investigated the effect of a CA-repeat polymorphism in intron 1 on salt sensitivity. They found that a shorter CA-repeat length was correlated with reduced tissue activity of the enzyme as well as salt sensitivity. It should be noted that a subgroup studied in this paper was also used by the group of Lovati $^{30}$ who explored the relation between the G534A polymorphism of the same gene.

\section{G-protein $\beta 3$ subunit C825T polymorphism}

Three studies were found regarding the GNB3 C825T polymorphism (Table 2.5). Schorr et $a l^{16}$ did not find an association between the GNB3 $825 T$ variant and blood pressure responses to dietary salt intake in young normotensive 
men. In hypertensives, the effect of acute volume expansion and depletion did not differ between genotype groups either ${ }^{18}$ but after monotherapy with hydrochlorothiazide for 4 weeks, the TT genotype appeared to be a significant predictor of greater falls in SBP and $\mathrm{DBP}^{17}$.

\section{Aldosterone synthase gene}

As shown in Table 2.6, three studies are available on salt sensitivity and the aldosterone synthase (CYP11B2) C-344T polymorphism but no association with a variant in this gene was found whatsoever ${ }^{18,22,27}$. Poch et al..$^{22}$ and Pamies-Andreu et $a l^{18}$ also studied a second polymorphism in the aldosterone synthase gene (intron 2 conversion) with conflicting results (Table 2.7). While no association was found in the former study using a dietary method, PamiesAndreu and coworkers found after saline loading and furosemide administration that the $\mathrm{W}$ allele is associated with an increased risk for salt sensitivity ${ }^{18}$.

\section{Other polymorphisms}

Two studies with respect to the angiotensin $\|$ receptor type $1 \mathrm{~A} 1166 \mathrm{C}^{18,22}$, one concerning the epithelial $\mathrm{Na}^{+}$channel $\gamma$ subunit $\mathrm{C} 649 \mathrm{G}^{28}$ and one on the ANP Hpa II polymorphism ${ }^{31}$ did not find any association of variant forms with salt sensitivity (Table 2.7).

\section{Discussion}

Although there are many studies about the relationship between genetic factors and hypertension as such, far less information is available about the association between variants of these genetic polymorphisms and salt sensitivity of blood pressure. This prompted us to perform a systematic review of the literature to explore the impact of some candidate genes on blood pressure responses to sodium. However, due to many differences between the studies selected for this review, caution is needed when drawing overall conclusions about the association. Considerable heterogeneity exists in methods of salt sensitivity testing, ranging from an acute sodium load to changes in dietary sodium and/or diuretic administration. While in some studies salt sensitivity was treated as a dichotomous trait, others focused on blood pressure as a continuous variable. In addition, studies differed also in definition of salt sensitivity, and the way blood pressure was expressed (SBP, DBP or MAP).

Another point that has to be emphasized is the fact that studies providinc negative results are less likely to be published, which could lead tc 
overestimation of those effects that have been reported. However, as there is no solid evidence for a role of most genetic polymorphisms in salt sensitivity, publication bias may not play a significant role.

With respect to studies on genes with a bearing on renal sodium retention, the majority of those investigating the $\alpha$-adducin Gly460Trp polymorphism in salt sensitivity have been performed by only one research group $4,5,11,13,15$. All show that the 460Trp variant is associated with a salt-sensitive form of hypertension. Despite these consistent results, from the information given in these studies, it cannot be excluded that one patient group was used in more than one study. Some caution is needed, therefore, in the interpretation of these data. The $460 T r p$ allele of the $\alpha$-adducin polymorphism appears to be associated also with low-renin hypertension ${ }^{33}$. Renin levels are lower in patients carrying the 460 Trp allele as compared with those with the Gly460Gly genotype ${ }^{4}$, and Grant et al. ${ }^{12}$ showed that in low-renin hypertension, the frequency of the Trp460Trp genotype was higher than in normal-renin hypertension. Although this does not necessarily mean that the $\alpha$-adducin variant is associated with salt-sensitive hypertension during short-term studies, it would at least be compatible with greater volume expansion in the long run.

With respect to the GNB3 C825T polymorphism, a similar effect has been found. The TT genotype was associated with lower renin levels and higher $\mathrm{DBP}^{34}$. Although no formal involvement of the GNB3 C825T polymorphism in salt sensitivity has been found during dietary manipulation ${ }^{16,18}$, the TT genotype is at least associated with a greater decline in SBP and DBP after diuretic treatment ${ }^{17}$. In the single studies investigating the relationship between the $\gamma 649 \mathrm{ENaC}$ polymorphism ${ }^{28}$ and the ANP Hpa 11 polymorphism $^{31}$ with salt sensitivity, no associations could be found.

As a counterpart to the 'sodium genes', several studies focused on genes encoding various components of the RAAS system. Whereas two studies did not show any involvement of the ACE I/D polymorphism on changes in blood pressure between high and low salt diets, in others the I allele was associated with a greater blood pressure increase after a high salt diet. One study showed a significant association between the $D$ allele and an increase in blood pressure after a high salt diet, whereas another study indicated a synergistic effect of ACE I/D (DD) and ADD1 (460Trp) on the blood pressure increase after saline infusion. On a high sodium diet, patients with the DD genotype show a blunted response of blood pressure to ACE inhibition ${ }^{35}$ as well as enhanced responses of blood pressure, plasma aldosterone and renal hemodynamics to angiotensin I infusion in comparison to II patients ${ }^{36}$. Thus, increased ACE levels in subjects with the DD genotype may be of functional importance under certain circumstances. Although this would suggest that the $D$ allele of the ACE I/D polymorphism is associated with greater blood pressure responses to salt, the available data are not consistent on this point. 
Data on the relationship between the angiotensinogen M235T polymorphism and salt sensitivity are not consistent and no conclusions can be drawn at this moment. One other (positive) study investigated the angiotensinogen G-6A polymorphism ${ }^{26}$, but this marker appears to be in almost complete linkage disequilibrium with the M235T polymorphism ${ }^{37}$.

Although only two studies have addressed the A1166C polymorphism of the angiotensin 11 type 1 receptor in relation to salt sensitivity, they are at least consistent in showing no association ${ }^{18,22}$. The same holds true for the $-344 \mathrm{C} / \mathrm{T}$ variant of the aldosterone synthase gene which was investigated in three different studies ${ }^{18,22,27}$. No definite conclusions can be drawn yet about the relationship between the CYP11B2 intron 2 conversion in the aldosterone synthase gene or the G534A polymorphism of the $11 \beta$-hydroxysteroid dehydrogenase type 2 gene and salt sensitivity. On the other hand, two studies have shown that certain polymorphisms which lead to reduced activity or enzyme levels of $11 \beta$-hydroxysteroid dehydrogenase type 2 do show an association with salt sensitivity.

Altogether, our analysis shows that the 460Trp variant of the $\alpha$-adducin polymorphism and some functional variants of the 11 1 -hydroxysteroid dehydrogenase type 2 gene are likely to be associated with a sodium-sensitive form of hypertension, although this needs confirmation in other populations. The polymorphisms of the angiotensin II type 1 receptor gene as well as the $-344 \mathrm{C} / \mathrm{T}$ variant of the aldosterone synthase gene are not associated with a sodium-sensitive phenotype. If we are to decipher the absence or presence of a relationship between certain genes and salt sensitivity of blood pressure, it is essential that studies are comparable regarding study design. This requires the development of a common protocol that could be applied to different populations in the world. Since some of the polymorphisms are associated with a low-renin form of hypertension (possibly reflecting a long-term increase in extracellular volume) and/or a greater response to extracellular volume depletion by diuretics, yet very little changes in blood pressure upon changes in sodium intake, it seems that there are still other mechanisms, e.g. residing the kidney, that determine the risk of being salt-sensitive. Further research is needed to identify these mechanisms. 


\section{References}

1 Weinberger MH. Salt sensitive human hypertension. Endocr Res 1991;17:43-51.

2 Luft FC and Weinberger MH. Heterogeneous responses to changes in dietary salt intake: the salt- sensitivity paradigm. Am J Clin Nutr 1997;65:612S-617S.

3 Hansson JH, Nelson-Williams C, Suzuki H, Schild L, Shimkets R, Lu Y, Canessa C, Iwasaki $T$, Rossier $B$ and Lifton RP. Hypertension caused by a truncated epithelial sodium channel gamma subunit: genetic heterogeneity of Liddle syndrome. Nat Genet 1995;11:76-82.

4 Cusi D, Barlassina C, Azzani T, Casari G, Citterio L, Devoto M, Glorioso N, Lanzani C, Manunta $P$, Righetti M, Rivera R, Stella $P$, Troffa $C$, Zagato $L$ and Bianchi G. Polymorphisms of alpha-adducin and salt sensitivity in patients with essential hypertension. Lancet 1997;349:1353-1357.

5 Glorioso N, Manunta P, Filigheddu F, Troffa C, Stella P, Barlassina C, Lombardi C, Soro A, Dettori $F$, Parpaglia PP, Alibrandi MT, Cusi $D$ and Bianchi $G$. The role of alpha-adducin polymorphism in blood pressure and sodium handling regulation may not be excluded by a negative association study. Hypertension 1999;34:649-654.

6 Siffert W, Rosskopf D, Moritz A, Wieland T, Kaldenberg-Stasch $S$, Kettler N, Hartung $K$, Beckmann $S$ and Jakobs $\mathrm{KH}$. Enhanced $\mathrm{G}$ protein activation in immortalized lymphoblasts from patients with essential hypertension. $J$ Clin Invest 1995;96:759-766.

7 Siffert W, Rosskopf D, Siffert G, Busch S, Moritz A, Erbel R, Sharma AM, Ritz E, Wichmann $\mathrm{HE}$, Jakobs $\mathrm{KH}$ and Horsthemke $\mathrm{B}$. Association of a human G-protein beta3 subunit variant with hypertension. Nat Genet 1998;18:45-48.

8 Krekels MM, Schaper NC and de Leeuw PW. Sensitivity of blood pressure and renin activation during sodium restriction. Hypertension 1997;30:1216-1222.

9 de la Sierra A, Lluch MM, Coca A, Aguilera MT, Giner V, Bragulat E and Urbano Marquez A. Fluid, ionic and hormonal changes induced by high salt intake in salt-sensitive and saltresistant hypertensive patients. Clin Sci Colch 1996;91:155-161.

10 Ulick S, Levine LS, Gunczler P, Zanconato G, Ramirez LC, Rauh W, Rosler A, Bradlow HL and New Ml. A syndrome of apparent mineralocorticoid excess associated with defects in the peripheral metabolism of cortisol. J Clin Endocrinol Metab 1979;49:757-764.

11 Manunta $P$, Cusi D, Barlassina $C$, Righetti $M$, Lanzani C, D'Amico M, Buzzi L, Citterio L, Stella P, Rivera $R$ and Bianchi G. Alpha-adducin polymorphisms and renal sodium handling in essential hypertensive patients. Kidney Int 1998;53:1471-1478.

12 Grant FD, Romero JR, Jeunemaitre X, Hunt SC, Hopkins PN, Hollenberg NH and Williams $\mathrm{GH}$. Low-renin hypertension, altered sodium homeostasis, and an alpha-adducin polymorphism. Hypertension 2002;39:191-196.

13 Barlassina C, Schork NJ, Manunta P, Citterio L, Sciarrone M, Lanella G, Bianchi G and Cusi $D$. Synergistic effect of alpha-adducin and $A C E$ genes causes blood pressure changes with body sodium and volume expansion. Kidney int 2000;57:1083-1090.

14 Ciechanowicz A, Widecka K, Drozd R, Adler G, Cyrylowski L and Czekalski S. Lack of association between Gly460Trp polymorphism of alpha-adducin gene and salt sensitivity of blood pressure in Polish hypertensives. Kidney Blood Press Res 2001;24:201-206.

15 Sciarrone MT, Stella P, Barlassina C, Manunta P, Lanzani C, Bianchi G and Cusi D. ACE and alpha-adducin polymorphism as markers of individual response to diuretic therapy. Hypertension 2003;41:398-403.

16 Schorr U, Blaschke K, Beige J, Distler A and Sharma AM. G-protein beta3 subunit 825T allele and response to dietary salt in normotensive men. J Hypertens 2000;18:855-859.

17 Turner ST, Schwartz GL, Chapman AB and Boerwinkle E. C825T polymorphism of the $G$ protein beta(3)-subunit and antihypertensive response to a thiazide diuretic. Hypertension 2001;37:739-743.

18 Pamies-Andreu E, Ramirez-Lorca R, Stiefel Garcia-Junco P, Muniz-Grijalbo O, VallejoMaroto I, Garcia Morillo S, Miranda-Guisado ML, Ortiz JV and Carneado de la Fuente J. Renin-angiotensin-aldosterone system and G-protein beta-3 subunit gene polymorphisms in salt-sensitive essential hypertension. J Hum Hypertens 2003;17:187-191. 
19 Kojima S. Inenaga T, Matsuoka $H$, Kuramochi M, Omae T, Nara $Y$ and Yamori $Y$. The association between salt sensitivity of blood pressure and some polymorphic factors. J Hypertens 1994;12:797-801

20 Hiraga $H$, Oshima $T$, Watanabe $M$, Ishida $M$, Ishida $T$, Shingu $T$, Kambe $M$, Matsura $H$ and Kajiyama $G$. Angiotensin l-converting enzyme gene polymorphism and salt sensitivity in essential hypertension. Hypertension 1996;27:569-572.

21 Dengel DR, Brown MD, Ferrell RE and Supiano MA. Role of angiotensin converting enzyme genotype in sodium sensitivity in older hypertensives. Am J Hypertens 2001;14:1178-1184.

22 Poch E, Gonzalez D, Giner V. Bragulat E, Coca A and de La Sierra A. Molecular basis of salt sensitivity in human hypertension. Evaluation of renin-angiotensin-aldosterone system gene polymorphisms. Hypertension 2001;38:1204-1209.

23 Johnson AG. Nguyen TV and Davis D. Blood pressure is linked to salt intake and modulated by the angiotensinogen gene in normotensive and hypertensive elderly subjects. $J$ Hypertens 2001:19:1053-1060.

24 Schorr U, Blaschke K, Beige J, Distler A and Sharma AM. Angiotensinogen M235T variant and salt sensitivity in young normotensive Caucasians. J Hypertens 1999;17:475-479.

25 Hunt SC, Geleijnse JM, Wu LL, Witteman JC, Williams RR and Grobbee DE. Enhanced blood pressure response to mild sodium reduction in subjects with the $235 \mathrm{~T}$ variant of the angiotensinogen gene. Am J Hypertens 1999;12:460-466.

26 Hunt SC, Cook NR, Oberman A, Cutler JA, Hennekens CH, Allender PS, Walker WG Whelton PK and Williams RR. Angiotensinogen genotype, sodium reduction, weight loss, and prevention of hypertension: trials of hypertension prevention, phase II. Hypertension 1998; 32:393-401.

27 Brand E, Schorr U, Ringel J, Beige J. Distler A and Sharma AM. Aldosterone synthase gene (CYP11B2) C-344T polymorphism in Caucasians from the Berlin Salt-Sensitivity Trial (BeSST). J Hypertens 1999;17:1563-1567.

28 Poch E, Gonzalez D, de la Sierra A, Giner V, Bragulat E, Botey A, Coca A and Rivera F. Genetic variation of the gamma subunit of the epithelial $\mathrm{Na}+$ channel and essential hypertension. Relationship with salt sensitivity. Am J Hypertens 2000;13:648-653.

29 Agarwal AK, Giacchetti G, Lavery G, Nikkila H, Palermo M, Ricketts M, McTernan C, Bianchi G, Manunta P, Strazzullo P, Mantero F, White PC and Stewart PM. CA-Repeat polymorphism in intron 1 of HSD11B2: effects on gene expression and salt sensitivity. Hypertension 2000; 36:187-194.

30 Lovati E, Ferrari P, Dick B, Jostarndt K, Frey BM, Frey FJ, Schorr U and Sharma AM. Molecular basis of human salt sensitivity: the role of the 11beta-hydroxysteroid dehydrogenase type 2. J Clin Endocrinol Metab 1999;84:3745-3749.

31 Schorr U, Beige J, Ringel J, Turan S, Kreutz R, Distler A and Sharma AM. Hpa II polymorphism of the atrial natriuretic peptide gene and the blood pressure response to salt intake in normotensive men. J Hypertens 1997;15:715-718.

32 Giner V, Poch E, Bragulat E, Oriola J, Gonzalez D, Coca A and De La Sierra A. Reninangiotensin system genetic polymorphisms and salt sensitivity in essential hypertension. Hypertension 2000;35:512-517.

33 Sugimoto $K$, Hozawa A, Katsuya T, Matsubara M, Ohkubo T, Tsuji I, Motone M, Higaki J, Hisamachi $S$, Imai $Y$ and Ogihara $T$. alpha-Adducin Gly460Trp polymorphism is associated with low renin hypertension in younger subjects in the Ohasama study. J Hypertens 2002; 20:1779-1784.

34 Schunkert $H$, Hense H-W, Doring A, Riegger GAJ and Siffert W. Association between a polymorphism in the $G$ protein beta 3 subunit gene and lower renin and elevated diastolic blood pressure levels. Hypertension 1998;32:510-513.

35 van der Kleij FG, Schmidt A, Navis GJ, Haas $M$, Yilmaz $N$, de Jong PE, Mayer $G$ and de Zeeuw $D$. Angiotensin converting enzyme insertion/deletion polymorphism and short-term renal response to ACE inhibition: role of sodium status. Kidney Int Suppl 1997;63:S23-S26.

36 van der Kleij FGH, de Jong PE, Henning RH, de Zeeuw D and Navis G. Enhanced responses of blood pressure, renal function, and aldosterone to angiotensin I in the DD genotype are blunted by low sodium intake. J Am Soc Nephrol 2002;13:1025-1033. 
Genetics and salt-sensitivity

37 Jeunemaitre $X$, Inoue I, Williams $C$, Charru A, Tichet J, Powers $M$, Sharma AM, GimenezRoqueplo A-P, Hata A, Corvol $P$ and Laouel J-M. Haplotypes of angiotensin in essential hypertension. Am J Hum Genet 1997;60:1448-1460. 


\section{Chapter 3}

Long-term follow-up of renal hemodynamics in patients with uncomplicated, mild essential hypertension

E Beeks, AA Kroon, WH Birkenhäger, MADH Schalekamp,

$\mathrm{J}$ Ligthart, MM van der Klauw, PW de Leeuw 


\section{Abstract}

\section{Background}

The arm of this study was to investigate long-term (longitudinal) changes in renal hemodynamics, glomerular filtration rate and neurohormones in uncomplicated essential hypertension.

\section{Methods}

We identfied 23 patients who met the inclusion criteria from a group that was first investigated during the period 1971-1981. These patients were studied 24 years later under identical conditions as before Two weeks after discontinuation of treatment and after five days of low sodium diet ( $55 \mathrm{mmol} \mathrm{Na}+$ per day), blood pressure. heart rate, glomerular filtration rate (GFR), effective renal plasma flow (ERPF), active plasma renin concentration (APRC), plasma aldosterone, plasma catecholamines and urinary sodium excretion were measured.

\section{Results}

Automatic blood pressure readings were similar during the first and the follow-up examination However, heart rate, GFR, ERPF, APRC and aldosterone were significantly decreased at followup Renal vascular resistance was increased but plasma catecholamines remained unchanged. Age was a significant predictor of ERPF at follow-up. When the change in ERPF over time is considered, older age and a higher ERPF at baseline predicted a greater fall in ERPF. Both age and GFR at baseline were predictors of GFR at follow-up and also of the decrement in GFR. Renin and aldosterone atso fell with time but no predictors could be identified for these changes.

\section{Conchusions}

The present data show that in uncomplicated essential hypertension which has been adequately treated, a significant decline in renal function is observed. In addition, the renin system is suppressed with aging. irrespective of hemodynamic factors. 


\section{Introduction}

Cross-sectional studies show that renal blood flow (RBF) falls with increasing age, the decline being greater in hypertensive patients than in normotensive controls. The latter is related to a steeper rise in renal vascular resistance (RVR) in hypertensives, possibly because structural changes develop in the resistance vessels as an adaptation to increased transmural pressure ${ }^{1,2}$. A vicious circle will then emerge where small increases in blood pressure can lead to small structural changes in arterioles which in turn maintain the increased pressure. Since RVR is already increased when RBF is still normal ${ }^{3}$, vascular alterations affecting the kidneys may be present even before hypertension becomes manifest ${ }^{4}$. Despite the fall in RBF, glomerular filtration rate (GFR) is well maintained in essential hypertension until a late stage of the disease and a rapid decline of GFR is often seen only in the malignant phase. Therefore, the decrease in GFR with increasing age is proportionally less than the decrease in RBF, leading to a rise in filtration fraction ${ }^{3}$. Similar changes in renal hemodynamics and renal function are seen during normal aging, although less pronounced ${ }^{5}$. Concurrent with the changes in renal function, renin levels tend to fall with increasing age ${ }^{6}$, although this finding is not consistent ${ }^{7}$. This decrease has been attributed to an increase in volume, reduced sympathetic activity, and a rise in intrarenal pressure and filtration fraction.

The relationship of renal hemodynamics and renin with age has been investigated mostly in cross-sectional studies, which may be biased with respect to patient selection. Although there are a few longitudinal follow-up studies which show a decline in RBF with age $e^{3,5,8,9}$, the time window of these studies is rather limited. Moreover, the effect of age on renin and aldosterone has still not be clearly defined. Therefore, to determine the 'true' effect of age on renal hemodynamics and neurohormones, longitudinal studies are needed with a sufficiently long follow-up period.

Between 1971 and 1981, a few of us have measured renal hemodynamics and neurohormones in a group of untreated patients with uncomplicated essential hypertension. In the period 2001 to 2003 it was possible to examine these variables again in several of these patients. In this follow-up study we investigated long-term changes in renal hemodynamics and neurohormones. In addition, we determined which variables could predict the changes in renal hemodynamics and hormonal levels. Baseline and follow-up measurements were performed in the same metabolic ward under similar standardized conditions. To ensure we would come to the natural history as close as possible, we excluded patients who in the meantime had sustained cardiovascular complications or in whom existing medication could not be interrupted. 


\section{Methods}

\section{Subjects and protocol}

In the seventies, we measured renal hemodynamics and several neurohormones in 265 consecutive hypertensive patients who had been referred for evaluation of their elevated blood pressure. Most of the data which we obtained at that time have been published before ${ }^{10}$. Between 2001 and 2003, using the old addresses of patients and/or the names of their general practitioners, we were able to trace 112 of these patients. The remaining ones had moved or were deceased. Ninety patients agreed to participate in a short preinvestigation, but only half of them appeared to be eligible for the follow-up study. The other half did not qualify because they had experienced some cardiovascular event since the time of the first investigation or their medication could not be safely withheld. Patients were eligible for the follow-up study only when they had stable, uncomplicated hypertension. Twenty-three of the 45 eligible patients agreed to undergo follow-up investigation. The measurements performed at follow-up were comparable to those at baseline and were performed in the same metabolic ward under similar conditions. On both occasions, i.e. at baseline and at follow-up, antihypertensive treatment, if any, was withdrawn at least two weeks prior to the study. Patients were always investigated after 5 days of a low sodium diet $\left(55 \mathrm{mmol} \mathrm{Na}^{+}\right.$per day). Compliance with the diet was checked by measuring sodium and creatinine output in 24-hour urine collections obtained on the last day of the dietary period. Patients had refrained from smoking, alcohol and caffeine from $10 \mathrm{PM}$ the evening before the measurements and they were only allowed to drink water in the morning of the measurements. Experiments started at $8 \mathrm{AM}$ in the morning and patients remained supine during the entire session. In both arms an antecubital vein was cannulated with a 20 -gauge cannula. The cannula in the right arm was connected to a 3-way tap for the infusion of paraaminohippurate (PAH) and inulin, whereas the cannula in the left arm was used for blood sampling. To ensure diuresis, patients consumed $200 \mathrm{ml}$ of water every hour until the last blood samples had been drawn. After a 2-hour equilibration period, necessary to reach steady state plasma concentrations of PAH and inulin, blood samples were drawn at 120,130, 140 and 150 minutes after the start of the PAH/inulin infusion. Additional blood samples were taken for the measurement of active plasma renin concentration (APRC), aldosterone and catecholamines. The study was approved by the Medical Ethical Committee of the Medical Center Rijnmond-Zuid (previously: Zuiderziekenhuis). Informed consent was obtained from each individual recruited. 


\section{Hemodynamic and assay methods}

Both at baseline and at follow-up, blood pressure and heart rate were measured with an oscillometric blood pressure device. Effective renal plasma flow (ERPF) was measured as the clearance of ${ }^{125}$-labeled hippuran at baseline, and as the clearance of PAH (Merck Sharp \& Dohme) at follow-up, using the continuous infusion method. Previous research by our group has shown that these two methods to determine renal plasma flow are entirely comparable and extraction ratios of both tracers are identical. GFR at baseline was measured as the plasma clearance of inulin (continuous infusion) in most patients; in a few early cases, however, cyanocobalamine had been used instead of inulin. At follow-up, GFR was always measured as the clearance of inulin (Inutest, Laevosan Gesellschaft) with the continuous infusion method ${ }^{11}$. GFR and ERPF are expressed in $\mathrm{ml} / \mathrm{min}$. When corrected for body surface area (BSA), data are expressed as $\mathrm{ml} / \mathrm{min} \cdot 1.73 \mathrm{~m}^{2}$. Effective renal blood flow (ERBF) was calculated as ERPF/(1-hematocrit) and renal vascular resistance (RVR) as (MAP/ERBF) 80.000 where MAP stands for mean arterial pressure. RVR data are expressed in dyne-s/cm ${ }^{5}$. Filtration fraction (FF) was calculated as GFR/ERPF.

Not unexpectedly, methods to measure neurohormonal levels have changed considerably over the years. In the early seventies, plasma renin concentrations were determined by bioassay. However, after the discovery of active and inactive renin, all available samples were assayed again using the method of Skinner et al. ${ }^{12}$. The results of this method have, therefore, been taken to represent APRC at baseline. At follow-up, APRC was measured by a 2 -site direct immunoassay (Nichols Institute Diagnostics) ${ }^{13}$, which provides almost similar results as the original method. Levels of aldosterone have been measured using a radioimmuno-assay kit at baseline ${ }^{14}$, while at follow-up a

${ }^{125}$ I-radioimmuno-assay (DiaSorin Inc.) has been used ${ }^{15}$. At the time of the first examination, concentrations of norepinephrine and epinephrine were measured by a radio-enzymatic method using high-performance liquid chromatography (HPLC) separation of the radiochemical products ${ }^{16}$. At follow-up, we measured these neurohormones by HPLC with fluorescent detection ${ }^{17}$.

\section{Statistical analysis}

The Mann-Whitney $\cup$ Test was used to determine whether the follow-up group could be qualified as a representative selection of the total baseline group and to determine the differences in characteristics between men and women. The Wilcoxon Signed Ranks Test was used to compare baseline and follow-up measurements. Linear regression analysis was applied to determine predictors of neurohormones, ERPF at follow-up and the change in ERPF per year, taking potential confounders into account. Data are presented as medians and 
interquartile ranges $(J Q R)$ because a considerable number of variables were not normally distributed. To allow a comparison of the changes in GFR, ERPF and RVR in the present study with those observed in other studies, some of the data are also presented as mean ( \pm standard deviation). Spearman correlation was used to calculate correlation coefficients. For all measurements reported here, the intra- and interassay variability were well below $10 \%$ at both occasions.

\section{Results}

Table 3.1 shows the comparison of baseline characteristics of the follow-up group (23 patients) with the remaining 242 patients at baseline. The follow-up group was younger and had a higher ERPF and ERBF, as well as a lower RVR and FF than the patients who were not included in the follow-up study. The hemodynamic differences, however, could be explained entirely by the difference in age. There were no differences in blood pressure and neurohormones, although aldosterone levels at baseline tended to be somewhat lower in the follow-up group $(p=0.083)$. Baseline and follow-up characteristics of the 23 patients are shown in Table 3.2. We did not find any differences in blood pressure and neurohormones between baseline and follow-up (Table 3.2).

When differences between baseline and follow-up data were considered, heart rate (Table 3.2), GFR and ERPF (Figure 3.1) and ERBF (Table 3.2) all fell with time. Conversely, renal vascular resistance significantly increased while FF remained unchanged (Figure 3.2). When corrected for BSA, ERPF at baseline (median $386($ IQR $328 ; 441) \mathrm{ml} / \mathrm{min} \cdot 1.73 \mathrm{~m}^{2}$ ) was significantly higher than at follow-up (median 304 (IQR 209;352) $\left.\mathrm{ml} / \mathrm{min} \cdot 1.73 \mathrm{~m}^{2} ; \mathrm{p}<0.001\right)$. GFR corrected for BSA was also higher at baseline (104 (IQR 91;155) $\left.\mathrm{ml} / \mathrm{min} \cdot 1.73 \mathrm{~m}^{2}\right)$ than at follow-up (87 (IQR 71;95) $\left.\mathrm{ml} / \mathrm{min} \cdot 1.73 \mathrm{~m}^{2} ; \mathrm{p}=0.001\right)$.

Univariate analysis showed an average fall in GFR of $0.7( \pm 1.0) \mathrm{ml} / \mathrm{min}$ per year (mean $\pm S D$ ) and an average decrease in ERPF of $4.3( \pm 4.4) \mathrm{ml} / \mathrm{min}$ per year. RVR showed an increase of $221( \pm 377)$ dyne.s $/ \mathrm{cm}^{5}$ per year. With linear regression analysis we evaluated which factors predicted GFR and ERPF at follow-up. When controlling for other variables, age and GFR at baseline were predictors of GFR at follow-up and the decrease in GFR per year (Tables 3.3 and 3.4). A higher age and a higher GFR at baseline were associated with a lower GFR at follow-up and a greater fall in GFR. Similarly, age was the only significant predictor of ERPF at follow-up (Table 3.3), meaning that a higher age was associated with a lower ERPF at follow-up. ERPF at baseline, MAP at baseline, BMI and gender did not predict ERPF at follow-up. When the fall in ERPF over time was analysed, both age and ERPF at baseline appeared to 
predict this fall (Table 3.4). In other words, a higher ERPF at baseline resulted in a greater fall in ERPF that was independent from the effect of a higher age. Other factors such as MAP at baseline, BMI and gender did not predict the magnitude of the fall in ERPF.

Table 3.1 Baseline characteristics of the total group and follow-up group.

$\begin{array}{lccc} & \begin{array}{c}\text { Baseline group without } \\ \text { follow-up }\end{array} & \begin{array}{c}\text { Baseline group with } \\ \text { follow-up }\end{array} & \text { P valuea } \\ \text { Number } & 242 & 23 & \\ \text { Age, years } & 47(35,54) & 33(28,37) & <0.001 \\ \text { Gender, } \mathrm{m} / \mathrm{f}(\% \text { male) } & 145 / 97(60 \%) & 16 / 7(70 \%) & 0.365^{\mathrm{b}} \\ \mathrm{BMI}, \mathrm{kg} / \mathrm{m}^{2} & 24.8(22.3,26.9) & 24.2(23.1,26.5) & 0.994 \\ \mathrm{SBP}, \mathrm{mmHg} & 151(135,172) & 146(134,158) & 0.219 \\ \mathrm{DBP}, \mathrm{mmHg} & 95(81,105) & 92(80,96) & 0.296 \\ \mathrm{MAP}, \mathrm{mmHg} & 115(100,128) & 110(96,116) & 0.116 \\ \text { Heart rate, bpm } & 71(63,80) & 73(66,82) & 0.240 \\ \text { GFR, ml/(min) } & 112(98,137) & 115(102,127) & 0.854 \\ \text { ERPF, ml/min } & 369(288,474) & 421(372,503) & 0.022 \\ \text { ERBF, ml/min } & 647(493,855) & 760(614,890) & 0.040 \\ \text { RVR, dyne.s/cm } & 14295(10544,19630) & 11796(9342,14348) & 0.033 \\ \text { Filtration fraction } & 0.33(0.29,0.42) & 0.27(0.24,0.30) & <0.001 \\ \text { APRC, mE/l } & 23.0(12.0,36.0) & 24.0(19.5,38.3) & 0.248 \\ \text { Aldosterone, pmol/l } & 458(300,633) & 351(199,539) & 0.083 \\ \text { Norepinephrine, nmol/l } & 1.39(0.96,1.95) & 1.27(0.81,2.31) & 0.729 \\ \text { Epinephrine, nmol/l } & 0.21(0.11,0.48) & 0.30(0.19,1.31) & 0.177 \\ U_{\text {NaV }} \text { mmol/24h } & 58(44,69) & 61(46,77) & 0.564\end{array}$

BMI, body mass index; SBP, systolic blood pressure; DBP, diastolic blood pressure; MAP, mean arterial pressure; GFR, glomerular filtration rate; ERPF, effective renal plasma flow; ERBF, effective renal blood flow; RVR, renal vascular resistance; $A P R C$, active plasma renin concentration; $U_{\mathrm{Na}} V_{2}, 24$-hour urinary sodium excretion. Data are presented as medians with interquartile ranges, ${ }^{a}$ Mann-Whitney $\cup$ Test; ${ }^{b} \chi^{2}$ test

Table 3.2 Baseline and follow-up characteristics of the 23 patients.

$\begin{array}{lccc} & \text { Baseline } & \text { Follow-up } & \text { P value }^{\text {a }} \\ \text { Age, years } & 33(28,37) & 55(54,60) & - \\ \mathrm{BMI}, \mathrm{kg} / \mathrm{m}^{2} & 24.2(23.1,26.5) & 27.6(24.5,29.8) & <0.001 \\ \mathrm{SBP}, \mathrm{mmHg} & 146(134,158) & 141(132,156) & 0.234 \\ \mathrm{DBP}, \mathrm{mmHg} & 90(80,96) & 84(80,94) & 0.115 \\ \mathrm{MAP}, \mathrm{mmHg} & 110(96,116) & 107(98,111) & 0.155 \\ \text { Heart rate, bpm } & 73(66,82) & 61(55,67) & 0.006 \\ \text { ERBF, ml/min } & 760(614,890) & 599(415,723) & <0.001 \\ \text { Filtration fraction } & 0.27(0.24,0.30) & 0.28(0.26,0.34) & 0.092 \\ \text { Norepinephrine, nmol/l } & 1.27(0.81,2.31) & 0.92(0.47,1.34) & 0.445 \\ \text { Epinephrine, nmol/l } & 0.30(0.19,1.31) & 0.09(0.03,0.12) & 0.715 \\ U_{\mathrm{Na}} \mathrm{V}, \mathrm{mmol} / 24 \mathrm{~h} & 61(46,77) & 68(48,86) & 0.753\end{array}$

$B M I$, body mass index; SBP, systolic blood pressure; DBP, diastolic blood pressure; MAP, mean arterial pressure; ERBF, effective renal blood flow; $U_{N a} V, 24$-hour urinary sodium excretion. Data are presented as medians with interquartile ranges, ${ }^{a}$ Wilcoxon Signed Rank Test 

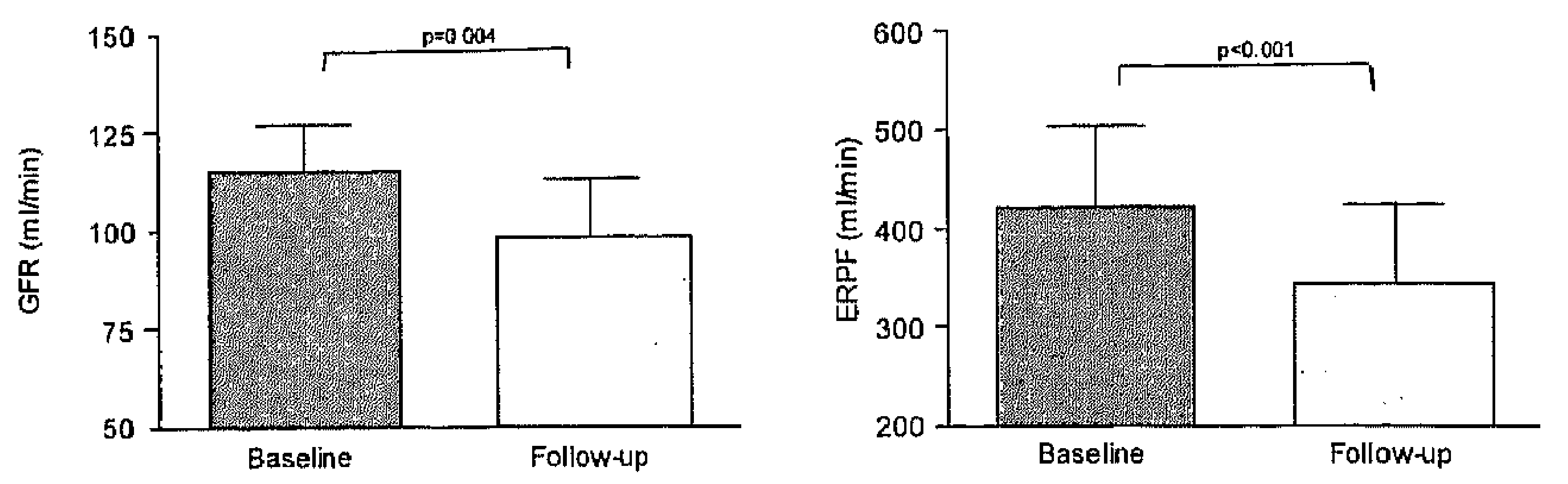

Figure 3.1 GFR and ERPF at baseline and follow-up (median with interquartile ranges).
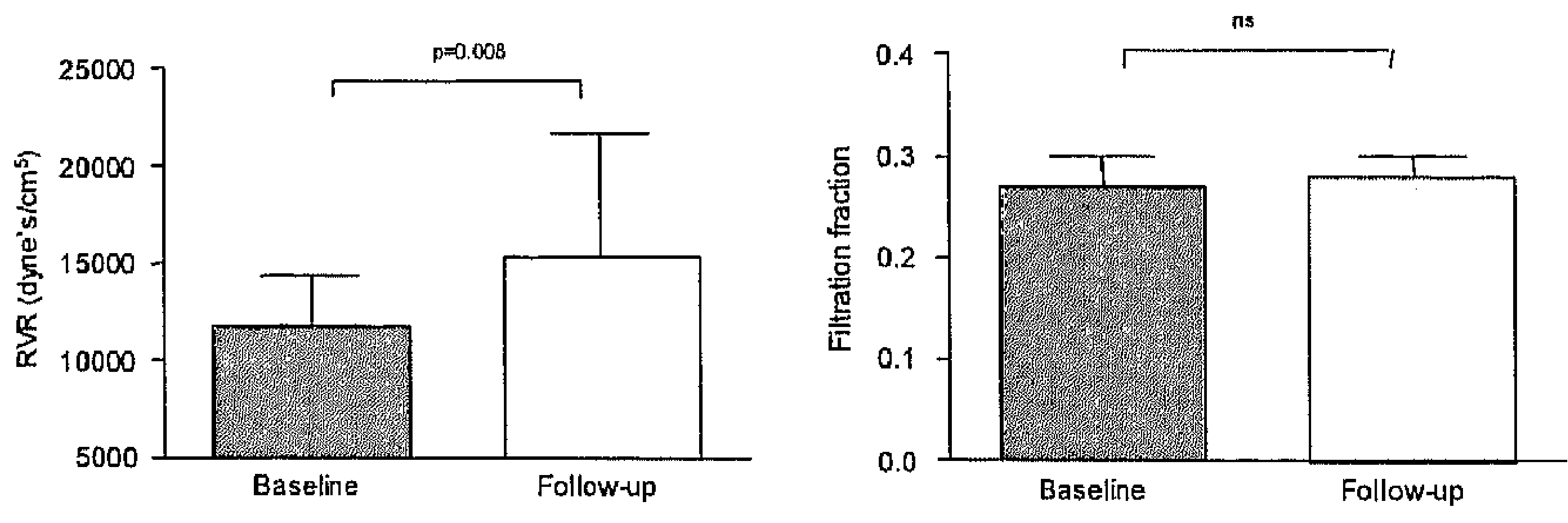

Figure 3.2 RVR and FF at baseline and follow-up (median with interquartile ranges).

Table 3.3 Multivariate linear regression analysis: ERPF at follow-up predicted by age and GFR at follow-up predicted by age and GFR at baseline.

\section{Determinants}

ERPF at follow-up

$\begin{array}{lc}\text { Intercept } & 902 \\ \text { Age } & -9.6 \\ \text { Gender } & -40 \\ \text { BMI at follow-up } & 4.9 \\ \text { MAP at follow-up } & -3.2 \\ \text { ERPF at baseline } & 0.5 \\ \text { GFR at follow-up } & \end{array}$

GFR at follow-up

Intercept

Age

Gender

BMl at follow-up

MAP at follow-up

GFR at baseline
Unstandardized $\beta$

902

$-9.6$

4.9

$-3.2$

100

$-1.5$

12.8

1.4

$-0.015$

0.34
$95 \% \mathrm{Cl}$

$133-1671$

$(-14.5)-(-4.7)$

$(-164)-84$

$(-4.5)-14.2$

$(-9.6)-3.2$

$(-0.01)-1.0$

$(-23)-224$

$(-2.5)-(-0.6)$

$(-4.3)-30$

$(-0.5)-3.3$

$(-0.68)-0.65$

$0.014-0.66$

$\mathrm{Cl}$, confidence interval; $\mathrm{BMI}$, body mass index; MAP, mean arterial pressure; ERPF, effective renal plasma flow; GFR, glomerular filtration rate 
Table 3.4 Multivariate linear regression analysis: decrease in ERPF per year predicted by age and ERPF at baseline and decrease in GFR per year predicted by age and GFR at baseline.

$\begin{array}{lcc}\text { Determinants } & \text { Unstandardized } \beta & 95 \% \mathrm{Cl} \\ \text { Decrease in ERPF per year } & & \\ \text { Intercept } & -17.8 & (-44)-8.3 \\ \text { Age } & 0.39 & 0.13-0.64 \\ \text { Gender } & 1.0 & (-3.1)-5.1 \\ \text { BMI at baseline } & -0.27 & (-1.3)-0.75 \\ \text { MAP at baseline } & -0.06 & (-0.20)-0.09 \\ \text { ERPF at baseline } & 0.026 & 0.008-0.045 \\ \text { Decrease in GFR per year } & & \\ \text { Intercept } & -4.1 & (-9.7)-(1.4) \\ \text { Age } & 0.09 & 0.03-0.14 \\ \text { Gender } & -0.3 & (-1.0)-0.4 \\ \text { BMI at baseline } & -0.10 & (-0.33)-0.13 \\ \text { MAP at baseline } & -0.001 & (-0.03)-0.03 \\ \text { GFR at baseline } & 0.042 & 0.023-0.061\end{array}$

$\mathrm{Cl}$, confidence interval; $\mathrm{BMI}$, body mass index; MAP, mean arterial pressure; ERPF, effective renal plasma flow; GFR, glomerular filtration rate

Both APRC and aldosterone levels fell with time (Figure 3.3), but for neither of these the concentrations at follow-up correlated significantly with age (APRC. Spearman $r=-0.15, p=0.494$; aldosterone, Spearman $r=-0.05, p=0.864$ ) Changes in renin levels were not related to changes in renal vascular resistance (Spearman $r=-0.30, p=0.316$ ) and differences in renin levels and aldosterone did not correlate with each other (Spearman $r=-0.09, p=0.803$ ).
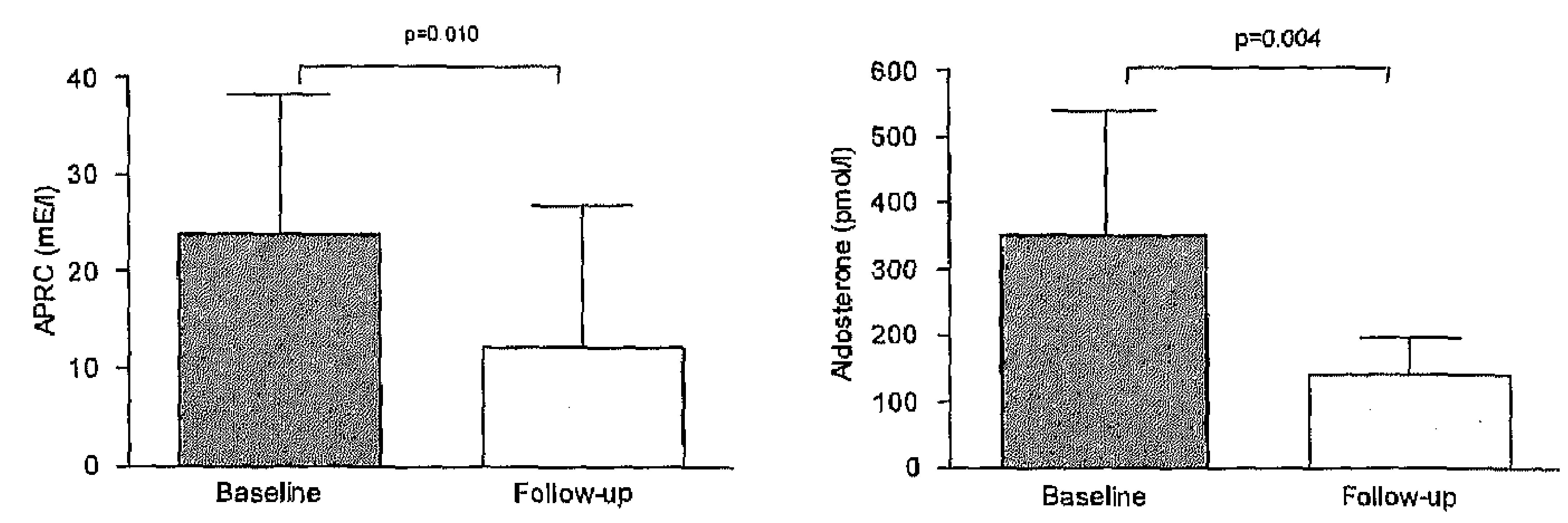

Figure 3.3 APRC and aldosterone at baseline and follow-up (median with interquartile ranges). 
Changes in the levels of APRC were not predicted by age, MAP, ERPF or RVR. In multivariate regression analysis to identify predictors of aldosterone at baseline, controlling for the variables age, BMI, MAP, ERPF and RVR, there was an association between APRC and aldosterone at baseline (unstandardized $\beta=0.059,95 \%$ confidence interval $0.008-0.11$ ) meaning that a higher level of APRC was associated with a higher aldosterone. In this model ERPF and RVR were not included together to prevent multicollinearity. Aldosterone levels at follow-up were not related to any of the abovementioned variables.

\section{Discussion}

The present data show that in uncomplicated essential hypertension which has been adequately treated, 'untreated' blood pressure remains remarkably stable over a prolonged period of time. Nevertheless, over the same time span a significant decline in renal function is demonstrable. In addition, the renin system is suppressed after 24 years of follow-up irrespective of renal hemodynamic factors.

Our longitudinal data confirm that renal blood flow falls with age and that age is the sole determinant of renal flow during follow-up. The magnitude of the fall in ERBF amounted to approximately $25 \%$ in 24 years or roughly $1 \%$ per year and was determined primarily by age and baseline flow. Taken together, this means that the decline in renal perfusion as such is an age-related process and that this process is accelerated when the kidney initially has a relatively high flow. As far as the latter is concerned, we cannot entirely rule out that this is due to regression towards the mean but given the rather low measurement error we do not think this phenomenon to play an important role. The fall in GFR was about $15 \%$ in 24 years or roughly $0.6 \%$ per year. Like renal flow, the fall in GFR was determined mainly by age and baseline GFR.

Previously, several cross-sectional studies have shown that age and blood pressure are independent determinants of renal plasma flow ${ }^{3,18,19}$. Although blood pressure was not significantly related to changes in renal blood flow in the present analysis, it must be emphasized that our patients had stable levels of blood pressure. This is different from the cross-sectional studies where a higher age usually was associated with higher blood pressure. Given the stability of blood pressure over time, the present data allow us to conclude that the age-related decline in renal perfusion must be attributed to an increase in renal vascular resistance with age. This, in turn, may result from structural and/or functional alterations in the renal vascular bed ${ }^{20}$. Our results are in line with Folkow's hypothesis ${ }^{21}$ that structural changes in resistance vessels will 
lead to progressive deterioration of local blood flow. Eventually, such structural alterations may lead to arteriolar nephrosclerosis.

In the literature, decreases in RPF are found of about $10 \mathrm{ml} / \mathrm{min} \cdot 1.73 \mathrm{~m}^{2}$ per year $^{5,22}$ which is more than twice the amount we found in our study $(4.3 \mathrm{ml} / \mathrm{min}$ per year). With increasing age, however, the decrement in ERPF becomes greater, suggesting an accelerated decline in ERPF at higher ages. Although the mean RPF at baseline of the patients in the study of Ljungman et al..$^{5}$ was somewhat lower than in our hypertensives ( 511 vs. $551 \mathrm{ml} /\left(\min \cdot 1.73 \mathrm{~m}^{2}\right)$, her patients were older which may have contributed to a greater fall in renal plasma flow in that study. Also, the duration of the follow-up period or a difference in sodium balance could explain some of the difference.

After the age of 50 , the rate of decline in glomerular filtration rate is approximately $1 \mathrm{ml} / \mathrm{year}^{3}$. Our hypertensive group exhibited a decrease in GFR of $0.7 \mathrm{ml} / \mathrm{min}$ per year which is close to the value from the cross-sectional studies. Another study from Ljungman's group has shown that in hypertensive patients GFR fell during the first 7 years by $2.7 \mathrm{ml} / \mathrm{min}$ per year, while during the next 7 years no further reduction in GFR was seen ${ }^{22}$. It is possible, therefore, that our hypertensive population also had no linear fall in GFR. Because we did not perform measurements of renal function between baseline and follow-up, we are not informed about differential changes in different time periods. In normotensives, GFR remained on the same level after a follow-up period of 14 years $^{22}$.

Cross-sectional studies further suggest that renin and aldosterone levels fall with increasing age and with progression of the hypertensive process. At the time that our baseline measurements were performed, there was much debate in the literature about the cause of the fall in renin. Whereas some have attributed this to an excess volume ${ }^{23}$, we and others favored increased pressure at the level of the juxtaglomerular apparatus as the prime determinant of renin suppression ${ }^{24}$. In our current study, however, APRC at follow-up was significantly lower than at baseline, suggesting that with increasing age renin levels fall even when blood pressure and filtration fraction (as a proxy for intrarenal pressure) remain unchanged. It is important to note that in the present analysis APRC is related to the duration of follow-up, not to age per se. When the relation between APRC and age is considered, age itself is not a determinant of the magnitude of the fall in APRC. Previous studies have shown that plasma renin levels were directly related to renal blood flow and inversely to renal vascular resistance. Although we found APRC to be lower and RVR to be higher after follow-up, we could not conclude that the fall in renin is related to the rise in RVR and increased glomerular pressure, possibly because the number of patients was rather small.

Intuitively, one would be inclined to believe that the age-dependent reduction in plasma aldosterone is coupled to the suppression of renin. Although we cannot 
exclude that possibility entirely, our analysis does not lend support for this hypothesis either. While it may still be true that the angiotensin-mediated stimulation of aldosterone depends on the renin status of the individual ${ }^{25}$ concurrent changes in baseline levels of renin and aldosterone should probably be viewed upon as separate phenomena.

Data from our previous cross-sectional study would predict an increase of about $15 \mathrm{mmHg}$ in MAP over a period of 24 years in untreated subjects ${ }^{10}$. However, in the present study blood pressure had not risen at all after the 24-year follow-up period. This could partly be explained by the fact that the patients who participated form a selected group of individuals with stable, uncomplicated hypertension. Evidently, these patients have been treated adequately during this period. Still, heart rate was significantly lower after the follow-up period. Theoretically, this could be related to reduced sympathetic activity, but the fact that plasma catecholamines remained unchanged does not fit into this supposition. Along the same line of reasoning, decreased sensitivity of $\beta$-receptors is unlikely to explain the results because then one would expect a rise in catecholamines. Although several studies have, indeed, demonstrated that with increasing age levels of catecholamines rise, this could not be confirmed by others. Even in this longitudinal study, we failed to find a change in plasma catecholamines when the baseline data were compared to those after follow-up. Perhaps, the fall in heart rate should be explained by intrinsic ageing of the sinus node.

Our study should be interpreted within the context of its limitations. Most importantly, this concerns the selection of our patients. Those who were willing to participate may have been more compliant with treatment and more concerned about their health than those who were not. Yet, in terms of physiological variables at baseline the study group did not differ substantially from the others making selection bias somewhat less likely. The fact that the follow-up group was younger at baseline only reflects that this group lived long enough to make it to the next investigation. The similarity of blood pressure at entry and after follow-up may be another source of concern. It could mean that the period during which treatment was washed-out was not long enough. On the other hand, it could also be seen as an advantage because blood pressure could now be ruled out as an important determinant of the observed changes. Nevertheless, it remains possible that more pronounced alterations would have been noted if blood pressure had risen. Finally, the natural history is not truly mimicked since patients had received treatment for a prolonged period of time. Still, the strength of our observations is that follow-up time was long, nearly a quarter of a century, and that we studied our patients under identical 
circumstances, in the same laboratory and by and large with the same measurement techniques.

In conclusion, this longitudinal study shows that with increasing age, glomerular filtration rate, effective renal plasma flow, renin and aldosterone all fall. Age by itself seems to be the most important determinant of the changes in renal hemodynamics. The factors which lead to suppression of renin are less well understood but may be related to the rise in renal vascular resistance. 


\section{References}

1 Juhus $S$ The blood pressure seeking properties of the central nervous system. J Hypertens 1988.6.177-185

2. Mulvany MJ. Aalkjaer C Structure and function of small arteries. Physiol Rev 1990; 70.921-961

3. de Leeuw PW. Birkenhager WH. The renal circulation in essential hypertension. J Hypertens $19831: 321-331$

4. van Hooft IM. Grobbee DE, Derkx FH, de Leeuw PW, Schalekamp MA, Hofman A. Renal hemodynamics and the renin-angiotensin-aldosterone system in normotensive subjects with hypertensive and normotensive parents. N Engl J Med 1991:324:1305-1311.

5. Ljungman S. Wikstrand J, Hartford M, Aurell M, Lindstedt G, Berglund G. Effects of long-term antihypertensive treatment and aging on renal function and albumin excretion in primary hypertension. Am J Hypertens 1993:6:554-563.

6 Schalekamp MA. Schalekamp-Kuyken MP, Birkenhager WH. Abnormal renal haemodynamics and renin suppression in hypertensive patients. Clin Sci 1970;38:101-110.

7. Trenkwalder $P$. James GD. Laragh JH. Sealey JE. Plasma renin activity and plasma prorenin are not suppressed in hypertensives surviving to old age. Am J Hypertens 1996;9:621-627.

8 Ljungman S. Aurell M, Hartford M. Wikstrand J, Berglund G. Renal function before and after withdrawal of long term antihypertensive treatment in primary hypertension. Drugs 1988;35 Suppl 5:55-58

9. Siewert-Delle A. Long-term renal function in primary hypertension. An epidemiological and pathophysiological study. Scand J Urol Nephrol Suppl 1999;199:1-36.

10. de Leeuw PW. Kho TL. Falke HE. Birkenhäger WH, Wester A. Haemodynamic and endocrinological profile of essential hypertension. Acta Med Scand 1978;204 (Suppl 622): 9-86.

11. Cole $B R$, Giangiacomo J, Ingelfinger JR, Robson AM. Measurement of renal function without urine collection. A critical evaluation of the constant-infusion technic for determination of inulin and para-aminohippurate. N Engl J Med 1972;287:1109-1114.

12. Skinner SL, Cran EJ, Gibson R, Taylor R, Walters WA, Catt KJ. Angiotensins I and II, active and inactive renin, renin substrate, renin activity, and angiotensinase in human liquor amnii and plasma. Am J Obstet Gynecol 1975;121:626-630.

13. Simon D. Hartmann DJ, Badouaille G, Caillot G, Guyenne TT, Corvol P, Pau B, Marchand J. Two-site direct immunoassay specific for active renin. Clin Chem 1992;38:1959-1962.

14. Malvano R, Gandoffi C, Giannessi D, Giannotti P, Grosso P. Radioimmunoassay of aldosterone in crude plasma extracts. J Nucl Biol Med 1976;20:37-44.

15. Kubasik NP, Warren K. Sine HE. Evaluation of a new commercial radioassay kit for aldosterone using an iodinated tracer. Clin Biochem 1979:12:59-61.

16. Endert $E$. Determination of noradrenaline and adrenaline in plasma by a radioenzymatic assay using high pressure liquid chromatography for the separation of the radiochemical products. Clin Chim Acta 1979;96:233-239.

17. Van der Hoorn FAJ, Boomsma F, Man in 't Veld AJ, Schalekamp MADH. Determination of catecholamines in human plasma by high-performance liquid chromatography: comparison between a new method with fluorescence detection and an established method with electrochemical detection. J Chromatogr 1989;487:17-28

18. Ribstein J. Du Cailar G. Mimran A. Glucose tolerance and age-associated decline in renal function of hypertensive patients. J Hypertens 2001;19:2257-2264.

19. Schmieder RE, Schachinger H, Messerli FH. Accelerated decline in renal perfusion with aging in essential hypertension. Hypertension 1994;23:351-357.

20 Epstein M. Aging and the kidney. J Am Soc Nephrol 1996;7:1106-1122.

21. Folkow B. The debate on the amplifier hypothesis' - some comments. J Hypertens 2000
$18 \cdot 375-378$ 
22. Siewert-Delle A, Ljungman $S$, Hartford $M$, Wikstrand J. Effect of 14 years of antihypertensive treatment on renal function and urinary albumin excretion in primary hypertension. Am $J$ Hypertens 1996;9:841-849.

23. Laragh JH. Lewis K. Dahl Memorial Lecture. The renin system and four lines fo hypertension research. Nephron heterogeneity, the calcium connection, the prorenin vasodilator limb, and plasma renin and heart attack. Hypertension 1992;20:267-279.

24. Schalekamp MA, Krauss XH, Kolsters G, Schalekamp MP. Birkenhager WH. Renin suppression in hypertension in relation to body fluid volumes, patterns of sodium excretion and renal haemodynamics. Clin Sci Mol Med Suppl 1973;45 Suppl 1:283-286.

25. Hollenberg NK, Williams GH. Abnormal renal function, sodium-volume homeostasis and renin system behavior in normal-renin essential hypertension: the evolution of the nonmodulator concept. In: Laragh JH, Brenner BM. Hypertension: Pathophysiology, Diagnosis and Management. New York: Raven Press Ltd.; 1995:1837-1856. 


\section{Chapter 4}

\section{Association between the $\alpha$-adducin Gly460Trp polymorphism and systolic blood pressure in familial combined hyperlipidemia}

E Beeks, RGJH Janssen, AA Kroon, ETP Keulen, JMW Geurts, PW de Leeuw, TWA de Bruin 


\section{Abstract}

\section{Background}

In a genome scan for familial combined hyperlipidemia ( $F C H L)$, a locus contributing to systolic blood pressure (SBP) has been identified on chromosome 4, containing the $\alpha$-adducin gene (ADD1). In previous studies, an association has been found between the $\alpha$-adducin Gly460Trp polymorphism and salt-sensitive hypertension. In this study, we investigated the association between the $\alpha$-adducin Gly460Trp polymorphism and blood pressure in FCHL patients.

\section{Methods}

Seventy-nine unrelated patients with FCHL and 121 unrelated controls (spouses) were recruited for the study. Blood pressure was measured in a standardized fashion, with the subject in sitting position after 10 minutes of rest. The $\alpha$-adducin Gly460Trp polymorphism was detected by mutagenically separated PCR.

\section{Results}

The genotype frequencies of both FCHL patients and controls were in Hardy-Weinberg equilibrium The $\alpha$-adducin Gly460Trp polymorphism showed a significant association with $\mathrm{FCHL}$, the number of subjects carrying a 460Trp allele was significantly higher in patients compared with controls $\left(53 \%\right.$ vs. $\left.33 \%, \chi^{2}=8.0, p=0.018\right)$. In $\mathrm{FCHL}$ patients carrying at least one 460Trp allele, SBP was significantly higher compared with patients homozygous for the $460 \mathrm{Gly}$ allele $(140 \mathrm{mmHg}$ and $130 \mathrm{mmHg}$ respectively, $p=0.015$ ).

\section{Conclusion}

This study shows that the 460Trp allele is associated with FCHL. Furthermore, SBP is increased in patients carrying the $460 \mathrm{Trp}$ allele. 


\section{Introduction}

Familial combined hyperlipidemia (FCHL) is a common lipid disorder characterized by elevated plasma cholesterol and triglyceride levels with segregation in first-degree relatives ${ }^{1}$. In a previous study, about one-third of families with $\mathrm{FCHL}$ and 27 percent of $\mathrm{FCHL}$ relatives appeared to have familial dyslipidemic hypertension ${ }^{2}$. Since insulin resistance is a frequent finding in $\mathrm{FCHL}^{1,3.4}$ and because insulin can increase renal tubular sodium reabsorption ${ }^{5}$, it is plausible that hyperinsulinemia could contribute to the pathogenesis of hypertension in $\mathrm{FCHL}$ by rendering blood pressure more sodium-dependent ${ }^{6}$. Although the mechanisms that cause sodium sensitivity of blood pressure are still unknown, several genes are thought to play a role in this process. Interestingly, the $\alpha$-adducin Gly460Trp polymorphism is associated with enhanced renal tubular sodium reabsorption and can account for a sodiumsensitive rise in blood pressure ${ }^{7,8}$. Recently, several genome scans have confirmed the multigenic nature of blood pressure ${ }^{9,10}$ and hypertension ${ }^{11}$ in humans. A locus that contributes to systolic blood pressure (SBP) in families with FCHL was identified on chromosome 4 (LOD score of 3.9), which contains the $\alpha$-adducin gene $(A D D 1)^{10}$. In Milan hypertensive rats, $A D D 1$ is a candidate gene for SBP, showing a LOD score of 3.2 with SBP. ${ }^{12}$ Based on these data, we set out to investigate the association between the $\alpha$-adducin Gly460Trp polymorphism and FCHL and to determine the relationship of different genotypes with blood pressure in patients with FCHL.

\section{Methods}

\section{Study population}

Seventy-nine unrelated Caucasian FCHL patients were identified at our Lipid Clinic. The FCHL patients met each of the following criteria: first, a primary hyperlipidemia including fasting total plasma cholesterol (TC) $>250 \mathrm{mg} / \mathrm{dl}$ $(6.5 \mathrm{mmol} / \mathrm{l})$ and/or fasting plasma triglyceride (TG) concentration $>200 \mathrm{mg} / \mathrm{dl}$ (2.3 mmol/l); second, at least one first-degree relative with a different hyperlipidemic phenotype (Fredrickson Classification Ila, IIb or IV); third, a positive family history of premature coronary artery disease (CAD). Premature CAD was defined as the occurrence of a myocardial infarction (MI) or other cardio-vascular disease before the age of 60 in at least one first-degree relative of the patient, or the patient him/herself. Secondary causes of hyperlipidemia (renal or hepatic insufficiency, hypothyroidism and medication), presence of the apo E2/E2 genotype, and subjects with tendon xanthomas or a diagnosis matching familial hypercholesterolemia were excluded. The control group, 
Chapter 4

which consisted of 121 spouses, was age-matched. These 121 spouses were married either with one of the 79 patients or with another family member with FCHL who was not included in this study. The study was approved by the hospital's Medical Ethical Committee. Informed consent was obtained from each individual recruited.

\section{Measurements}

All measurements were performed at the Clinical Research Unit in the morning $\left(08^{00}-10^{00}\right)$ after an overnight fast. Subjects had refrained from smoking and were only allowed to drink water in the morning. Participants also had abstained from alcohol for at least 72 hours. All participants were weighed in underwear, the height was determined and the body mass index (BMI) was subsequently calculated as weight in kilograms / (height in meters) ${ }^{2}$. The waist $(W)$ was measured at the level of the umbilicus, the hip circumference $(H)$ was measured at the level of the trochanter major and the waist to hip ratio $(W / H)$ was calculated from these figures. Blood pressure was measured twice in a standardized fashion, with the subject in sitting position after 10 minutes of rest. Cuff size was adjusted to the circumference of the arm, and the arm was placed with the cuff at heart-level. The average of two measurements was used
for analysis.

\section{Biochemical analysis}

Any lipid lowering medication had been withdrawn during the two weeks before blood samples were collected. After an overnight fast, venous blood was collected in pre-cooled EDTA $(1-\mathrm{mg} / \mathrm{ml})$ vacutainer tubes for measurement of lipids and insulin. Total cholesterol (TC) and fasting triglyceride (TG) concentrations were measured in duplicate by a commercially available colorimetric assay (Monotest Cholesterol kit, Boehringer Mannheim \# 1442350 and GPO-PAP, Boehringer Mannheim, \# 701912, respectively). Fasting insulin concentration $(\mathrm{FI})$ was determined using an Elisa (Mercodia $A B$, Uppsala, Sweden), with a cross-reactivity with pro-insulin of $<0.01 \%$.

\section{Genetic analysis}

DNA was extracted from whole blood using the Wizard Genomic DNA Purification Kit (Promega, Leiden, the Netherlands). The $\alpha$-adducin Gly460Trp polymorphism was detected by mutagenically separated PCR. ${ }^{13,14}$ Briefly, two allele-specific primers (FP614G: 5'-GGG GCG ACG AAG CTT CCG AGG TAG-3'; FP614T: 5'-GCT GAA CTC TGG CCC AGG CGA CGA AGC TTC CGA GGA TT-3') and their nonselective complementary strand primer (RP614: 5'-CCT CCG AAG CCC CAG CTA CCC A-3') were mixed and used for the 
PCR amplification in a single reaction. Deliberate differences were introduced into the allele-specific primers in addition to the base substitution, to drastically reduce cross-reactions between two allelic PCRs in a mixed reaction. The mutagenically separated PCR products (corresponding with the Gly460 and 460 Trp alleles), varying $14 \mathrm{bp}$ in size, were resolved on a $3 \%$ agarose gel and visualized using ethidium bromide and UV light. Genotypes were scored by two experienced researchers independently.

\section{Statistical analysis}

The calculation of allele frequencies to test for Hardy-Weinberg equilibrium was carried out using $\chi^{2}$ analysis comparing expected against observed frequencies. To test for associations, genotype frequencies (Gly460Gly, Gly460Trp and Trp460Trp) were compared by $\chi^{2}$ analysis. Mann-Whitney $U$ test and $\chi^{2}$ analysis were used to determine differences in clinical characteristics between FCHL patients and their controls and between the two genotype groups (Gly460Gly vs. 460Trp allele) of the $\alpha$-adducin Gly460Trp polymorphism. Analysis of variance (ANOVA) was done to determine the combined effect of the $\alpha$-adducin Gly460Trp polymorphism and FCHL on SBP. Forty-three patients with $\mathrm{FCHL}(55 \%)$ were not using antihypertensive medication. To exclude the effect of antihypertensive treatment on blood pressure values, analyses on the genotype level were done only with patients who were not using antihypertensive medication. Data are presented as medians with interquartile ranges. A $P$ value of less than 0.05 was considered statistically significant. Statistical analyses were performed using SPSS for Windows (version 10.0).

\section{Results}

The clinical characteristics of the 79 unrelated FCHL patients and the 121 spouse controls are summarized in Table 4.1. SBP was significantly higher in the $\mathrm{FCHL}$ patients compared with controls, age and diastolic blood pressure (DBP) were not significantly different between patients and controls. As expected, differences were found between FCHL patients and spouse controls for gender, BMI, waist-hip ratio, total plasma cholesterol and plasma triglyceride concentration and insulin levels. Genotypes were obtained from 79 patients and 121 controls. Both the groups of $\mathrm{FCHL}$ patients and spouse controls were in Hardy-Weinberg equilibrium. The $\alpha$-adducin Gly460Trp polymorphism showed a significant association with FCHL. Notably, the number of 460Trp allele carriers was significantly higher in the patients (42/79, 
Chapter 4

$53 \%)$ compared with spouse controls $\left(40 / 121,33 \%, \chi^{2}=8.0, p=0.018\right.$, Figure
$4.1)$.

Table 4.1 Clinical characteristics of all FCHL patients and spouse controls.

$\begin{array}{lcc}\text { Number } & \text { FCHL } & \text { Spouses } \\ \text { Age (yrs) } & 79 & 121 \\ \text { Sex }(\mathrm{M} / \mathrm{F}) & 54(46,59) & 50(43,60) \\ \text { BMI }\left(\mathrm{kg} / \mathrm{m}^{2}\right) & 48 / 31 & 50 / 71^{\mathrm{b}} \\ \text { WHR } & 27.3(25.0,29.7) & 24.7(22.5,28.1)^{\mathrm{a}} \\ \text { TC (mmol/l) } & 0.94(0.88,0.98) & 0.85(0.79,0.92)^{\mathrm{a}} \\ \text { TG (mmol/l) } & 6.71(5.90,7.77) & 5.45(4.93,6.02)^{\mathrm{a}} \\ \text { Insulin }(\mathrm{mU} / \mathrm{l}) & 2.78(2.06,4.31) & 1.17(0.92,1.55)^{\mathrm{a}} \\ \text { SBP }(\mathrm{mmHg}) & 10.0(6.0,14.1) & 5.0(2.0,8.0)^{\mathrm{a}} \\ \text { DBP }(\mathrm{mmHg}) & 138(125,145) & 128(118,140)^{\mathrm{b}}\end{array}$

BMI, body mass index; WHR, waist/hip ratio; TC, total cholesterol; TG, plasma triglyceride values are medians with interquartile ranges; ${ }^{a} p<0.001 ;{ }^{b} p<0.01$

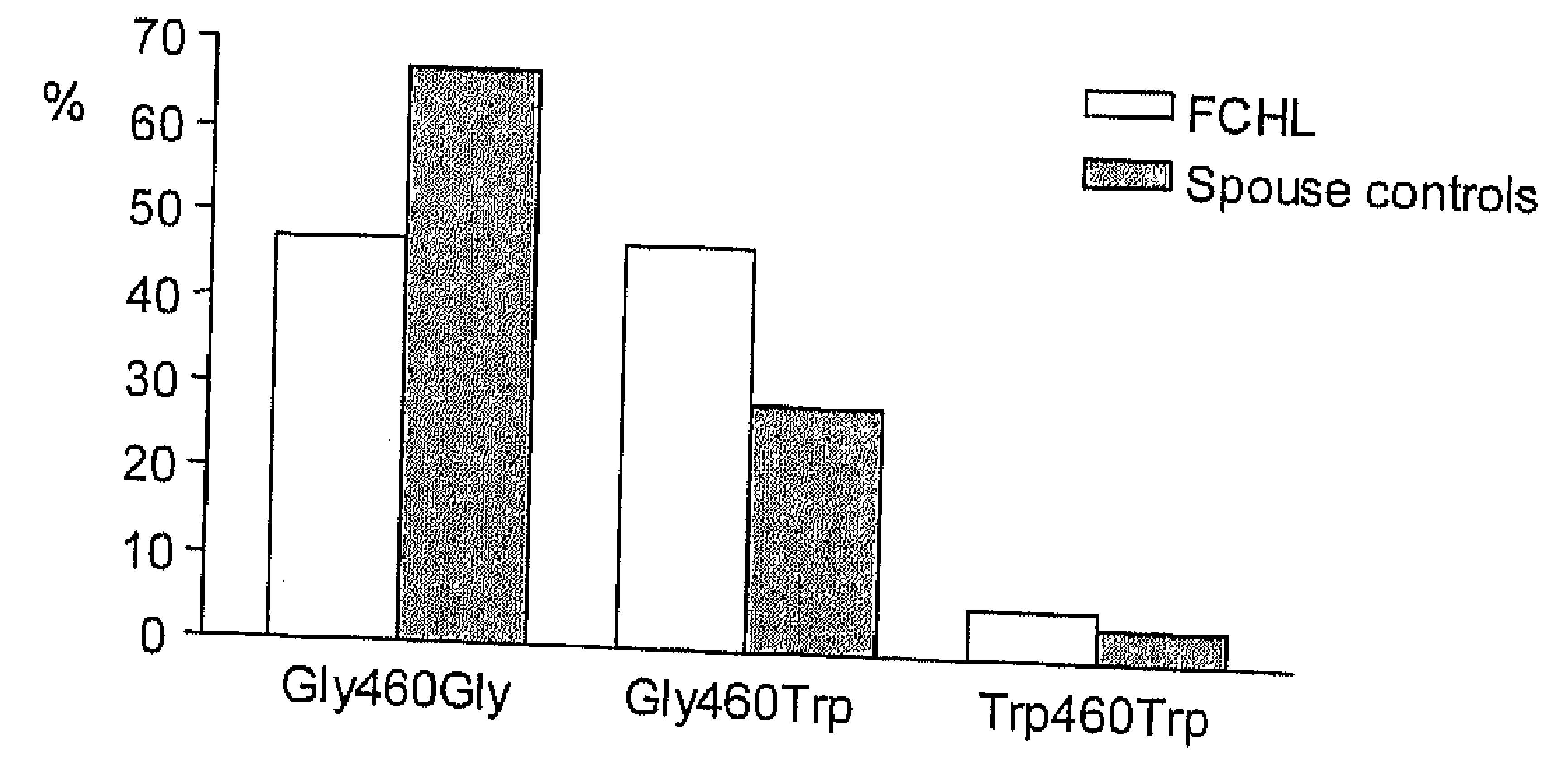

Figure $4.1 \alpha$-Adducin Gly460Trp polymorphism genotype distribution in 79 unrelated FCHL patients and 121 spouse controls. Forty-two out of $79 \mathrm{FCHL}$ patients were $460 \mathrm{Trp}$ $p=0.018$.

Because it is known that the $G$ to $T$ substitution in the $\alpha$-adducin gene has When FCHL patients, ${ }^{7}$ genotype-phenotype relationships were studied. considered separately $\mathrm{SBP}$ aut antihypertensive treatment $(n=43)$ were carriers compared with 460 was significantly higher in the 460Trp allele range 130-152) and $130 \mathrm{mmHg}$ (interquarygotes $(140 \mathrm{mmHg}$ (interquartile Figure 4.2A). No differences 
460Gly homozygotes in DBP, age, BMI, waist-hip ratio, insulin levels and lipids (Table 4.2). In spouse controls without antihypertensive medication no significant differences were found between the two genotype groups (Figure $4.2 \mathrm{~B})$.

\section{A. FCHL patients}

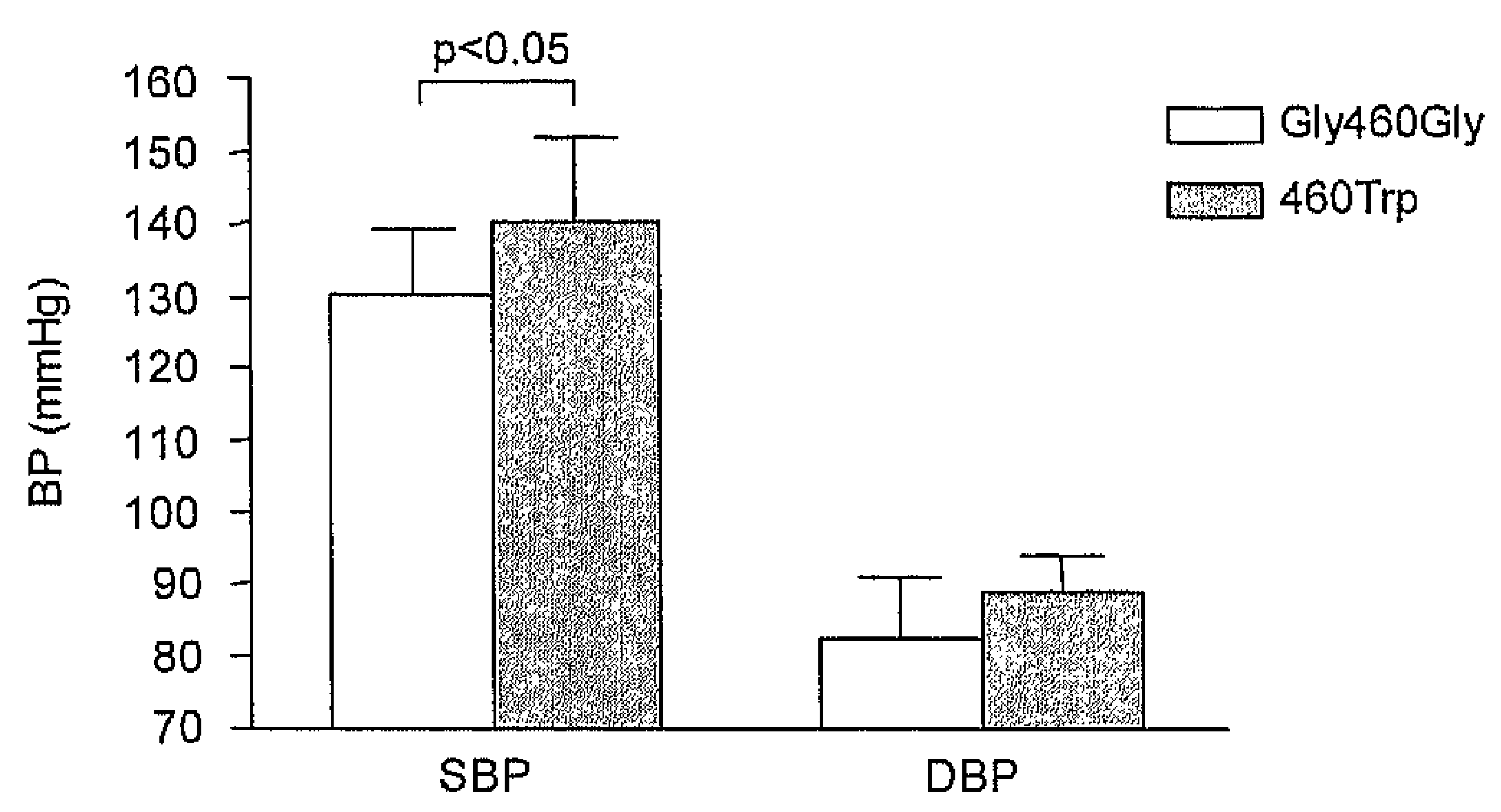

B. Spouse controls

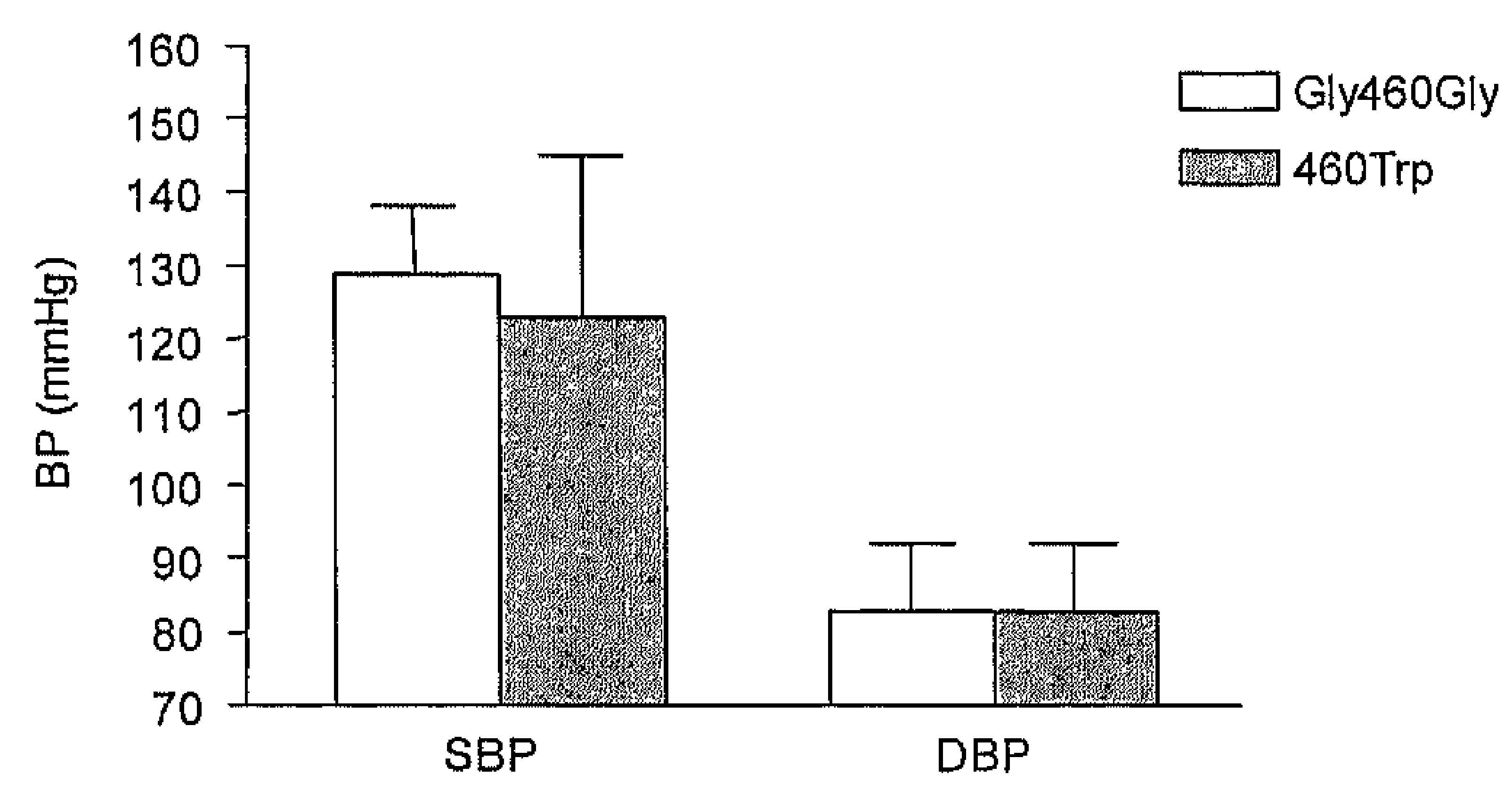

Figure 4.2 SBP and DBP by genotype groups of the $\alpha$-adducin Gly460Trp polymorphism in patients with $\mathrm{FCHL}$ without antihypertensive medication. (A) SBP in Gly40Gly genotype $(n=22): 130[115,139] \mathrm{mmHg}, \operatorname{SBP}$ in 460Trp allele carriers $(n=21): 140$ $[130,152] \mathrm{mmHg}, p=0.015$, (B) SBP in Gly460Gly genotype: $129[119,138] \mathrm{mmHg}$, SBP in 460Trp allele carriers: $123[113,145] \mathrm{mmHg}, p=0.700$. Data are presented as medians with interquartile ranges. 
Chapter 4

Table 4.2 Clinical characteristics in FCHL patients without antihypertensive treatment by genotype groups.

$\begin{array}{lcc} & \text { Gly460Gly } & 460 \text { Trp } \\ \text { Number } & 22 & 21 \\ \text { Age }(\mathrm{yrs}) & 51(39,57) & 51(47,60) \\ \text { Sex }(\mathrm{M} / \mathrm{F}) & 15 / 7 & 13 / 8 \\ \text { BMI }\left(\mathrm{kg} / \mathrm{m}^{2}\right) & 27.5(25.5,29.6) & 27.8(25.6,29.9) \\ \text { WHR } & 0.94(0.89,0.98) & 0.98(0.89,1.01) \\ \text { TC (mmol/l) } & 7.11(6.30,8.51) & 7.15(6.47,8.07) \\ \text { TG (mmol/l) } & 3.80(2.22,5.83) & 2.77(2.09,4.46) \\ \text { Insulin }(\mathrm{mU} / \mathrm{l}) & 9.5(5.3,16.5) & 11.5(8.3,14.0)\end{array}$

For abbreviations see Table 4.1; values are medians with interquartile ranges

Table 4.3 shows the effect of the $\alpha$-adducin Gly460Trp polymorphism and $\mathrm{FCHL}$ on SBP and DBP. Although in univariate analysis the combination of $\mathrm{FCHL}$ and the 460Trp allele is associated with elevated SBP, ANOVA just failed to reach statistical significance $(F=2.577, p=0.056)$.

Table 4.3 Association between the $\alpha$-adducin Gly460Trp polymorphism, FCHL and blood pressure.

$\begin{array}{lcc} & \text { FCHL } & \text { Spouses } \\ \text { G/y460G/y } & \mathrm{n}=22 & \mathrm{n}=76 \\ \text { SBP } & 130(115,139) & 129(119,138) \\ \text { DBP } & 82(74,91) & 83(76,92) \\ \text { 460Trp } & \mathrm{n}=21 & \mathrm{n}=37 \\ \text { SBP } & 140(130,152) & 123(113,145) \\ \text { DBP } & 89(80,94) & 83(75,92)\end{array}$

Subjects without antihypertensive medication; data are presented as medians (interquartile ranges)

\section{Discussion}

The present study shows that the 460Trp allele of the $\alpha$-adducin gene is associated with FCHL. In addition, we found that SBP is increased in FCHL patients carrying the 460Trp allele.

The frequency of the 460Trp allele varies in different populations. In this study, $53 \%$ of the FCHL patients carried the 460Trp allele while in the spouse controls $33 \%$ were $460 \mathrm{Trp}$ allele carriers. The genotype distribution in our control group is comparable to that in a Scottish population ${ }^{15}$ with low to normal blood pressure and to the distribution in a normotensive Finnish population. ${ }^{16}$ In Italians, lower frequencies of the 460Trp allele were found, ${ }^{8}$ whereas in a 
Japanese study ${ }^{14}$ and in an Anglo-Celtic population ${ }^{17}$ the frequency of subjects with this genotype was much higher. At present, genotype frequencies of the $\alpha$-adducin Gly460Trp polymorphism in FCHL populations have not been reported.

Our Dutch FCHL population comprised more men than women, which resulted in an expected significant gender difference between FCHL patients and spouse controls. The $\alpha$-adducin polymorphism was equally distributed between men and women. Because risk factors for elevated SBP such as gender, age, waist-hip ratio and $\mathrm{BMI}$ were not significantly different between patients carrying the 460Trp allele and patients homozygous for the 460Gly allele, in univariate analysis the 460Trp allele emerged as a new risk factor for elevation of SBP in FCHL.

Analyses on the genotype level were performed only in patients without antihypertensive medication ( $54 \%$ of all patients with $\mathrm{FCHL}$ ) to exclude an effect of treatment on the association between the $\alpha$-adducin polymorphism and blood pressure. Only eight percent of the spouse controls were using antihypertensive medication. Even when all FCHL patients were considered $(n=79)$, including those on antihypertensive treatment, SBP was still higher in the 460Trp allele carriers, but this difference just failed to reach statistical significance $(140 \mathrm{mmHg}$ vs. $130 \mathrm{mmHg}, \mathrm{p}=0.058)$.

The mechanism by which $\alpha$-adducin could increase blood pressure is not fully known. $\alpha$-Adducin is thought to regulate ion transport through changes in the actin cytoskeleton. ${ }^{18,19}$ The heterodimer protein is present in many tissues, including the kidney. ${ }^{19}$ Adducin is thought to stimulate Na-K-ATPase, thus promoting sodium reabsorption by renal tubular cells. Indeed, there is evidence to show that adducin polymorphisms are involved in genetic alterations of cell $\mathrm{Na}+$ transport and the pathogenesis of primary hypertension in rats and humans. ${ }^{20}$ Our present data suggest that there may be an interaction between $\mathrm{FCHL}$, the $\alpha$-adducin polymorphism and blood pressure. Theoretically, this could be related to obesity, insulin resistance ${ }^{21}$ and salt sensitivity. ${ }^{22}$ Essential hypertensives who are salt sensitive are relatively insulin resistant compared with essential hypertensives who are less salt sensitive, independently of confounding factors such as age, obesity and glucose tolerance. Furthermore, there is a significant correlation between salt-induced changes in blood pressure and fasting insulin levels, suggesting a relationship between hyperinsulinemia and salt sensitivity. ${ }^{6}$ In our study, the 460Trp allele of the $\alpha$-adducin polymorphism that can induce a sodium dependent rise in blood pressure is associated with a rise in SBP in patients with $\mathrm{FCHL}$, but not in normal subjects. A possible explanation is that $\mathrm{FCHL}$ patients have significantly higher plasma insulin levels compared to controls. The hyperinsulinemia is a key background feature to explain the expression of hypertension in FCHL and explain the association. Another possible explanation for our present results is 
the fact that patients with $\mathrm{FCHL}$ have impaired vascular function. ${ }^{23}$ In hypercholesterolemia and hypertension, impaired endothelium dependent vasodilation has been documented ${ }^{24}$ and vasodilation to acetylcholine is blunted in sodium-sensitive hypertensive patients even on restricted sodium diets. This abnormality may contribute to blood pressure elevation when sodium intake is increased. ${ }^{25}$ However, other studies suggest that patients with hypercholesterolemia who have impaired endothelial dependent relaxation remain normotensive. ${ }^{26}$ Therefore, decreased $\mathrm{NO}$ availability in itself does not necessarily result in systemic hypertension, but it may enhance the individual's sensitivity to the hypertensinogenic effect of dietary sodium. ${ }^{27}$ In this theory, endothelial dysfunction mediates, in part, the expression of higher SBP and hypertension, especially in FCHL.

In conclusion, the present study shows that the 460Trp allele of the $\alpha$-adducin polymorphism is associated with FCHL. Furthermore, systolic blood pressure is increased in patients carrying the 460Trp allele. However, it is still possible that another gene in this chromosomal region in linkage disequilibrium with the 460Trp allele is the true cause of hypertension in FCHL. Future work should include functional studies to reveal whether the $\alpha$-adducin Gly460Trp polymorphism is a marker for functional changes associated with blood pressure elevation in FCHL. 


\section{References}

1. Grundy SM, Chait A, Brunzell JD. Familial combined hyperlipidemia workshop. Arteriosclerosis. 1987;7:203-207.

2. Keulen ETP, Voors-Pette $C$, de Bruin TWA. Familial dyslipidemic hypertension syndrome: familial combined hyperlipidemia, and the role of abdominal fat mass. Am J Hypertens. 2001:14:357-363.

3. Ascaso JF, Lorente R, Merchante A, Real JT, Priego A, Carmena R. Insulin resistance in patients with familial combined hyperlipidemia and coronary artery disease. Am J Cardiol. 1997:80:1484-1487.

4. Hunt SC, Wu LL, Hopkins PN, Stults BM, Kuida H, Ramirez ME, Lalouel JM, Williams RR. Apolipoprotein, low density lipoprotein subfraction, and insulin associations with familial combined hyperlipidemia. Study of Utah patients with familial dyslipidemic hypertension. Arteriosclerosis. 1989;9:335-344.

5. DeFronzo RA, Cooke CR, Andres R, Faloona GR, Davis PJ. The effect of insulin on renal handling of sodium, potassium, calcium, and phosphate in man. J Clin Invest. 1975;55: $845-855$.

6. Sharma AM, Schorr U. Salt sensitivity and insulin resistance: is there a link? Blood Press Suppl. 1996;1:59-63.

7. Cusi D, Barlassani C, Azzani T, Casari G, Citterio L, Devoto M, Glorioso N, Lanzani C, Manunta P, Righetti M, Rivera R, Stella P, Troffa C, Zagato L, Bianchi G. Polymorphisms of alpha-adducin and salt sensitivity in patients with essential hypertension. Lancet. 1997;349:1353-1357.

8. Glorioso N, Manunta $P$, Filigheddu $F$, Troffa $C$, Stella $P$, Barlassina $C$, Lombardi $C$, Soro $A$ Dettori F, Parpaglia PP, Alibrandi MT, Cusi D, Bianchi $G$. The role of alpha-adducin polymorphism in blood pressure and sodium handling regulation may not be excluded by a negative association study. Hypertension. 1999;34:649-654

9. Levy D, DeStefano AL, Larson MG, O'Donnell CJ, Lifton RP, Gavras H, Cupples LA, Myers $\mathrm{RH}$. Evidence for a gene influencing blood pressure on chromosome 17 : genome scan linkage results for longitudinal blood pressure phenotypes in subjects from the framingham heart study [In Process Citation]. Hypertension. 2000;36:477-483.

10. Allayee $\mathrm{H}$, Bruin TWAd, Dominguez KM, Ipp E, Aouizerat $B$, Cantor R, Lusis AJ, Rotter Jl. Genome scan in Dutch dyslipidemic families reveals novel blood pressure loci. Am J Hum Genet. 1999;65:A16.

11. Sharma $P$, Fatibene J, Ferraro $F$, Jia $H$, Monteith $S$, Brown $C$, Clayton $D$, O'Shaughnessy $K_{1}$ Brown MJ. A genome-wide search for susceptibility loci to human essential hypertension. Hypertension. 2000;35:1291-1296.

12. Zagato L, Modica R, Florio M, Torielli L, Bihoreau MT, Bianchi G, Tripodi G. Genetic mapping of blood pressure quantitative trait loci in milan hypertensive rats. Hypertension. 2000;36: 734-739.

13. Rust S, Funke H, Assmann G. Mutagenically separated PCR (MS-PCR): a highly specific one step procedure for easy mutation detection. Nucleic Acids Res. 1993;21:3623-3629.

14. Kato N, Sugiyama T, Nabika T, Morita H, Kurihara H, Yazaki Y, Yamori Y. Lack of association between the alpha-adducin locus and essential hypertension in the Japanese population. Hypertension. 1998;31:730-733.

15. Kamitani A, Wong ZYH, Fraser R, Davies DL, Connor JM, Foy CJW, Watt GCM, Harrap SB. Human alpha-adducin gene, blood pressure, and sodium metabolism. Hypertension. 1998; 32:138-143.

16. Melander $\mathrm{O}$, Bengtsson K, Orho-Melander M, Lindblad U, Forsblom C, Rastam L, Groop L, Hulthen UL. Role of the Gly460Trp polymorphism of the alpha-adducin gene in primary hypertension in Scandinavians. J Hum Hypertens. 2000;14:43-46.

17. Wang WY, Adams DJ, Glenn CL, Morris BJ. The Gly460Trp variant of alpha-adducin is not associated with hypertension in white Anglo-Australians. Am J Hypertens. 1999;12:632-636. 
18. Matsuoka $Y$, Hughes $C A$, Bennett $V$. Adducin regulation. Definition of the calmodulin-binding domain and sites of phosphorylation by protein kinases A and C. J Biol Chem. 1996;271: 25157-25166.

19. Hughes $C A$, Bennett $V$. Adducin: a physical model with implications for function in assembly of spectrin-actin complexes. J Biol Chem. 1995;270:18990-18996.

20. Ferrandi M, Salardi S, Tripodi G, Barassi P, Rivera R, Manunta P, Goldshleger R, Ferrari $P$, Bianchi $G$, Karlish SJ. Evidence for an interaction between adducin and $\mathrm{Na}(+)-\mathrm{K}(+)-\mathrm{ATP}$ ase: relation to genetic hypertension. Am J Physiol. 1999;277:H1338-1349.

21. Meigs JB, D'Agostino RB, Sr., Wilson PW, Cupples LA, Nathan DM, Singer DE. Risk variable clustering in the insulin resistance syndrome. The Framingham Offspring Study. Diabetes. 1997:46:1594-1600.

22. Rocchini AP, Key J, Bondie D, Chico R, Moorehead C, Katch V, Martin M. The effect of weight loss on the sensitivity of blood pressure to sodium in obese adolescents. $N$ Engl $J$ Med. 1989;321:580-585.

23. Stroes E, de Bruin TWA, Valk Hd, Erkelens W, Banga JD, van Rijn $H$, Koomans $H$, Rabelink T. NO activity in familial combined hyperlipidemia: potential role of cholesterol remnants Cardiovasc Res. 1997;36:445-452.

24. John S, Schmieder RE. Impaired endothelial function in arterial hypertension and hypercholesterolemia: potential mechanisms and differences. J Hypertens. 2000;18:363-374.

25. Miyoshi A, Suzuki H, Fujiwara M, Masai M, Iwasaki T. Impairment of endothelial function in salt-sensitive hypertension in humans. Am J Hypertens. 1997;10:1083-1090.

26. Chowienczyk PJ, Watts GF, Cockcroft JR, Ritter JM. Impaired endothelium-dependent vasodilation of forearm resistance vessels in hypercholesterolaemia. Lancet. 1992;340: 1430-1432.

27. Hayakawa $H$, Raij L. Relationship between hypercholesterolaemia, endothelial dysfunction and hypertension. J Hypertens. 1999;17:611-619. 


\section{Chapter 5}

a-Adducin Gly460Trp polymorphism and renal hemodynamics in essential hypertension

E Beeks, MM van der Klauw, AA Kroon, W Spiering, MJMJ Fuss-Lejeune, PW de Leeuw

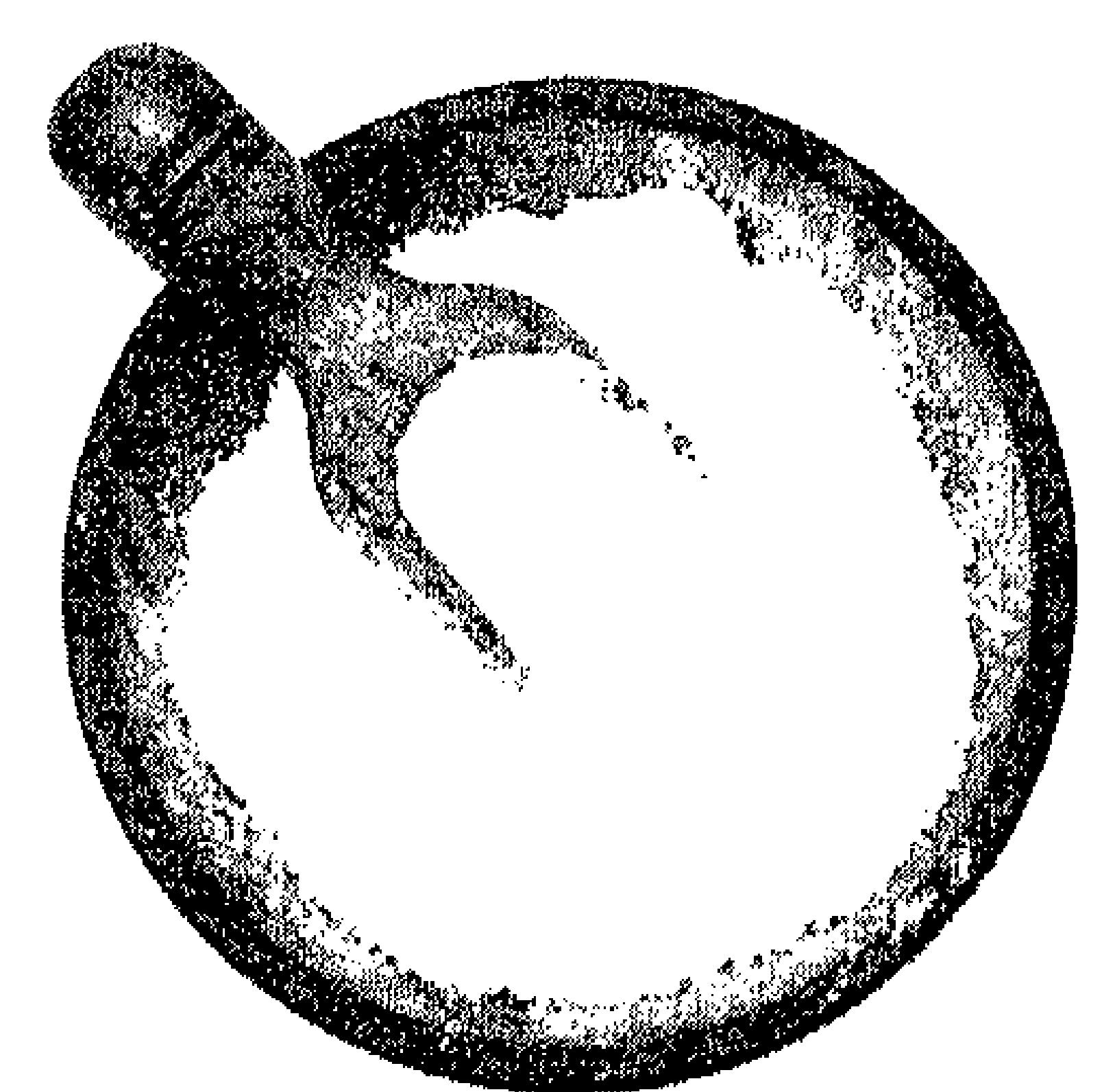


Chapter 5

\section{Abstract}

\section{Background}

Previous studies have shown an association between the $\alpha$-adducin Gly460Trp polymorphism and polymorphism hon rertension. Not much is known about the effects of the variants of this namics and function.

\section{Methods}

We performed this study to investigate the effect of the 460Trp allele of the $\alpha$-adducin gene on renal hemodynamics in one hundred and seventeen essential hypertensive patients who were put period, blood pressure sodium diet (randomized order). On the last day of each one-week dietary neurohormones were measured. Effective flasma flow (ERPF), glomerular filtration rate (GFR) and filtration fraction were calculated.

\section{Results}

ERPF, ERBF and GFR were lower in patients homozygous for the 460Trp allele compared with significantly higher in patients with the low sodium diet. Levels of atrial natriuretic peptide were Gly460Gly genotype. In multivariate analysis, Trp460Trpotype as compared to patients with the were predictors of ERPF, while Trp460Trp , TrP460Trp genotype, age and mean arterial pressure

\section{Conclusion}

The present study shows that the Trp460Trp genotype is significantly associated with a reduced renal plasma flow and a reduced glomerular filtration rate as compared to the wild-type variant. 
$\alpha$-Adducin and renal hemodynamics in hypertension

\section{Introduction}

Essential hypertension is a complex disease, involving a variety of genetic, physiological and environmental factors. However, according to modern physiology, no form of hypertension can persist without the presence of a renal defect ${ }^{1}$. Predictably, a rise in blood pressure by whatever cause is followed by enhanced renal sodium output (pressure natriuresis) until the original situation is restored. Only when the sodium excretory capacity of the kidney is impaired, hypertension may develop. Not surprisingly, therefore, virtually all forms of monogenic hypertension are characterized by disturbances in sodium metabolism².

In Milan Hypertensive rats (MHS), a genetically determined cellular defect caused by a mutation in the $\alpha$-adducin gene involving faster $\mathrm{Na}$ transport across the renal cell membranes is considered to be a probable cause of the elevated blood pressure in these animals. Considering the many similarities in renal and cellular dysfunctions between MHS rats and patients with essential hypertension and given the very high degree of sequence homology between rat and human $\alpha$-adducin, it is possible that this molecular mechanism is also relevant to humans ${ }^{3}$. Indeed, the $\alpha$-adducin Gly460Trp polymorphism has been associated with enhanced renal tubular sodium reabsorption which could account for a sodium-sensitive rise in blood pressure ${ }^{4,5}$. Several studies have been performed on the association between this mutation in the $\alpha$-adducin gene and sodium-sensitive hypertension. By and large, the results of these studies confirm that the 460Trp variant is associated with a greater degree of sodium sensitivity ${ }^{4-7}$. In contrast to the many studies investigating the association between the $\alpha$-adducin variants and the reaction of blood pressure to sodium, far less is known about the effect of these variants on renal hemodynamics and renal function. This is surprising in view of the central role of the kidney and its blood supply on the regulation of sodium homeostasis. This lack of information prompted us to study the impact of the 460Trp allele of the $\alpha$-adducin gene on renal hemodynamics in hypertensive patients during different sodium diets.

\section{Methods}

\section{Patients and protocol}

One hundred and seventeen patients with hypertension attending the outpatient clinic of the University Hospital Maastricht were enrolled in this study. Hypertension was defined as a systolic blood pressure of at least $140 \mathrm{mmHg}$ and/or a diastolic blood pressure of at least $90 \mathrm{mmHg}$ without 
treatment. Inclusion criteria were age between 30 and 75 years, no secondary causes of hypertension and no other significant medical illness, including diabetes mellitus and renal insufficiency. Antihypertensive treatment, if any, was withdrawn three weeks prior to the study. Patients were investigated after one week of low sodium diet ( $55 \mathrm{mmol} \mathrm{Na}$ per day) and one week of high sodium diet $(220 \mathrm{mmol} \mathrm{Na}$ per day), given in randomized order. Compliance with the diet was checked by measuring sodium, potassium and creatinine output in 24-hour urine collections obtained on the last two days of each dietary period. Because the initial high sodium diet of $220 \mathrm{mmol} \mathrm{Na}$ per day was not reached by most of the patients, we decided not to use this term but speak in future of a normal sodium diet. Patients had to refrain from smoking, alcohol and caffeine from 10 PM the evening before the measurements and they remained supine during the entire session. Effective renal plasma flow (ERPF) and glomerular filtration rate (GFR) were measured by infusion of paraaminohippurate (PAH) and inulin. Before infusion, baseline blood samples were taken. After a 2-hour equilibration period, necessary to reach steady state plasma concentrations of PAH and inulin, blood samples were drawn at 120 , 130, 140 and 150 minutes. Effective renal blood flow (ERBF), filtration fraction $(F F)$ and renal vascular resistance (RVR) were calculated ${ }^{8}$. Blood samples were taken for measurement of active plasma renin concentration (APRC), aldosterone and atrial natriuretic peptide (ANP). To ensure diuresis, patients consumed $200 \mathrm{ml}$ of water every hour until the last blood samples had been drawn. The study was approved by the Medical Ethical Committee of the University Hospital Maastricht. Informed consent was obtained from each individual recruited.

\section{Genetic analysis}

DNA was extracted from whole blood using the Wizard Genomic DNA Purification Kit (Promega, Leiden, the Netherlands). The genotypes of the $\alpha$-adducin Gly460Trp polymorphism (Gly460Gly, Gly460Trp and Trp460Trp) were detected by mutagenically separated $P C R^{9,10}$, as described previously ${ }^{11}$.

\section{Hemodynamic and assay methods}

Blood pressure, renal hemodynamics (ERPF and GFR) were measured as described previously ${ }^{8}$. APRC, aldosterone, ANP and PAH and inulin levels were assayed as mentioned earlier ${ }^{8}$.

\section{Statistical analysis}

We estimated sample size by a power calculation based on the assessment of ERPF, the variable with the highest variation $(6.4 \%$ variability for repeated 
measurements). To detect a difference in ERPF between groups of more than $10 \%$ with a type 1 error of 0.05 , a statistical power of $80 \%$ and a standard deviation of $60 \mathrm{ml} /\left(\min \cdot 1.73 \mathrm{~m}^{2}\right)$, we calculated that there should be at least 11 subjects in the Trp460Trp group and 80 subjects in the 460Gly group, using a power calculation program with sample size technique for unequal group sizes $^{12}$. The calculation of allele frequencies to test for Hardy-Weinberg equilibrium was carried out using $\chi^{2}$ analysis comparing expected against observed frequencies. Kruskal-Wallis test was used to determine the association between the three genotype groups of the $\alpha$-adducin Gly460Trp polymorphism and clinical characteristics and for univariate testing of differences in renal hemodynamics and neurohormones between the genotype groups. When the Kruskal-Wallis test revealed a significant effect of genotype, Mann-Whitney $U$ test with Hochberg correction was used as post-hoc analysis ${ }^{13}$. Linear regression analysis was done to determine the effect of the $\alpha$-adducin genotype on ERPF and GFR, taking potential confounders (age and MAP) into account. Analysis of Covariance was used to detect differences between the three genotype groups with respect to the relationship between ERPF and age. Wilcoxon Signed Ranks test was performed to test for differences in neurohormones between the two sodium diets.

\section{Results}

Since the $\alpha$-adducin Gly460Trp polymorphism was the only genetic polymorphism studied in this paper, no adjustments were made regarding multiple testing. The clinical characteristics of the three genotype groups on both the low and the normal sodium diet are summarized in Table 5.1. The genotype distribution of the $\alpha$-adducin polymorphism did not deviate significantly from Hardy-Weinberg's expectation $\left(\chi^{2}=1.187, p=0.552\right)$. However, the distribution of the $\alpha$-adducin Gly460Trp polymorphism was significantly different compared with another Caucasian population $\left(\chi^{2}=12.1, p=0.002\right)^{4}$, the frequency of the Trp460Trp genotype being higher in our population (10\% vs. $4 \%$ ). Before the washout period, no difference in use of antihypertensive medication was found among the three genotype groups. No significant differences between the three genotype groups were found with the exception of ANP which was significantly higher in patients homozygous for the 460Trp allele on both low and high sodium diet (Kruskal-Wallis test, $p=0.026$ and $p=0.009$ respectively). Post-hoc analyses revealed a significant difference in ANP on the low and the high sodium diet between patients with the Trp460Trp and Gly460 Gly genotype ( $p=0.015$ and $p=0.009$ respectively). 
Chapter 5

Table 5.1 Clinical characteristics of the patients by genotype group of $\alpha$-adducin.

\begin{tabular}{|c|c|c|c|c|}
\hline & Gly460Gly & Gly460Trp & Trp460Trp & P value ${ }^{a}$ \\
\hline Number (\%) & $62(53 \%)$ & $43(37 \%)$ & $12(10 \%)$ & \\
\hline Age & $53(49,61)$ & $54(46,61)$ & $55(43,63)$ & 0.896 \\
\hline Sex, $\%$ male & $55 \%$ & $65 \%$ & $42 \%$ & $0.297^{b}$ \\
\hline \multicolumn{5}{|l|}{ Low sodium } \\
\hline BMI, $\mathrm{kg} / \mathrm{m}^{2}$ & $26.4(24.7,29.7)$ & $28.0(24.6,31.2)$ & $24.9(22.5,30.5)$ & 0.419 \\
\hline $\mathrm{SBP}, \mathrm{mmHg}$ & $169(146,182)$ & $164(148,185)$ & $169(145,188)$ & 0.983 \\
\hline $\mathrm{DBP}, \mathrm{mmHg}$ & $93(85,100)$ & $93(87,99)$ & $88(83,100)$ & 0.461 \\
\hline MAP, $\mathrm{mmHg}$ & $121(109,133)$ & $120(114,139)$ & $121(107,143)$ & 0.555 \\
\hline $\mathrm{HR}, \mathrm{bpm}$ & $63(56,69)$ & $65(60,74)$ & $61(54,68)$ & 0.242 \\
\hline APRC, $\mu \mathrm{U} / \mathrm{ml}$ & $12.8(8.5,23.0)$ & $13.3(7.2,25.6)$ & $11.0(7.3,23.2)$ & 0.950 \\
\hline Aldosterone, pmol/l & $232(133,359)$ & $177(110,380)$ & $158(75,478)$ & 0.695 \\
\hline ANP, $\mathrm{pg} / \mathrm{ml}$ & $68.6(47.4,83.9)$ & $68.2(47.0,110.9)$ & $104.1(69.5,155.4)$ & 0.026 \\
\hline$U_{\mathrm{Na}} \mathrm{V}, \mathrm{mmol} / 24 \mathrm{~h}$ & $70(42,99)$ & $77(37,119)$ & $77(42,94)$ & 0.986 \\
\hline \multicolumn{5}{|l|}{ odium } \\
\hline BMI, $\mathrm{kg} / \mathrm{m}^{2}$ & $26.7(24.7,30.0)$ & $27.6(24.6,31.7)$ & $25.2(22.7,29.9)$ & 0.399 \\
\hline $\mathrm{SBP}, \mathrm{mmHg}$ & $165(150,185)$ & $164(153,184)$ & $178(147,187)$ & 0.955 \\
\hline DBP, $\mathrm{mmHg}$ & $94(86,103)$ & $95(88,103)$ & $93(84,103)$ & 0.718 \\
\hline MAP, mmHg & $123(112,134)$ & $121(114,132)$ & $124(116,141)$ & 0.898 \\
\hline $\mathrm{HR}, \mathrm{bpm}$ & $62(57,70)$ & $65(60,71)$ & $63(58,68)$ & 0.686 \\
\hline APRC, $\mu \mathrm{U} / \mathrm{ml}$ & $10.7(6.8,18.7)$ & $10.5(6.0,13.3)$ & $10.9(9.0,16.9)$ & 0.366 \\
\hline Aldosterone, pmol/l & $143(88,282)$ & $141(80,215)$ & $133(69,190)$ & 0.529 \\
\hline ANP, $\mathrm{pg} / \mathrm{ml}$ & $69.8(51.0,100.2)$ & $83.9(64.3,110.2)$ & $117.2(91.8,155.5)$ & 0.009 \\
\hline $\mathrm{U}_{\mathrm{Na}} \mathrm{V}, \mathrm{mmol} / 24 \mathrm{~h}$ & $178(134,226)$ & $172(125,230)$ & $140(116,186)$ & 0.225 \\
\hline
\end{tabular}

$\mathrm{BMl}$, body mass index; SBP, systolic blood pressure; DBP, diastolic blood pressure; MAP, mean arterial pressure; $H R$, heart rate; $A P R C$, active plasma renin concentration; ANP, atrial natriuretic peptide; $U_{\mathrm{Na}} V$, urinary sodium excretion. Data are presented as median with interquartile ranges. ${ }^{a}$ Kruskal-Wallis Test, ${ }^{\mathrm{b}} \chi^{2}$ test

\section{Low sodium diet}

In univariate analysis, differences in renal hemodynamics between the three genotype groups were statistically significant (Kruskal-Wallis test, $p=0.041$ and $p=0.036$ respectively, Table 5.2). Post-hoc analyses revealed a significant difference in ERPF and ERBF between patients with the Trp460Trp and Gly460Gly genotypes ( $p=0.039$ and $p=0.030$ respectively). GFR was also different between the three genotype groups (Kruskal-Wallis test, $p=0.035$, Table 5.2). Patients homozygous for the 460Trp allele had a lower GFR compared with patients homozygous for the $460 \mathrm{Gly}$ allele (post-hoc analysis, $p=0.018$ ). FF did not differ between the three genotype groups. RVR was higher in the Trp460Trp genotype group compared to the other groups but the difference was only of borderline significance $(0.05<p<0.10)$. Taking possible confounders into account, we performed a linear regression analysis to determine predictors for renal hemodynamics and renal function. We expected age and mean arterial blood pressure (MAP) to be important predictors of 
ERPF and GFR. In Table 5.3 the results of the linear regression models are given. The Trp460Trp genotype, age and MAP were predictors of ERPF. Regarding GFR, the Trp460Trp genotype and age were predictors of GFR. When ERPF was plotted against age, no differences in slopes for the three genotype groups were found (Analysis of Covariance, $p=0.968$ ).

Table 5.2 Renal hemodynamics and renal function of the three genotype groups.

\begin{tabular}{|c|c|c|c|c|}
\hline & Gly460Gly & Gly460Trp & Trp460Trp & $P$ value ${ }^{2}$ \\
\hline \multicolumn{5}{|l|}{ Low sodium } \\
\hline ERPF, $\mathrm{ml} /\left(\mathrm{min} \cdot 1.73 \mathrm{~m}^{2}\right)$ & $375(309,436)$ & $354(305,412)$ & $312(227,367)$ & 0.041 \\
\hline ERBF, $\mathrm{ml} /\left(\mathrm{min} \cdot 1.73 \mathrm{~m}^{2}\right)$ & $643(532,750)$ & $643(533,734)$ & $548(374,604)$ & 0.036 \\
\hline $\mathrm{GFR}, \mathrm{m} / /\left(\min \cdot 1.73 \mathrm{~m}^{2}\right)$ & $104(94,122)$ & $107(82,126)$ & $86(73,100)$ & 0.035 \\
\hline FF & $0.29(0.25,0.33)$ & $0.30(0.25,0.38)$ & $0.29(0.26,0.32)$ & 0.411 \\
\hline RVR, dyne $\cdot s / \mathrm{cm}^{5}$ & $15339(11925,18551)$ & $15598(13130,19792)$ & $19103(14782,26190)$ & 0.085 \\
\hline \multicolumn{5}{|l|}{ Normal sodium } \\
\hline ERPF, $\mathrm{ml} /\left(\mathrm{min} \cdot 1.73 \mathrm{~m}^{2}\right)$ & $382(308,441)$ & $352(294,412)$ & $347(221,372)$ & 0.255 \\
\hline$E R B F, \mathrm{ml} /\left(\mathrm{min} \cdot 1.73 \mathrm{~m}^{2}\right)$ & $638(516,780)$ & $595(501,695)$ & $607(363,627)$ & 0.228 \\
\hline $\mathrm{GFR}, \mathrm{ml} /\left(\mathrm{min} \cdot 1.73 \mathrm{~m}^{2}\right)$ & $110(100,124)$ & $106(86,125)$ & $90(72,111)$ & 0.184 \\
\hline FF & $0.30(0.27,0.35)$ & $0.30(0.26,0.35)$ & $0.30(0.25,0.38)$ & 0.903 \\
\hline RVR, dyne.s $/ \mathrm{cm}^{5}$ & $15491(11527,19171)$ & $16087(13386,19301)$ & $16972(15952,25871)$ & 0.174 \\
\hline
\end{tabular}

ERPF, effective renal plasma flow; ERBF, effective renal blood flow; GFR, glomerular filtration rate; FF, filtration fraction; RVR, renal vascular resistance. Data are presented as median with interquartile ranges. ${ }^{a}$ Kruskal-Wallis Test

Table 5.3 Linear regression analyses: ERPF and the $\alpha$-adducin Gly460Trp polymorphism on low sodium diet.

Determinants in the model

Univariate analysis
Unstandardized $\beta(95 \% \mathrm{Cl})$

ERPF

ADD1 Gly460Trp ${ }^{a}$ ADD1 Trp460Trp ${ }^{\mathrm{a}}$

Age

MAP

GFR

ADD1 Gly460Trp ${ }^{a}$ ADD1 Trp460Trpa

Age

MAP
Multivariate analysis Unstandardized $\beta(95 \% \mathrm{Cl})$

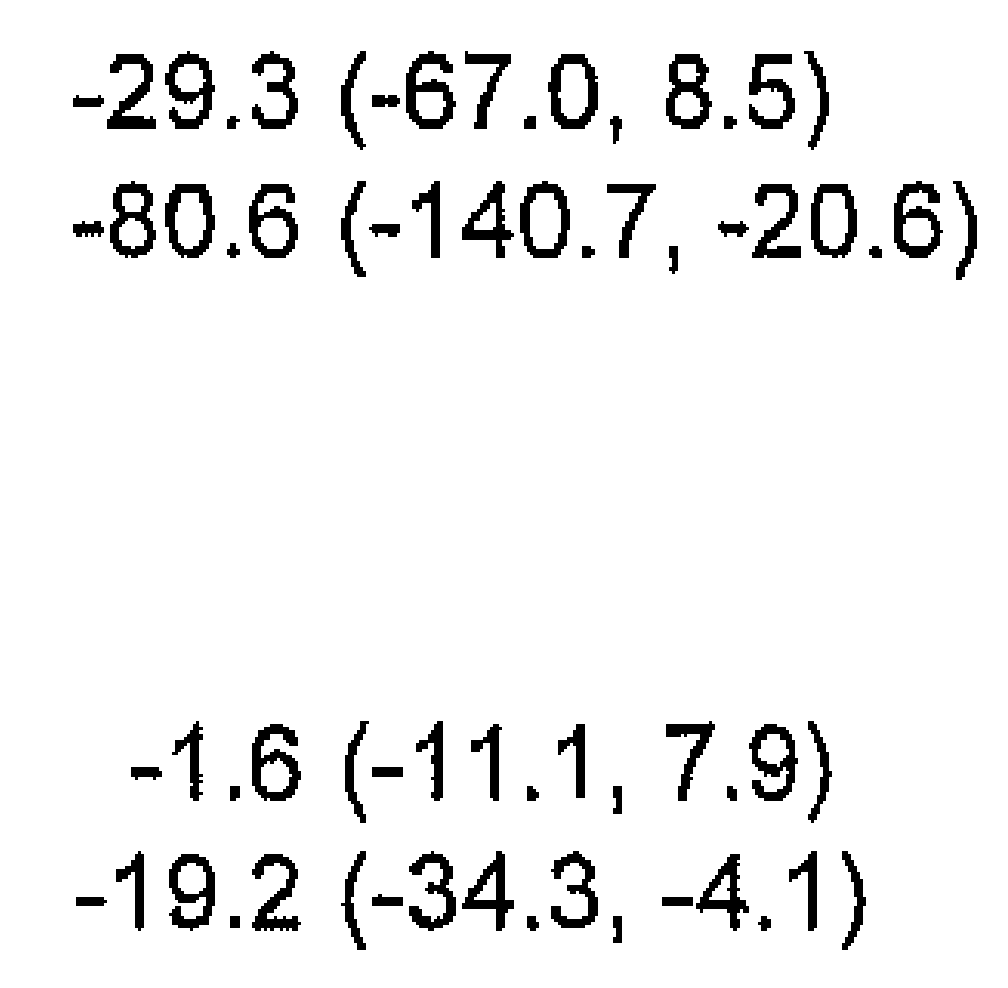

a Unstandardized $\beta$ compared to ADD1 Gly460Gly (reference category). 
Normal sodium diet

Univariate analyses failed to show significant differences in ERPF, ERBF, RVR, GFR and FF between the three genotype groups (Table 5.2). As on the low sodium diet, no differences in slopes for the three genotype groups were found when ERPF was plotted against age (Analysis of Covariance, $p=0.955$ ).

\section{Changes during the switch from low to normal sodium diet}

Since there was no time-treatment effect concerning the order of the sodium diets, the data from both periods were pooled for analysis. When changing from a low to normal sodium diet, no significant changes in blood pressure, ERPF, ERBF, RVR, and GFR were found in either genotype group. FF was lower during the low sodium diet in the Gly460Gly genotype group $(0.29(0.25$, $0.31)$ vs. $0.31(0.27,0.35)$, Wilcoxon Signed Ranks test, $p=0.004)$. In patients carrying a $460 \mathrm{Gly}$ allele, aldosterone and APRC were decreased after the switch from low to normal sodium diet (Table 5.4), ANP was significantly increased. In the Trp460Trp genotype group, only a decrease in aldosterone was seen.

Table 5.4 Neurohormones on low and normal sodium diet per genotype group of $\alpha$-adducin.

$\begin{array}{lccr} & \text { Low sodium diet } & \text { Normal sodium diet } & \text { P value }^{\mathrm{a}} \\ \text { Gly460G/y } & & & \\ \text { APRC, } \mu \mathrm{U} / \mathrm{ml} & 13.2(8.7,22.8) & 10.7(6.8,18.6) & 0.009 \\ \text { Aldosterone, pmol/l } & 239(135,357) & 150(90,280) & <0.001 \\ \text { ANP, pg/ml } & 68.6(47.1,83.9) & 69.0(48.3,99.9) & 0.002 \\ \text { Gly460Trp } & & & \\ \text { APRC, } \mu \mathrm{U} / \mathrm{ml} & 13.3(7.3,25.3) & 10.6(6.0,14.4) & <0.001 \\ \text { Aldosterone, pmol/l } & 179(113,371) & 142(80,210) & <0.001 \\ \text { ANP, pg/ml } & 69.1(47.9,112.8) & 82.3(61.2,109.5) & 0.022 \\ \text { Trp460Trp } & & & \\ \text { APRC, } \mu \mathrm{U} / \mathrm{ml} & 11.0(7.3,23.2) & 10.9(9.0,16.9) & 0.333 \\ \text { Aldosterone, pmol/l } & 158(75,478) & 133(69,190) & 0.021 \\ \text { ANP, pg/ml } & 104.1(69.5,155.4) & 117.2(91.8,155.5) & 0.374\end{array}$

APRC, active plasma renin concentration; ANP, atrial natriuretic peptide. a Wilcoxon Signed Ranks Test.

\section{Discussion}

This study demonstrates that the $\alpha$-adducin Gly460Trp polymorphism has a profound influence on renal hemodynamics in hypertensive patients. With low sodium intake, the Trp460Trp genotype was significantly associated with 
decreased renal plasma flow and glomerular filtration rate. On the normal sodium diet, no differences between the three genotype groups were seen regarding renal hemodynamics, possibly due to a suppressed reninangiotensin system. When the patients were put on the low sodium diet, the mechanism of sodium retention is activated. Patients with the 460Trp allele could show an increase in extracellular volume and could be more sensitive to angiotensin II, leading to more marked alterations in renal hemodynamics during this dietary period. Also on the normal sodium diet, sodium excretion was markedly lower in the Trp460Trp group, this could also be an explanation for not being able to detect differences on this sodium diet.

Earlier studies in MHS rats indicated that the mutated human adducin variant displayed an increased affinity for Na-K ATPase over that of the wild-type variant ${ }^{14}$. In MHS rats, during the development of hypertension, GFR is higher and plasma renin lower compared with Milan normotensive (MNS) rats. This is in contrast with our findings, patients wit the Trp460Trp genotype showed a significant lower GFR. The duration of hypertension could play an important role in these distinctions. During the development of hypertension in MHS rats, GFR could remain on its level due to compensatory mechanisms for some time. In our patients who have hypertension for a longer period of time, we suppose that compensatory mechanisms fail leading to the decrease in GFR. A transient phase of renal sodium retention that could lead to an increase in body fluid volumes has also been observed in MHS rats. The maintenance of a normal sodium balance, despite a higher GFR, could be explained by assuming an increased renal tubular reabsorption ${ }^{15}$. Although the 460Trp allele has been associated with an increase in renal (proximal) tubular reabsorption ${ }^{16}$, it is not certain whether body fluid volumes are elevated in the Trp460Trp genotype group. However, levels of ANP were markedly elevated in this genotype group, which could point to a mechanism counteracting the tendency to retain more sodium. In this regard, the increase in ANP could be viewed upon as a compensatory mechanism to increase postglomerular resistance and hydrostatic pressure in the glomerular capillaries ${ }^{17}$. The same mechanism may also be responsible for a reduced ERBF.

Despite the small number of patients in the Trp460Trp group, we clearly found a reduction in ERPF and GFR in this group. Due to the fact that patients homozygous for the 460Trp allele are rare in most Caucasian populations, the Gly460Trp and Trp460Trp genotypes are usually combined to find an effect of this polymorphism on outcome parameters like blood pressure. This implicitly suggests that the 460Trp allele is dominant. However, the present data indicate that patients homozygous for the 460Trp allele are actually different from patients carrying the Gly460Trp genotype. The 460Gly allele seems to be the dominant one regarding renal hemodynamics. This is an important issue in studies on genetic polymorphisms. 
In our study, the relationship between ERPF and age was not different between the three genotype groups. This is in contrast with the findings of Castellano et $a l^{18}$ who have suggested that the pathogenic effect of the $\alpha$-adducin Gly460Trp polymorphism is more evident at older age, possible due to a reduced efficiency of compensatory mechanisms. Although our results do not substantiate this finding, we cannot exclude the possibility that we would have found age-related effects in the presence of other disturbances in kidney function. It should be noticed that the population of Castellano et al. concerns a sample of the general population, in contrast with our sample of hypertensive patients.

\section{Perspectives}

The present study shows that the Trp460Trp genotype is significantly associated with a reduction in renal plasma flow and a reduction in glomerular filtration rate. Future studies will have to concentrate on subgroups of hypertensive patients with additional risk factors such as diabetes mellitus with renal insufficiency. Indeed, the presence of an additional risk factor could modulate the effect of the $\alpha$-adducin Gly460Trp polymorphism. Moreover, it would be interesting to find out if patients with the Trp460Trp genotype group respond differently to treatment with ACE inhibitors or other antihypertensive agents capable of lowering renal vascular resistance compared to patients with the Gly460Gly genotype. 


\section{References}

1. Guyton AC, Hall JE. Dominant role of the kidney in long-term regulation of arterial pressure and hypertension: The integrated system for pressure control. In: Textbook of medical physiology. 10th ed. Philadelphia: W.B. Saunders Company; 2000:195-209.

2. Lifton RP. Molecular genetics of human blood pressure variation. Science. 1996;272: 676-680.

3. Bianchi G, Tripodi G, Casari G, Salardi S, Barber BR, Garcia R, Leoni P, Torielli L, Cusi D, Ferrandi $\mathrm{M}$, et al. Two point mutations within the adducin genes are involved in blood pressure variation. Proc Natl Acad Sci U S A. 1994;91:3999-4003.

4. Cusi D, Barlassani C, Azzani T, Casari G, Citterio L, Devoto M, Glorioso N, Lanzani C, Manunta P, Righetti M, Rivera R, Stella P, Troffa C, Zagato L, Bianchi G. Polymorphisms of alpha-adducin and salt sensitivity in patients with essential hypertension. Lancet. 1997; 349:1353-1357.

5. Glorioso N, Manunta $P$, Filigheddu F, Troffa $C$, Stella $P$, Barlassina $C$, Lombardi $C$, Soro A, Dettori F, Parpaglia PP, Alibrandi MT, Cusi D, Bianchi G. The role of alpha-adducin polymorphism in blood pressure and sodium handling regulation may not be excluded by a negative association study. Hypertension. 1999;34:649-654.

6. Sciarrone MT, Stella P, Barlassina C, Manunta P, Lanzani C, Bianchi G, Cusi D. ACE and alpha-adducin polymorphism as markers of individual response to diuretic therapy. Hypertension. 2003;41:398-403.

7. Grant FD, Romero JR, Jeunemaitre $X$, Hunt SC, Hopkins PN, Hollenberg NH, Williams GH. Low-renin hypertension, altered sodium homeostasis, and an alpha-adducin polymorphism. Hypertension. 2002;39:191-196.

8. Spiering $W$, Kroon AA, Fuss-Lejeune MM, Daemen MJ, de Leeuw PW. Angiotensin II sensitivity is associated with the angiotensin II type 1 receptor $A(1166) C$ polymorphism in essential hypertensives on a high sodium diet. Hypertension. 2000;36:411-416.

9. Rust S, Funke H, Assmann G. Mutagenically separated PCR (MS-PCR): a highly specific one step procedure for easy mutation detection. Nucleic Acids Res. 1993;21:3623-3629.

10. Kato N, Sugiyama T, Nabika T, Morita H, Kurihara H, Yazaki Y, Yamori Y. Lack of association between the alpha-adducin locus and essential hypertension in the Japanese population. Hypertension. 1998;31:730-733.

11. Beeks E, Janssen RG, Kroon AA, Keulen ET, Geurts JM, de Leeuw PW, de Bruin TW. Association between the alpha-adducin Gly460Trp polymorphism and systolic blood pressure in familial combined hyperlipidemia. Am J Hypertens. 2001;14:1185-1190.

12. Schouten HJ. Sample size formula with a continuous outcome for unequal group sizes and unequal variances. Stat Med. 1999;18:87-91.

13. Hochberg $Y$. A sharper Bonferroni procedure for multiple testing of significance. Biometrika. 1988;75:800-802.

14. Ferrandi $M$, Salardi S, Tripodi G, Barassi $P$, Rivera R, Manunta $P$, Goldshleger R, Ferrari $P$, Bianchi $G$, Karlish SJ. Evidence for an interaction between adducin and $\mathrm{Na}(+)-\mathrm{K}(+)-A T P a s e:$ relation to genetic hypertension. Am J Physiol. 1999;277:H1338-1349.

15. Bianchi $G$, Ferrari $P$, Barber BR. The Milan hypertensive strain. In: de Jong $W$, ed. Handbook of hypertension: Experimental and genetic models of hypertension. 1st ed. Amsterdam: Elsevier Science Publishers B.V.; 1984:328-349.

16. Manunta $P$, Cusi $D$, Barlassina $C$, Righetti $M$, Lanzani $C$, D'Amico M, Buzzi L, Citterio L, Stella $P$, Rivera $R$, Bianchi $G$. Alpha-adducin polymorphisms and renal sodium handling in essential hypertensive patients. Kidney Int. 1998;53:1471-1478.

17. Brenner BM, Ballermann BJ, Gunning ME, Zeidel ML. Diverse biological actions of atrial natriuretic peptide. Physiol Rev. 1990;70:665-699.

18. Castellano M, Barlassina C, Rossi F, Giacche M, Rivadossi F, Muiesan ML, Beschi M, Cusi D, Bianchi G, Agabiti-Rosei E. Age-dependency of alpha-adducin polymorphism modulation of blood pressure. J Hypertens. 2003;21:S219. 


\section{Chapter 6}

Comparison of two sodium loading techniques in hypertensive and normotensive subjects

E Beeks, MM van der Klauw, AA Kroon, PW de Leeuw

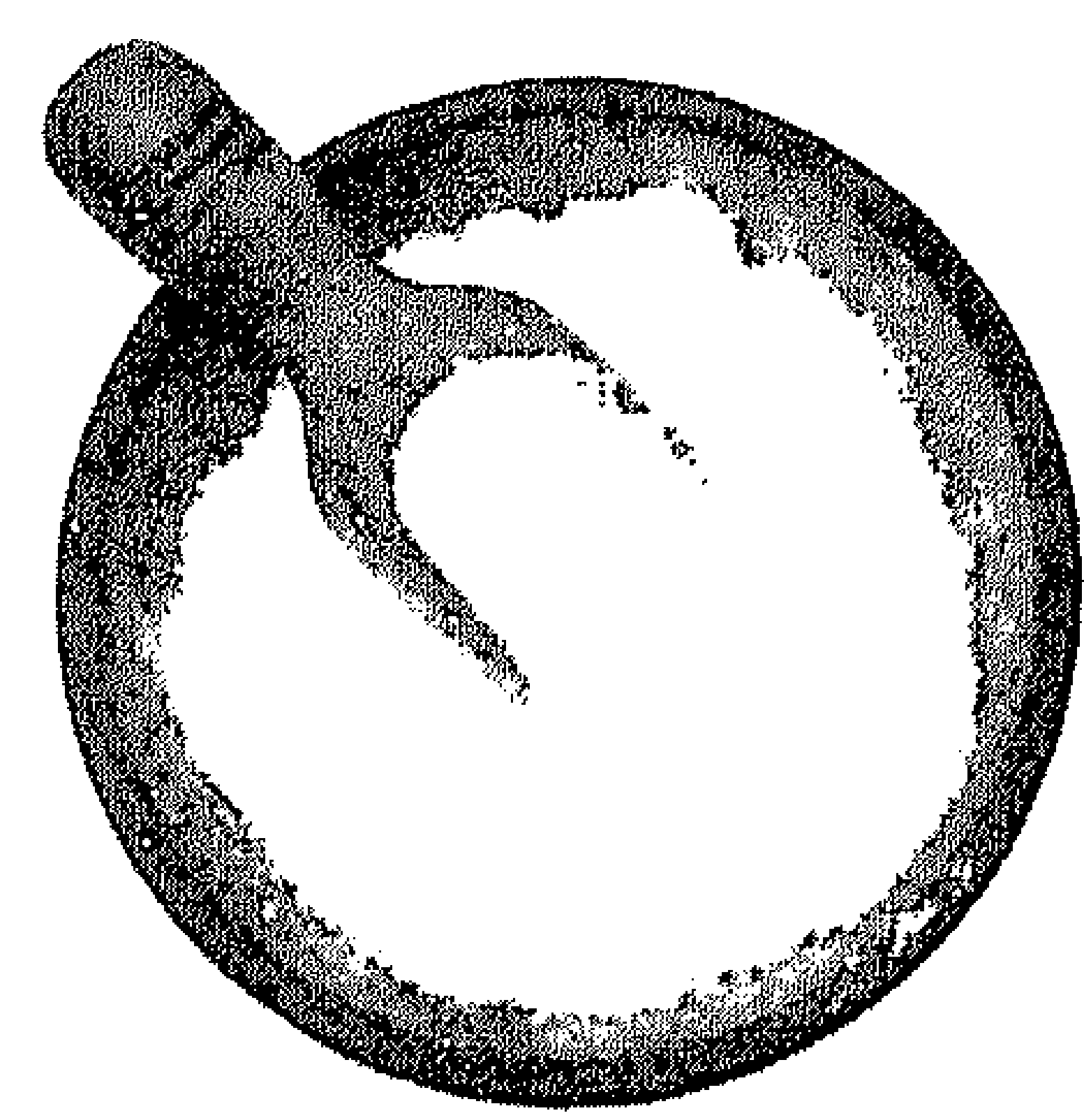




\section{Abstract}

\section{Background}

The aim of this study was to compare the responses of blood pressure and several neurohormones to two types of sodium loading, i.e. hypertonic saline infusion and increased detary intake.

\section{Methods}

Forty-six hypertensive patients and 50 normotensive controls were subjected to two types of sodium challenges In an acute test, $300 \mathrm{ml}$ of a hypertonic saline solution (3\%) was infused within 30 minutes. The chronic (dietary) test consisted of a one-week period of low (55 mmol $\mathrm{Na}+/$ day) and a one-week period of high $(220 \mathrm{mmol} \mathrm{Na}+/$ day $)$ sodium intake, in randomized order. Blood pressure, changes in active plasma renin concentration (APRC), and aldosterone were measured before and after infusion, as well as after each dietary period

\section{Results}

When all subjects were taken together, only a minute difference in systolic blood pressure changes between the two types of sodium loading were observed. Yet, these tests were not in good agreement with each other due to large intra-individual variations in blood pressure responses. In the hypertensives. changes in diastolic pressure after saline infusion were opposite to those after dietary intervention $(1 \pm 1$ vs. $-2 \pm 1 \mathrm{mmHg}$ respectively, $p<0.05)$. The falls in APRC $(-8.3 \pm 0.8$ vs. $-3.9 \pm 0.7 \mu \mathrm{U} / \mathrm{ml}, p<0.001)$ and aldosterone levels $(-188 \pm 13 \mathrm{vs} .-45 \pm 8 \mathrm{pmol} / \mathrm{l}, \mathrm{p}<0.001)$ were greater after the saline infusion than after dietary sodium loading. After saline infusion, the rise in mean arterial pressure was more pronounced in normotensives than in hypertensives $(3 \pm 1 \mathrm{vs}$ $-0 \pm 1 \mathrm{mmHg} . p<0.05)$; this was associated with greater falls in APRC $(-10.7 \pm 1.0 \mathrm{vs} .-5.7 \pm 1.2 \mu \mathrm{U} / \mathrm{ml}$, $p<0.01)$ and aldosterone $(-221 \pm 18$ vs. $-154 \pm 18 \mathrm{pmol} / \mathrm{p}, \mathrm{p}<0.01)$ in the normotensives. The increase in dietary sodium, on the other hand, produced similar changes in these variables in the two groups

\section{Conclusion}

The two methods of sodium loading were not comparable regarding blood pressure responses and changes in neurohormones. In general, normotensives showed larger responses than hypertensives after saline infusion but not after an increase in dietary sodium. These differences should be taken into account when testing for salt sensitivity among different groups of patients and
controls. 


\section{Introduction}

Although a high salt intake may contribute to the development of hypertension, the changes in blood pressure in response to a sodium challenge vary widely among individuals. In the past, several protocols have been developed to assess whether a subject is sodium-sensitive or not. But as we concluded in a recent review ${ }^{1}$, there is too much heterogeneity among these protocols to allow a valid comparison of the results from different studies. By and large, though, the tests can be divided in those utilizing an acute sodium challenge (isotonic saline infusion with or without diuretic administration) and those with a more chronic intervention, i.e. dietary sodium manipulation. Several studies have addressed the question whether these two approaches are comparable as far as the diagnosis of sodium sensitivity is concerned ${ }^{2-6}$. Most of these studies applied a (modified) Weinberger protocol ${ }^{7}$, but the amount of sodium that was given during dietary intervention was variable. Usually, the high sodium diet consisted of a sodium intake greater than $200 \mathrm{mmol}$ per day whereas the intake on the low sodium diet varied from about 20 to $50 \mathrm{mmol}$ per day. While some studies showed agreement between the results of the acute and the chronic protocols ${ }^{3,4,6}$, others failed to do $\mathrm{so}^{2,5}$. This discrepancy is most likely explained by differences in the amount of sodium that was administered during either the acute or the chronic test. Moreover, isotonic saline infusion may produce variable volume effects because part of the infused amount will rapidly move into the interstitial tissue. How much volume will dissipate cannot be predicted with great precision as this will depend upon vascular resistance and interstitial compliance.

In the present study, therefore, we evaluated in both normotensive and hypertensive subjects the responses to a rapid hypertonic saline infusion and compared these responses to those following dietary sodium intervention. We deliberately used hypertonic saline because this will remain longer in the intravascular compartment thus producing virtually comparable volume effects between individuals. The amount of sodium that was administered was almost equal to the amount of sodium which was gained during the transition from a low to a high salt intake before a new steady state was reached. Outcome measures in this study were blood pressure as well as changes in active plasma renin concentration (APRC), plasma aldosterone and levels of atrial natriuretic peptide (ANP). 


\section{Methods}

\section{Subjects}

Forty-six patients with essential hypertension attending the outpatient clinic of the University Hospital Maastricht and 50 normotensive controls were enrolled in this study. Hypertension was defined as a systolic blood pressure (SBP) of at least $140 \mathrm{mmHg}$ and/or a diastolic blood pressure (DBP) of at least $90 \mathrm{mmHg}$ in subjects without treatment. Other inclusion criteria were: age between 30 and 75 years, and absence of significant medical illness including diabetes mellitus and renal impairment (serum creatinine $>120 \mu \mathrm{mol} / \mathrm{l}$ ). Antihypertensive treatment, if any, was withdrawn three weeks prior to the study. Control subjects were either spouses of the patients selected for this study or $130 \mathrm{mmH}$. Exclusion criteria for the control group were: SBP greater than $130 \mathrm{mmHg}$ and/or DBP greater than $90 \mathrm{mmHg}$, cardiovascular disease, renal was approved by the Maastricht. Informed Medical Ethical Committee of the University Hospital

\section{Saline infusion protocol}

Patients were investigated after one week of low salt diet $\left(55 \mathrm{mmol} \mathrm{Na}{ }^{+}\right.$per day). Compliance with the diet was checked by measuring sodium and the dietary period. Patients had to refrain from obtained on the last two days of from 10 PM the evening baf to refrain from smoking, alcohol and caffeine to drink water on the me measurements and they were only allowed and patients remained supine the study day. Experiments started at 8.30 AM antecubital vein was can session. In both arms an right arm was connected cannula in the left arm was 3-way tap for the infusion of saline, whereas the period of 30 minutes, 300 used for blood sampling. After an acclimatization over a period of 30 minutes ${ }^{8}$ a hypertonic $(3 \%)$ saline solution was infused heart rate were monitored ${ }^{\circ}$. SBP, DBP, mean arterial pressure (MAP) and APRC, aldosterone, and ANP won) during saline infusion. Plasma levels of after the infusion $\left(T_{30}\right)$ and at were determined at baseline $\left(T_{0}\right)$, immediately

\section{Dietary sodium protocol}

This protocol consisted of a low sodium diet ( $55 \mathrm{mmol} \mathrm{Na}^{+}$per day) and a high sodium diet $\left(220 \mathrm{mmol} \mathrm{Na}{ }^{+}\right.$per day), each for a one-week period and given in randomized order. Compliance with the diet was checked on the last two days 
of each dietary period. On the morning of each study day supine blood pressure was measured after 30 minutes of rest. Also, fasting blood samples were taken for measurement of APRC, aldosterone and ANP.

\section{Assay methods}

APRC, aldosterone and ANP levels were assayed as described earlier ${ }^{9}$.

\section{Statistical analysis}

The degree of agreement between the effects of the two sodium loading protocols was assessed using Bland-Altman analysis ${ }^{10}$. Independent (Student's) T-test and $\chi^{2}$ test were performed to check for differences between the hypertensives and the normotensive controls regarding clinical characteristics. Paired-samples T-test was used to compare changes in blood pressure and neurohormones between saline infusion and dietary sodium intervention; this was done separately for hypertensives and controls. Factorial Analysis of Variance (ANOVA) was used to evaluate the effect of the change in urinary sodium excretion, the type of subject (hypertensives or normotensives), the order of the sodium diets, and their respective interaction terms on the change in SBP. Linear regression analysis was used to assess the responses of blood pressure and neurohormones between hypertensives and normotensives, adjusted for the order of the sodium diets. With random effect models we evaluated whether differences exist in changes in neurohormones during the saline infusion test ${ }^{11}$. We used a random intercept + slope model for aldosterone and APRC, and a random intercept model for ANP. All analyses were performed with SPSS 11.5 software. Data are presented as medians with interquartile ranges and a $p$-value of less than 0.05 was considered statistically significant.

\section{Results}

\section{Population characteristics}

Forty-six hypertensive patients and 50 normotensive controls completed both the saline infusion and dietary protocols. Clinical characteristics of these individuals are presented in Table 6.1. In normotensives, plasma sodium was slightly, yet significantly, lower than in hypertensives but this was probably not clinically relevant. During the dietary intervention period, changes in urinary sodium excretion (high sodium minus low sodium) were greater in the normotensives ( $122 \pm 59 \mathrm{mmol} / \mathrm{day}$ vs. $83 \pm 69 \mathrm{mmol} / \mathrm{day}, \mathrm{p}=0.003$ ), suggesting that the control population better adhered to the low sodium diet. 
Chapter 6 Table 6.1 Clinical characteristics of the hypertensives and the normotensive control group at
baseline.

N

Age. years

Gender, M/F

BMI, $\mathrm{kg} / \mathrm{m}^{2}$

SBP, $\mathrm{mmHg}$

DBP, $\mathrm{mmHg}$

MAP, $\mathrm{mmHg}$

Heart rate, bpm

Plasma sodium, mmol/

Plasma potassium, mmol/

Plasma creatinine, $\mu \mathrm{mol} / \mathrm{l}$

Urinary sodium excretion, mmol/24h
Normotensives

50

$55(7)$

$21 / 29$

$25.7(3.1)$

$118(15)$

$72(7)$

$89(10)$

$60(8)$

$138(3)$

$4.0(0.3)$

$80(13)$

57 (42)

Hypertensives
46
$56(9)$
$25 / 21$
$27.6(4.3)$
$158(23)$
$89(11)$
$116(16)$
$66(10)$
$139(2)$
$4.1(0.4)$
$81(14)$
$74(37)$

Significance

ns

ns

$p<0.05$

$-$

$-$

$p<0.01$

$p<0.05$

ns

ns
$p<0.05$ Data are presented as mean (SD); BMI, body mass index; SBP, systolic blood pressure; DBP,
diastolic blood pressure; MAP, mean arterial pressure; bpm, beats per minute.

\section{Blood pressure responses}

We first assessed the degree of agreement between the saline infusion test and the dietary intervention in normotensives and hypertensives together by means of the Bland-Altman analysis (Figure 6.1). The data show that the mean difference between the results of the two tests is close to zero. However, due to large intra- and inter-individual variations we also found discrepancies of up to $30 \mathrm{mmHg}$ SBP. Consequently, there is a considerable lack of agreement between the two tests. Figure 6.2 illustrates the average changes in blood pressure, comparing the saline infusion test with dietary sodium loading in normotensives and hypertensives separately. Analyses were adjusted for the order of the sodium diets. In the normotensive group changes in both SBP and DBP tended to be more pronounced after dietary intervention than after the infusion, but differences failed to reach statistical significance. In hypertensives, there was a significant difference in response of DBP to the two sodium loading tests with a rise after dietary sodium loading and a fall after saline infusion. The difference in DBP responses between normotensives and hypertensives was almost statistically significant $(p=0.057)$. For the remainder of the outcome Although, theoretically the and hypertensives showed comparable changes. normotensives couly, the greater change in urinary sodium excretion in the responses, factorial ANOVA for some small differences in blood pressure sodium excretion the order of the sodium diets, of subject (normotensive or hypertensive), nor in blood pressure significantly nor their interaction terms affected the changes in blood pressure significantly. Increases in SBP were only marginally related 
to the change in urinary sodium excretion (factorial ANOVA, $p=0.059$ ) but type of subject and the order of the sodium diets did not influence changes in SBP at all $(p=0.245$ and $p=0.709$, respectively). However, there was a significant interaction effect between the change in urinary sodium excretion and the order of the sodium diets on the one hand and the change in SBP on the other $(p=0.043)$, meaning that SBP responded differently to a high sodium diet when this was preceded by a low salt diet as compared to the situation where the low salt diet was given last. The interaction between type of subject and change in urinary sodium excretion was not statistically significant $(p=0.961)$.

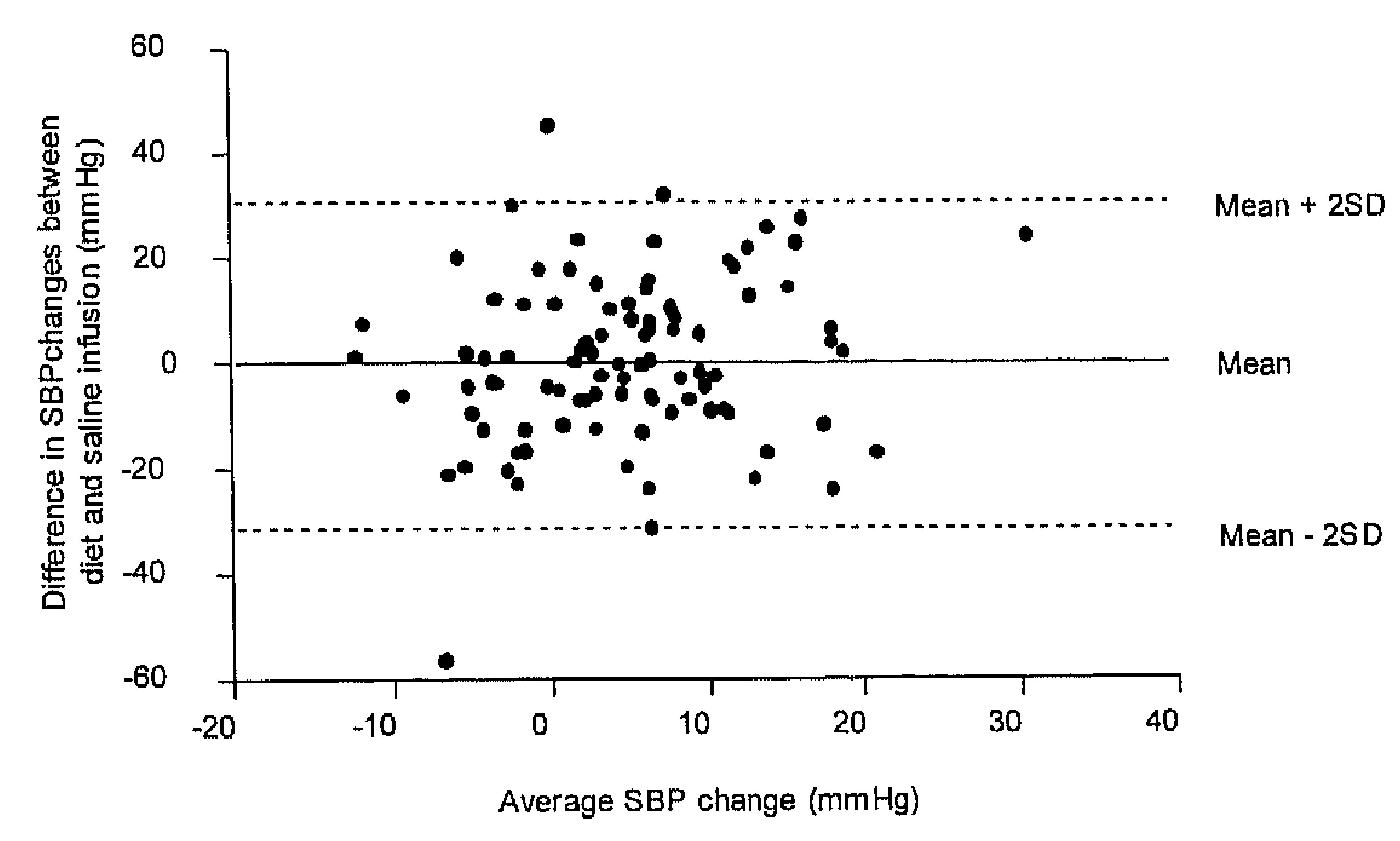

Figure 6.1 Agreement of systolic blood pressure pressures to two methods of sodium sensitivity testing for the combined group of normotensives and hypertensives (Bland-Altman plot).
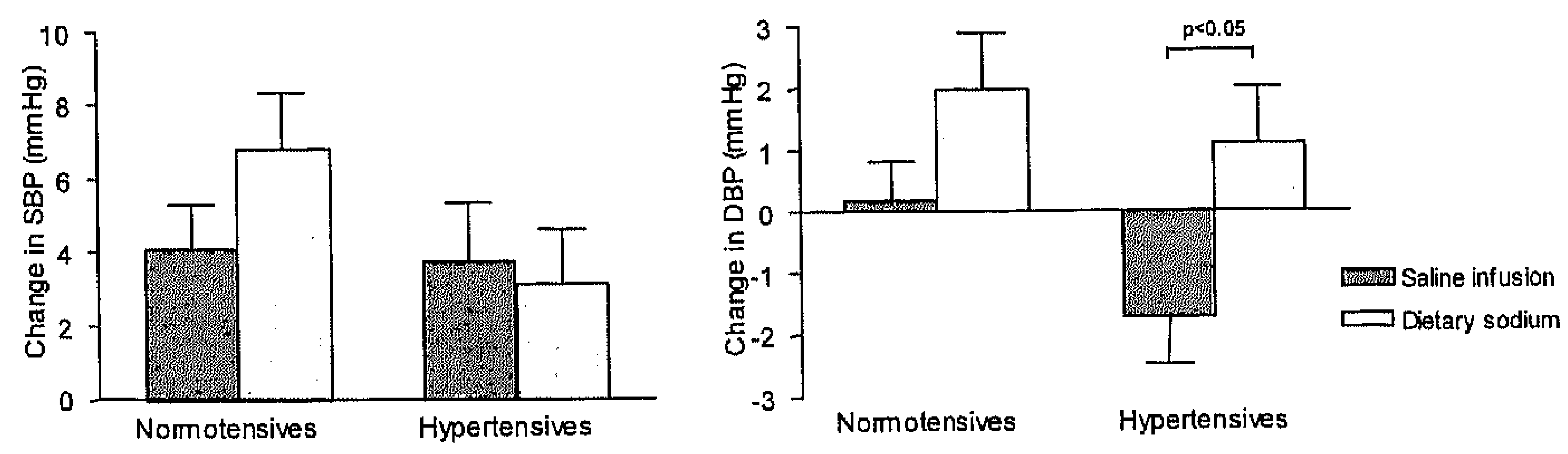

Figure 6.2 Changes in systolic blood pressure (SBP) and diastolic blood pressure (DBP) in response to the two sodium loading protocols in normotensives and hypertensives. 
Figure 6.3 shows the individual responses of SBP after both sodium loading techniques in hypertensive and normotensive subjects. In at least $35 \%$ of cases, discordant results were obtained, i.e. an increase during one test vs. a decrease during the other or vice versa.

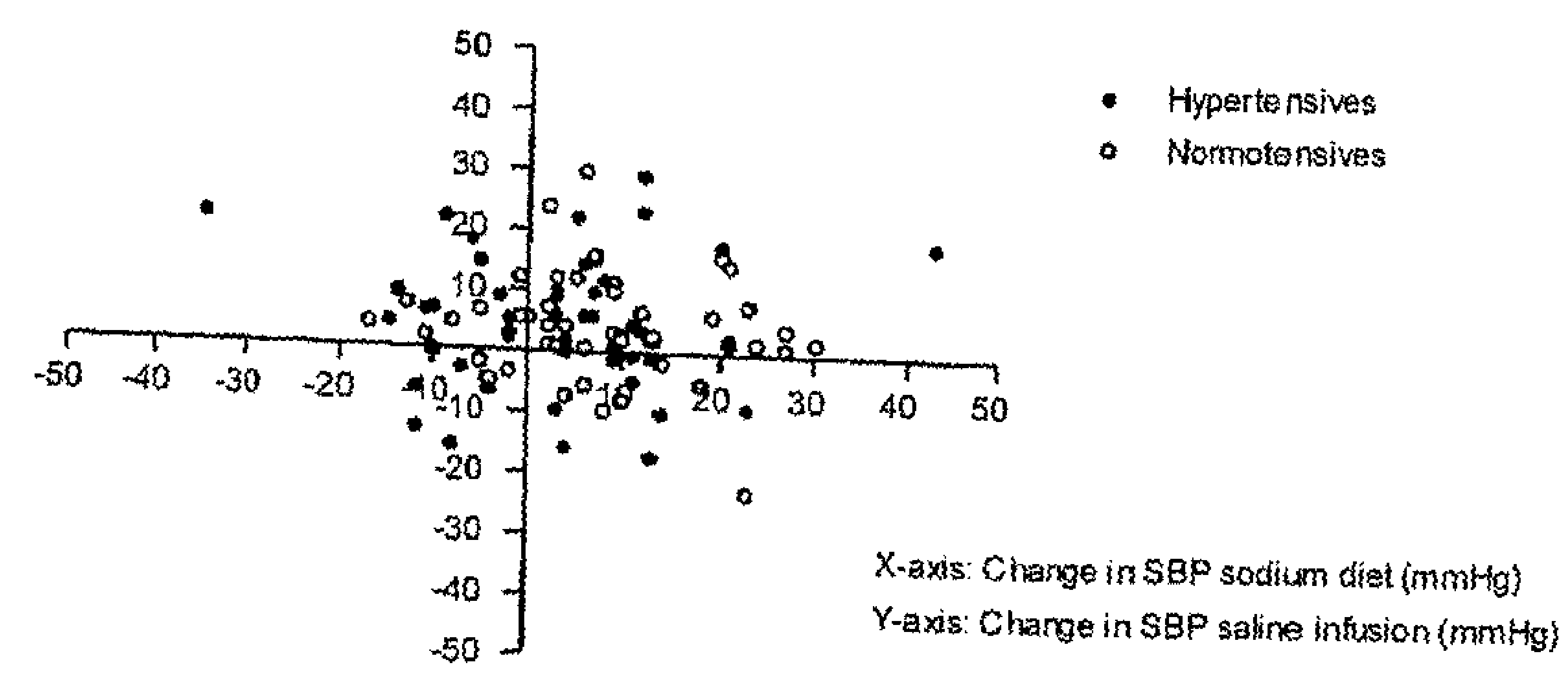

Figure 6.3 Changes in systolic biood pressure after saline infusion and dietary sodium intake.

\section{Neurohormonal responses}

Baseline levels of APRC and aldosterone were significantly lower in the hypertensives than in the normotensives while ANP concentrations were comparable. Both in normotensives and hypertensives the falls in APRC and aldosterone were greater after saline infusion than after the dietary intervention (Figure 6.4). Although ANP tended to rise more after saline loading than during the high-salt diet in the normotensive group, changes were not statistically different when the two approaches were compared.

Using a random intercept + slope model, we found that the falls in APRC and aldosterone immediately after saline infusion $\left(T_{30}\right)$ and one hour after the end of infusion $\left(T_{90}\right)$ were greater in normotensives than in hypertensives (Figure $6.5)$. ANP increased significantly from baseline to one hour after infusion $(\rho<0.001)$, there being no differences between normotensives and
hypertensives (Figure 6.5 ) 

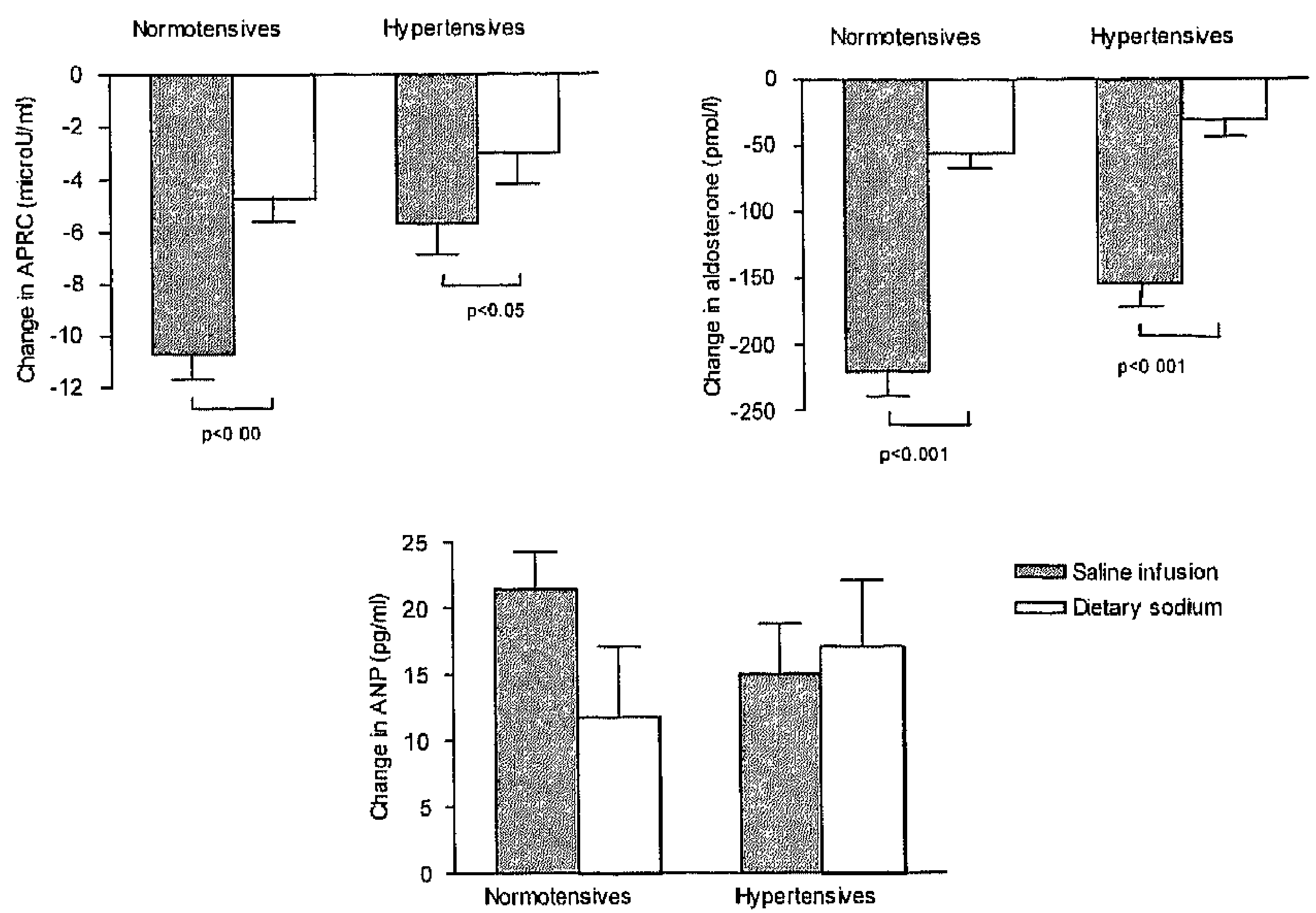

Saline infusion $\leftrightharpoons$ Dietary sodium

Figure 6.4 Changes in neurohormones elicited by the two sodium loading protocols in normotensives and hypertensives. The values for the saline infusion represent $T_{90}$ minus $T_{0}$.
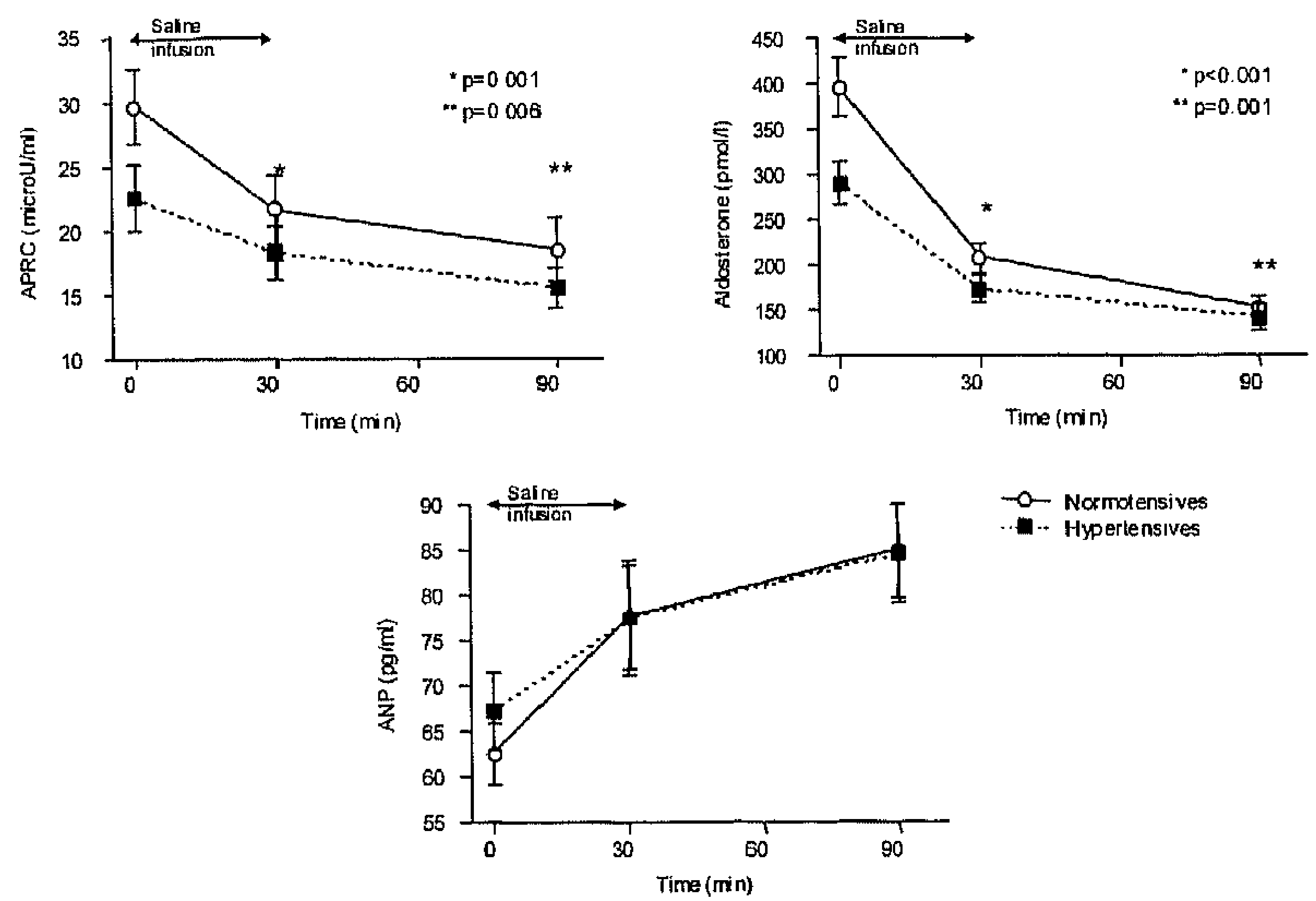
-O- Normotensives

Figure 6.5 Time course of neurohormonal changes during saline infusion in normotensives and hypertensives. Asterisks represent significant differences as compared to baseline $\left(T_{0}\right)$. 


\section{Discussion}

In the present study, we evaluated whether acute saline loading produced similar effects on blood pressure and neurohormones as dietary sodium intervention. Although the mean difference in systolic blood pressure changes during the two sodium loading tests was close to zero (Bland-Altman plot), there was a considerable lack of agreement due to a large variation in responses. Despite the fact that the amount of sodium which was administered intravenously was about the same as that which was gained (or lost) when subjects had attained a new steady state of sodium balance after the dietary switch $^{12}$, the responses of blood pressure clearly differed with both challenges. In other words, it matters whether a sodium load is given acutely or more chronically, with opposite responses of particularly SBP in at least one-third of subjects. A likely explanation for this phenomenon is that different regulatory systems are activated in response to rapid salt loading or the more physiologic dietary intervention. The saline infusion protocol consists of a hypertonic solution that will largely keep the volume within the intravascular space, thus causing a strong hemodynamic stimulus within a short period of 30 minutes. Thus, while a rise in blood pressure induced by hypertonic saline infusion may depend more on vascular compliance and cardiac output, the increment in blood pressure induced by dietary salt intake may rather be determined by the renal retention of sodium or changes in circulating factors such as renin and aldosterone. In general, renin and aldosterone fell more during the infusion than during the diet, thereby supporting the notion that the rate of (volume) changes has a greater effect on neurohumoral compensatory mechanisms than the amount of sodium administered. Apparently, this does not apply to ANP as this peptide behaves similarly during the two tests.

Although blood pressure responses during both tests tended to be somewhat greater in normotensives than in hypertensives, differences between groups were by no means statistically significant with the exception of the behavior of DBP after saline infusion. Theoretically, the greater change in urinary sodium excretion could be responsible for a more pronounced rise of SBP in the normotensives. However, factorial analysis indicated that if such an effect would exist, it would likely be small and only of borderline statistical significance. Nevertheless, there was an interaction between the change in urinary sodium excretion and the order of the sodium diets which suggests that methods of salt sensitivity testing should also take into account the sequence of the diets.

In line with a previous study ${ }^{13}$, the rise of ANP was similar in hypertensives and normotensives during the two sodium loading techniques. In contrast, upon acute sodium loading, renin and aldosterone fell to a lesser degree in 
hypertensives as compared to the normotensives. This is consistent with other observations showing that, when switching from a high to a low sodium diet, normotensives exhibit a greater rise in renin and aldosterone than hypertensives ${ }^{14}$. Earlier reports also suggest that an exaggerated fall in blood pressure after sodium restriction in essential hypertension is related to a blunted renin response ${ }^{6.14 .15}$. In this regard, one would have expected somewhat greater blood pressure changes in the hypertensives rather than the other way around but since these patients had already lower renin and aldosterone levels to begin with, this may have counterbalanced the haemodynamic alterations.

In conclusion, acute saline loading and dietary intervention are not interchangeable in testing for sodium sensitivity. Hypertensives showed a less pronounced response of APRC and aldosterone on sodium infusion compared to normotensive controls, indicating that they had a more suppressed reninangiotensin system. On the other hand, ANP had less discriminatory potential. Finally, when the diet method is applied to assess sodium sensitivity the order of diets (low vs high salt intake) needs to be taken into account. 


\section{References}

1. Beeks E, Kessels AG, Kroon AA, van der Klauw MM, de Leeuw PW. Genetic predisposition to salt-sensitivity: a systematic review. J Hypertens 2004;22:1243-1249.

2. de la Sierra A, Giner V, Bragulat E, Coca A. Lack of correlation between two methods for the assessment of salt sensitivity in essential hypertension. J Hum Hypertens 2002;16:255-260.

3. Galletti F, Ferrara I, Stinga F, lacone R, Noviello F, Strazzullo P. Evaluation of a rapid protocol for the assessment of salt sensitivity against the blood pressure response to dietary sodium chloride restriction. Am J Hypertens 1997; 10:462-466.

4. Kato $N$, Kanda $T$, Sagara M, Bos $A$, Moriguchi EH, Moriguchi $Y$, et al. Proposition of a feasible protocol to evaluate salt sensitivity in a population-based setting. Hypertens Res 2002;25:801-809.

5. Sharma AM, Schorr U, Cetto $C$, Distler A. Dietary $v$ intravenous salt loading for the assessment of salt sensitivity in normotensive men. Am J Hypertens 1994;7:1070-1075.

6. Weinberger MH, Stegner JE, Fineberg NS. A comparison of two tests for the assessment of blood pressure responses to sodium. Am J Hypertens 1993;6:179-184.

7. Weinberger MH, Miller JZ, Luft FC, Grim CE, Fineberg NS. Definitions and characteristics of sodium sensitivity and blood pressure resistance. Hypertension 1986;8:11127-134.

8. Lavrijssen AT, Kroon AA, Fuss-Lejeune $M$, Schiffers $P M$, de Leeuw PW. Renal haemodynamics and sodium excretory capacity during urapidil treatment in patients with essential hypertension. J Hypertens 2000;18:963-969.

9. Spiering $W$, Kroon $A A$, Fuss-Lejeune MM, Daemen MJ, de Leeuw PW. Angiotensin II sensitivity is associated with the angiotensin II type 1 receptor $A(1166) C$ polymorphism in essential hypertensives on a high sodium diet. Hypertension 2000;36:411-416.

10. Bland JM, Altman DG. Statistical methods for assessing agreement between two methods of clinical measurement. Lancet 1986;1:307-310.

11. Snijders TAB, Bosker RJ. Multilevel analysis. An introduction to basic and advanced multilevel modeling. London: SAGE Publications Ltd; 1999.

12. Krekels MME, Schaper NC, De Leeuw PW. Sensitivity of blood pressure and renin activation during sodium restriction. Hypertension 1997;30:1216-1222.

13. Ishimitsu T, Minami J, Nishikimi T, Kawano Y, Takishita S, Kangawa $K$, et al. Responses of natriuretic peptides to acute and chronic salt loading in normotensive and hypertensive subjects. Hypertens Res 1998;21:15-22.

14. He FJ, Markandu ND, MacGregor GA. Importance of the renin system for determining blood pressure fall with acute salt restriction in hypertensive and normotensive whites. Hypertension 2001;38:321-325.

15. Krekels MME, Van Es PN, Leunissen KML, P.W. DL. Sodium sensitivity of blood pressure is not related to sodium, but rather to renin. J Hum Hypertens 1996;10:S127-S130. 


\title{
Chapter 7
}

\section{Exaggerated natriuresis following hypertonic saline loading in subjects with the TRP460TRP variant of the $\alpha$-adducin gene}

\author{
E Beeks, MM van der Klauw, AA Kroon, PW de Leeuw
}




\section{Abstract}

\section{Background}

In this study, we investigated the responses to a hypertonic saline load among the three genotype groups of the $\alpha$-adducin Gly460Trp polymorphism.

\section{Methods}

Forty-six hypertensive patients and 50 normotensive control subjects participated in the study and were challenged with $300 \mathrm{ml}$ of a $3 \%$ saline solution that was infused within 30 minutes. Besides blood pressure, plasma electrolytes and creatinine levels, active plasma renin concentration (APRC), aldosterone and atrial natriuretic peptide (ANP) were measured at baseline, immediately after infusion, and one hour after infusion. Urinary sodium excretion was assessed at the same time intervals as well as after two hours of infusion.

\section{Results}

In all three groups systolic blood pressure tended to rise after the saline infusion but none of these changes were statistically significant. Diastolic pressure tended to fall in all three genotype groups, but again changes were not significant. The infusion caused a greater rise in ANP in subjects with the Trp460Trp genotype than in those who carried the 460Gly allele (random effect models, $p<0.001$ ), while the falls in APRC and aldosterone were similar. One and two hours after infusion, cumulative urinary sodium excretion was greater in subjects with the Trp460Trp genotype as compared to the Gly460Trp group (random effect models, $p<0.05$ ).

\section{Conclusion}

Subjects with the Trp460Trp genotype respond to acute saline loading with hypernatriuresis, possibly mediated by an excessive rise in ANP. This could be important in counteracting a saitinduced elevation of blood pressure. 


\section{Introduction}

Blood pressure responses to changes in sodium intake vary widely among individuals $^{1-3}$. In this respect, older age, black race and certain genetic characteristics have all been associated with a salt-sensitive phenotype ${ }^{2,4,5}$. Of the various genetic factors, variants of the $\alpha$-adducin gene in particular seem to be associated with a salt-sensitive form of hypertension ${ }^{6}$. Indeed, patients carrying at least one 460Trp allele of the $\alpha$-adducin Gly460Trp polymorphism showed a greater rise in blood pressure after saline infusion than those with the wild-type (Gly460Gly) ${ }^{7-9}$.

Normally, an acute sodium load lowers active plasma renin concentration (APRC) and aldosterone levels while increasing atrial natriuretic peptide $(A N P)^{10,11}$. Not much is known, however, about the association between the $\alpha-$ adducin Gly460Trp polymorphism and the time course of APRC, aldosterone, ANP and sodium excretion during saline infusion. Previous work from our group suggests that both on a low and a high sodium diet. ANP levels are higher in the Trp460Trp genotype group as compared to patients carrying the 460 Gly allele ${ }^{12}$. This could be a mechanism counteracting the tendency of Trp460Trp patients to retain more sodium ${ }^{8}$.

In the present study, we assessed the responses of blood pressure, neurohormones and sodium excretion to a hypertonic saline infusion in relation to the variants of the $\alpha$-adducin Gly460Trp polymorphism.

\section{Methods}

\section{Subjects}

Forty-six patients with hypertension attending the outpatient clinic of the University Hospital Maastricht and 50 normotensive controls were enrolled in this study. Hypertension was defined as systolic blood pressure (SBP) of at least $140 \mathrm{mmHg}$ and/or diastolic blood pressure (DBP) of at least $90 \mathrm{mmHg}$ without treatment. Other inclusion criteria were age between 30 and 75 years and no secondary causes of hypertension or other significant medical illness, including diabetes mellitus or renal impairment. Antihypertensive treatment, if any, was withdrawn three weeks prior to the study. Control subjects were either spouses of the patients selected for this study or volunteers. Exclusion criteria for this group were: SBP greater than $130 \mathrm{mmHg}$ and/or DBP greater than $90 \mathrm{mmHg}$, cardiovascular disease, renal impairment or diabetes mellitus. The study was approved by the Medical Ethical Committee of the University Hospital Maastricht. Informed consent was obtained from each individual recruited. 
Chapter 7

\section{Saline infusion protocol}

Patients were investigated after one week of low salt diet $\left(55 \mathrm{mmol} \mathrm{Na}^{+}\right.$per day). Compliance with the diet was checked by measuring sodium and creatinine output in 24-hour urine collections obtained on the last two days of the dietary period. Patients had refrained from smoking, alcohol and caffeine from $10 \mathrm{PM}$ the evening before the measurements and were only allowed to drink water in the morning of the study day. Experiments started at 8.30 A.M. and patients remained supine during the entire session. In both arms an antecubital vein was cannulated with a 20 -gauge cannula. The cannula in the right arm was connected to a 3-way tap for the infusion of saline, whereas the cannula in the left arm was used for blood sampling. After an acclimatization period of 30 minutes, $300 \mathrm{ml}$ of a hypertonic (3\%) saline solution was infused over a period of 30 minutes $^{10}$. SBP, DBP, mean arterial pressure (MAP) and heart rate were monitored with a semiautomatic oscillometric device (Dinamap Vital Signs Monitor 1846, Critikon). Plasma levels of sodium, potassium, and creatinine, APRC, aldosterone, ANP as well as urinary sodium excretion were determined at baseline $\left(T_{0}\right)$, immediately after the infusion $\left(T_{30}\right)$ and at one hour after the end of infusion $\left(T_{90}\right)$. Plasma levels of sodium and urinary sodium excretion were also assessed two hours after the infusion $\left(T_{150}\right)$.

\section{Assay methods and genetic analysis}

APRC, aldosterone and ANP levels were assayed as described earlier ${ }^{13}$. DNA was extracted from whole blood using the Wizard Genomic DNA Purification Kit (Promega, Leiden, the Netherlands). The $\alpha$-adducin Gly460Trp polymorphism was detected by mutagenically separated $P C R,{ }^{14,15}$ as reported previously ${ }^{16}$.

\section{Statistical analysis}

The calculation of allele frequencies to test for Hardy-Weinberg equilibrium was carried out by $\chi^{2}$ analysis comparing expected against observed frequencies. The $\chi^{2}$ test was also used to test the frequencies of the $\alpha$-adducin Gly460Trp polymorphism and gender between the hypertensives and normotensive controls. Kruskal-Wallis test was applied for univariate testing of differences in clinical characteristics and changes in blood pressure between the three genotype groups. When the Kruskal-Wallis test revealed a significant effect of genotype, Mann-Whitney $U$ test with Hochberg correction was used as posthoc analysis ${ }^{17}$. With random effect models we evaluated whether differences existed in changes in neurohormones, plasma sodium levels and cumulative urinary sodium excretion during the acute sodium loading test between the three genotype groups of $\alpha$-adducin ${ }^{18}$. We used a random intercept + slope model for aldosterone, APRC and cumulative urinary sodium excretion, and a 
random intercept model for ANP and plasma sodium levels. All analyses were performed with SPSS 11.5 software.

\section{Results}

\section{Population characteristics}

Subjects were included in the analyses only when they had completed all measurements. The total group consisted of 96 subjects, of whom 44 carried the Gly460Gly genotype (46\%), while 42 were Gly460Trp carriers $(44 \%)$ and 10 had the less common Trp460Trp genotype (10\%). The genotype distribution of the $\alpha$-adducin polymorphism in hypertensives as well as in normotensive controls did not deviate significantly from Hardy-Weinberg's expectation $\left(\chi^{2}=0.206, p=0.902\right.$ and $\chi^{2}=0.417, p=0.812$ respectively). Also, no difference in genotype frequencies of the $\alpha$-adducin Gly460Trp polymorphism was detected between hypertensives and controls $\left(\chi^{2}=2.4, p=0.309\right)$. Although clinical characteristics, blood pressure and neurohormones differed to some extent between the hypertensives and the normotensive controls, after saline infusion these variables showed the same pattern in these two groups of subjects. Therefore, these two groups could be combined for analyses. Characteristics of all subjects by genotype group of $\alpha$-adducin are presented in Table 7.1. Serum potassium increased with increasing number of 460Trp alleles $(p<0.05)$. Urinary sodium excretion prior to the investigations was higher in subjects with the Gly460Trp genotype as compared to subjects homozygous for the 460Gly allele (Mann-Whitney $U$ test with Hochberg correction, $p=0.036$ ).

Table 7.1 Clinical characteristics by genotype group of $\alpha$-adducin in all subjects.

$\begin{array}{lccc} & \text { Gly460Gly } & \text { Gly460Trp } & \text { Trp460Trp } \\ & n=47 & n=43 & n=10 \\ \text { HT/NT } & 19 / 25 & 20 / 22 & 7 / 3 \\ \text { Age, years } & 55(48,60) & 57(49,61) & 53(44,64) \\ \text { Gender, M/F (\% male) } & 22 / 26(46 \%) & 25 / 18(58 \%) & 2 / 8(20 \%) \\ \text { BMI, kg/m } 2 & 26.5(24.7,28.9) & 24.9(23.1,28.6) & 25.8(24.0,31.9) \\ \text { SBP, mmHg } & 135(114,157) & 130(112,161) & 139(125,188) \\ \text { DBP, mmHg } & 79(72,85) & 78(71,91) & 78(73,102) \\ \text { MAP, mmHg } & 96(89,112) & 101(87,116) & 108(95,136) \\ \text { Heart rate, bpm } & 62(55,66) & 63(56,70) & 63(59,67) \\ \text { Plasma sodium, mmol/l } & 139(138,140) & 139(138,140) & 139(137,140) \\ \text { Plasma potassium, mmol/l } & 4.0(3.7,4.2) & 4.1(3.9,4.3) & 4.3(4.2,4.7)^{\mathrm{a}} \\ \text { Plasma creatinine, } \mu \mathrm{mol} / \mathrm{l} & 80(67,87) & 80(74,92) & 79(70,87) \\ \text { U }_{\text {NaV }} \text { mmol/24h } & 50(31,76) & 73(44,90)^{\mathrm{b}} & 57(39,74)\end{array}$

Data are presented as medians (interquartile ranges). HT indicates hypertensives; NT, normotensives; BMI, body mass index; SBP, systolic blood pressure; DBP, diastolic blood pressure; MAP, mean arterial pressure; $\mathrm{U}_{\mathrm{Na}} \mathrm{V}, 24$-hour urinary sodium excretion (after one week of low sodium diet). Variables are measured before saline infusion. ${ }^{a} p<0.05,{ }^{b} p=0.036$ compared with Gly460Gly 


\section{Saline infusion test}

All three groups tended to show a rise in SBP and a fall in DBP (Table 7.2). However, none of these changes was statistically significant, neither within nor between groups. Regardless of genotype, APRC and aldosterone decreased significantly during sodium loading, while ANP increased. Using a random intercept + slope model, we found that the falls in aldosterone and APRC were not different between the three genotype groups (Figure 7.1). ANP, on the other hand, rose significantly more immediately after infusion $\left(T_{30}\right)$ and one hour after infusion ( $\left.T_{90}\right)$ in subjects with the Trp460Trp genotype as compared to those carrying the 460 Gly allele (Table 7.3, Figure $7.1, p<0.001$ ). In all subjects, cumulative urinary sodium excretion and plasma sodium levels were significantly increased two hours after infusion as compared to baseline. One and two hours after infusion ( $T_{90}$ and $T_{150}$ ), the increase in baseline-corrected cumulative urinary sodium output was significantly greater in subjects with the Trp460Trp genotype as compared to the other two genotype groups $(p=0.031$ and $p=0.020$ respectively; Figure 7.2 ). Changes in plasma sodium levels were not different between the genotype groups of $\alpha$-adducin (Figure 7.2).

Table 7.2 Changes in blood pressure after saline infusion per genotype group.

\begin{tabular}{lccc} 
& Gly460Gly & \multicolumn{1}{c}{ Gly460Trp } & Trp460Trp \\
$\Delta$ SBP, mmHg & $2.7(-1.2,8.3)$ & $4.7(-1.3,11.3)$ & $5.8(-9.8,11.2)$ \\
$\Delta$ DBP, mmHg & $-0.3(-3.0,2.0)$ & $0.7(-2.3,2.7)$ & $-3.5(-8.1,0.8)$ \\
$\triangle$ MAP, mmHg & $2.7(-1.7,7.0)$ & $1.7(-3.3,6.7)$ & $-1.7(-8.7,2.8)$
\end{tabular}

Data are presented as medians (interquartile ranges). SBP indicates systolic blood pressure; $D B P$, diastolic blood pressure; MAP, mean arterial pressure

Table 7.3 Random intercept model showing the association between atrial natriuretic peptide and the $\alpha$-adducin genotypes.

$\begin{array}{lcccc}\text { Variable } & \text { Estimate }(b) & \text { SE } & \text { P-value } & -2 \text { log likelihood } \\ \text { Intercept } & 64.5 & 10.6 & <0.001 & 2755.855 \\ \text { Time at } 30 \text { minutes }\left(T_{30}\right)^{\mathrm{a}} & 55.1 & 8.8 & <0.001 & \\ \text { Time at } 90 \text { minutes }\left(\mathrm{T}_{90}\right)^{\mathrm{a}} & 52.9 & 7.7 & <0.001 \\ \text { Gly460Gly }\left(\mathrm{G}_{\mathrm{GG}}\right)^{\mathrm{b}} & -0.7 & 11.6 & 0.949 \\ \text { Gly460Trp }\left(\mathrm{G}_{\mathrm{GT}}\right)^{\mathrm{b}} & 0.1 & 11.7 & 0.993 \\ \text { Interaction } \mathrm{T}_{30} \cdot \mathrm{G}_{\mathrm{GG}} & -45.8 & 9.5 & <0.001 \\ \text { Interaction } \mathrm{T}_{30} \cdot \mathrm{G}_{\mathrm{GT}} & -46.8 & 9.6 & <0.001 \\ \text { Interaction } \mathrm{T}_{90} \cdot \mathrm{G}_{\mathrm{GG}} & -36.7 & 8.5 & <0.001 \\ \text { Interaction } \mathrm{T}_{90} \cdot \mathrm{G}_{\mathrm{GT}} & -36.5 & 8.5 & <0.001 \\ \text { Intercept variance } & 825.1 & 132.4 & \\ \text { ICC } & 0.73 & & \end{array}$
${ }^{a}$ Estimate (b) compared to time at baseline ( $T_{0}$ ) (reference category); ${ }^{b}$ Estimate (b) compared to
Trp460Trp (reference category); ICC indicates intra class correlation 

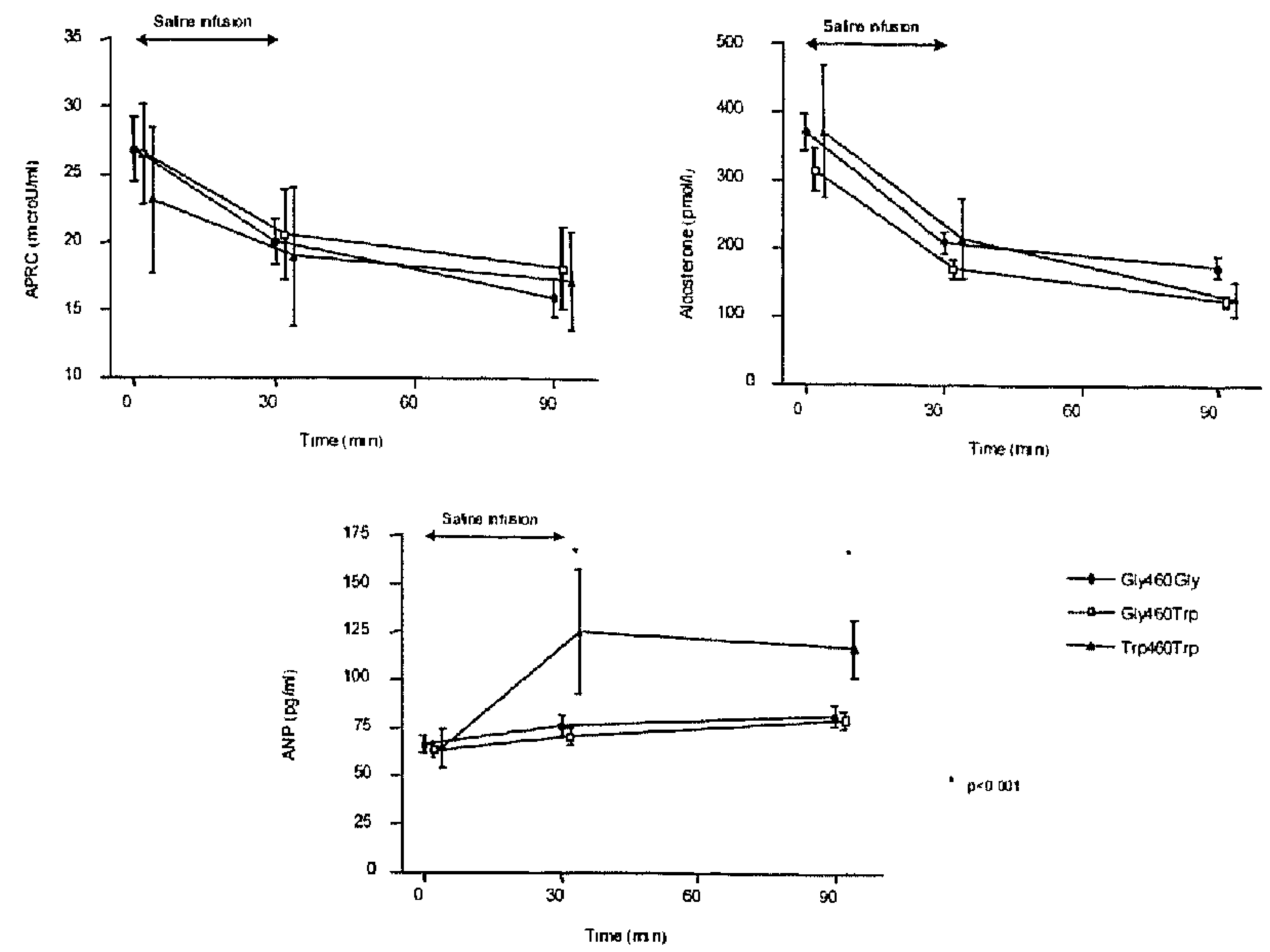

$\rightarrow-$ TrPA60Trp

Figure 7.1 Active plasma renin concentration, aldosterone and atrial natriuretic peptide before and after saline infusion. Values are means with standard error.
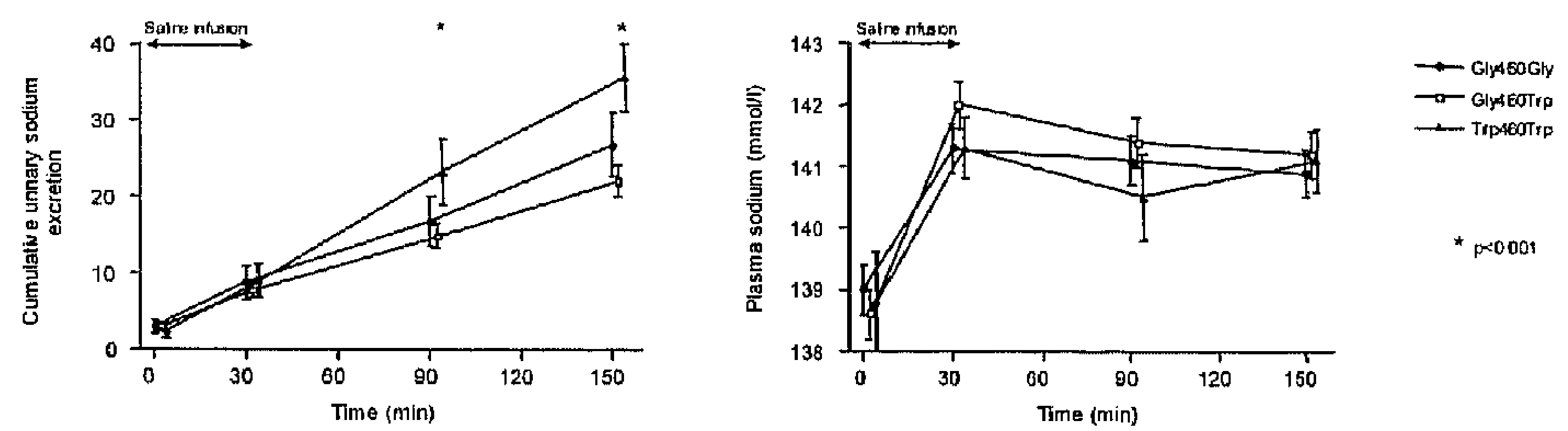

Figure 7.2 Cumulative urinary sodium excretion and plasma sodium levels before and after saline infusion. Values are means with error.

\section{Discussion}

In the present study, the effects of the $\alpha$-adducin Gly460Trp polymorphism on responses of blood pressure, neurohormones and body fluid volumes to acute sodium loading (saline infusion) were investigated in normotensive and hypertensive subjects. Although blood pressure was higher in the 
hypertensives, changes in blood pressure and neurohormones after saline infusion showed the same pattern as in the normotensive controls. Therefore, hypertensives and normotensive controls were grouped together for the analyses.

After saline infusion, there were no significant differences in the changes of blood pressure between the three genotype groups. Our subjects with the Trp460Trp genotype showed the same blood pressure response as $460 \mathrm{Gly}$ allele carriers, contrary to findings from other studies. ${ }^{7-9}$ Nevertheless, changes in SBP tended to be somewhat greater in the Trp460Trp group, thereby leaving the possibility that the lack of statistical significance was due to the small number of subjects in this group. During salt loading neural and endocrine systems show adaptive responses to maintain homeostasis of body fluid volumes and blood pressure. These adaptive responses include suppression of the renin-angiotensin-aldosterone axis, ${ }^{19.20}$ and stimulation of natriuretic peptides $^{21}$. In our study, saline infusion led to a greater rise in ANP levels in subjects with the Trp460Trp genotype than in those carrying the 460Gly allele. The potentiated rise in ANP could suggests that subjects who are homozygous for the abnormal genotype were relatively volume overloaded or had at least a greater effective circulating volume than the others. This is further corroborated by the fact that the increase in natriuresis was greatest in this group. In this respect, the enhanced stimulation of ANP and of natriuresis in Trp460Trp subjects could be important in counteracting a salt-induced elevation of blood pressure. However, the decreases in APRC and aldosterone on the other hand, were not different between the various genotype groups which argues against an absolute volume excess in those with two 460Trp alleles. Alternatively, a greater rise in ANP may reflect enhanced atrial stretch, e.g. secondary to a reduced capacity of the venous system to dilate in response to an acute saline challenge.

After one week of low sodium, potassium levels were significantly higher in subjects homozygous for the 460Trp allele. This could provide for an additional mechanism to maintain blood pressure at a lower level. The phenomenon remains unexplained, however, in particular because plasma levels of aldosterone were not different between the genotype groups. Although, at steady state, subjects with the Gly460Trp genotype had a somewhat higher 24-hour urinary sodium excretion, this did not affect our results.

Most studies on the association between the $\alpha$-adducin Gly460Trp polymorphism and salt sensitivity of blood pressure have utilized either an isotonic saline infusion or diuretics ${ }^{7.9 .22}$. We chose an infusion with a hypertonic saline solution because with this procedure more of the administered volume will remain within the intravascular space and can create a strong hemodynamic stimulus within a short period of time. This is certainly different from infusion with an isotonic saline solution where the volume will 'leak' into 
the interstitium. Differences in these sodium loading techniques make it difficult to compare our results with previous studies on this matter.

Because the Trp460Trp genotype is rather uncommon, all subjects carrying the 460Trp allele are usually taken together in analyses. We considered the three genotypes separately to obtain more extensive information about the different variants of the $\alpha$-adducin Gly460Trp polymorphism ${ }^{12}$. As a result, the number of subjects homozygous for the 460Trp allele is relatively small, which is a limitation to this study.

\section{Perspectives}

After rapid sodium loading (saline infusion), the change in blood pressure was not different between the genotype groups. Also, the falls in APRC and aldosterone did not differ between the genotype groups. Levels of ANP increased more in the Trp460Trp genotype group, and the rise in natriuresis was also greatest in this group. This calls for further studies focusing at the relationship between the degree and rate of a disturbance in volume regulating systems and response variables. For instance, it should be tested whether the Trp460Trp genotype is associated with altered body fluid volumes and why subjects with this genotype respond with an enhanced rise in ANP. It is also worthwhile to explore whether our results are related to the sodium load or rather to the volume load per se. In addition, it is relevant to investigate whether subjects with the adducin 460Trp variant respond differently to a more chronic change in sodium load, i.e. when dietary sodium is increased. Finally, from a clinical perspective it would be important to know whether Trp460Trp subjects are more prone to e.g. congestive heart failure. 


\section{References}

1. Weinberger MH. Salt sensitive human hypertension. Endocr Res. 1991;17:43-51.

2. Overlack A. Ruppert M, Kolloch R, Gobel B, Kraft K, Diehl J, Schmitt W, Stumpe KO Divergent hemodynamic and hormonal responses to varying salt intake in normotensive subjects. Hypertension. 1993;22:331-338

3. Luft FC. Weinberger MH. Heterogeneous responses to changes in dietary salt intake: the salt-sensitivity paradigm. Am J Clin Nutr. 1997;65:612S-617S.

4. Sullivan JM Salt sensitivity. Definition, conception, methodology, and long-term issues. Hypertension. 1991;17:161-68.

5 Luft FC. Miller JZ, Weinberger MH, Christian JC, Skrabal F. Genetic influences on the response to dietary salt reduction, acute salt loading, or salt depletion in humans. $J$ Cardiovasc Pharmacol. 1988;12 Suppl 3:S49-55.

6. Beeks $E$, Kessels AG, Kroon AA. van der Klauw MM, de Leeuw PW. Genetic predisposition to salt-sensitivity: a systematic review. J Hypertens. 2004;22:1243-1249.

7. Cusi D, Barlassina C. Azzani T, Casari G. Citterio L, Devoto M, Glorioso N, Lanzani C. Manunta P. Righetti M, Rivera R, Stella P, Troffa C, Zagato L, Bianchi G. Polymorphisms of alpha-adducin and salt sensitivity in patients with essential hypertension. Lancet. 1997, 349:1353-1357.

8. Manunta P, Cusi D. Barlassina C, Righetti M, Lanzani C, D'Amico M, Buzzi L, Citterio L Stella $P$, Rivera $R$, Bianchi $G$. Alpha-adducin polymorphisms and renal sodium handling in essential hypertensive patients. Kidney Int. 1998;53:1471-1478.

9. Barlassina C, Schork NJ, Manunta P. Citterio L, Sciarrone M, Lanella G, Bianchi G, Cusi D. Synergistic effect of alpha-adducin and ACE genes causes blood pressure changes with body sodium and volume expansion. Kidney Int. 2000;57:1083-1090.

10. Lavrijssen AT, Kroon AA, Fuss-Lejeune $M$, Schiffers PM, de Leeuw PW. Renal haemodynamics and sodium excretory capacity during urapidil treatment in patients with essential hypertension. J Hypertens. 2000;18:963-969.

11. Ishimitsu T, Minami J, Nishikimi T, Kawano Y, Takishita S, Kangawa K, Matsuo H, Matsuoka $H$. Responses of natriuretic peptides to acute and chronic salt loading in normotensive and hypertensive subjects. Hypertens Res. 1998;21:15-22.

12. Beeks E, van der Klauw MM, Kroon AA, Spiering W. Fuss-Lejeune MJ, de Leeuw PW. Alphaadducin Gly460Trp polymorphism and renal hemodynamics in essential hypertension. Hypertension. 2004;44:419-423.

13. Spiering W, Kroon AA, Fuss-Lejeune MM, Daemen MJ, de Leeuw PW. Angiotensin II sensitivity is associated with the angiotensin 11 type 1 receptor $A(1166) C$ polymorphism in essential hypertensives on a high sodium diet. Hypertension. 2000;36:411-416.

14. Rust S, Funke H, Assmann G. Mutagenically separated PCR (MS-PCR): a highly specific one step procedure for easy mutation detection. Nucleic Acids Res. 1993;21:3623-3629.

15. Kato $N$, Sugiyama T, Nabika T, Morita H, Kurihara H, Yazaki Y, Yamori Y. Lack of association between the $\alpha$-adducin locus and essential hypertension in the Japanese population Hypertension. 1998;31:730-733

16. Beeks E, Janssen RG, Kroon AA, Keulen ET, Geurts JM, de Leeuw PW, de Bruin TW Association between the alpha-adducin Gly460Trp polymorphism and systolic blood pressure in familial combined hyperlipidemia. Am J Hypertens. 2001;14:1185-1190.

17. Hochberg $Y$, Benjamini $Y$. More powerful procedures for multiple significance testing. Stat Med. 1990;9:811-818.

18. Snijders TAB, Bosker RJ: Multilevel analysis. An introduction to basic and advanced multilevel modeling. in, London, SAGE Publications Ltd, 1999.

19. Kawasaki T, Delea CS, Bartter FC, Smith $H$. The effect of high-sodium and low-sodium intakes on blood pressure and other related variables in human subjects with idiopathic hypertension. Am J Med 1978;64:193-198.

20. Fujita T, Henry WL, Bartter FC, Lake CR, Delea CS. Factors influencing blood pressure in salt-sensitive patients with hypertension. Am J Med. 1980;69:334-344. 
21. Kohno M, Yasunari K, Murakawa K, Kanayama $Y$, Matsuura T, Takeda T. Effects of highsodium and low-sodium intake on circulating atrial natriuretic peptides in salt-sensitive patients with systemic hypertension. Am J Cardiol. 1987;59:1212-1213.

22. Sciarrone MT, Stella P, Barlassina C, Manunta P, Lanzani C, Bianchi G, Cusi D. ACE and alpha-adducin polymorphism as markers of individual response to diuretic therapy. Hypertension. 2003;41:398-403. 


\section{Chapter 8}

Response to dietary sodium loading in subjects with variants of the $\alpha$-adducin Gly460Trp polymorphism

E Beeks, AA Kroon, MM van der Klauw, PW de Leeuw 


\section{Abstract}

\section{Background}

In this study we investigated the responses to a change in sodium diet among the three genotype groups of the $a$-adducin Gly460Trp polymorphism.

\section{Methods}

Forty-six hypertensive patients and 50 normotensive individuals were subjected to dietary sodium loading. The dietary test consisted of a one-week period of low (55 mmol Na $/$ day) and high $\left(220 \mathrm{mmol} \mathrm{Na}^{*} /\right.$ day) sodium, in randomized order. Blood pressure, active plasma renin concentration (APRC), piasma aldosterone and atrial natriuretic peptide (ANP) were measured after each dietary period. Since changes in blood pressure after the switch in sodium load were dependent upon the order of the diets, the analyses were adjusted for this sequence effect.

\section{Results}

Changes in systolic blood pressure and neurohormones did not differ between the three genotype groups. On the other hand, an increased sodium intake had different effects on diastolic blood pressure (DBP) in the three groups with, on average, no change or even a tendency to fall in the subjects with the Gly 460 Gly genotype $(-3.9 \mathrm{mmHg} ; 95 \%$ confidence interval: $-7.9-0.2 \mathrm{mmHg})$ and a small rise in those with the Trp460Trp genotype: $2.6(0.6-4.5) \mathrm{mmHg}$. These responses differed significantly from each other $(p=0.005)$. When the changes in DBP and ANP were plotted against the changes in 24-hour urinary sodium excretion, the regression lines in the Trp460Trp group were steeper than those in the Gly460Gly group (ANCOVA, $p=0.006$ and $p=0.027$ respectively).

\section{Conclusion}

These results suggest that subjects with the Trp460Trp genotype may have been more volume overloaded than the others. 


\section{Introduction}

Blood pressure responses to changes in sodium intake vary widely among individuals ${ }^{1-3}$. In some, blood pressure falls with salt restriction whereas in others little or no change or even a rise in blood pressure occurs. The reverse is true when salt intake is increased. Older age, black race and genetic factors have all been associated with a salt-sensitive phenotype $e^{2,4,5}$. Among the genetic factors, variants of the $\alpha$-adducin gene in particular seem to be associated with a salt-sensitive form of hypertension ${ }^{6}$. Indeed, patients carrying at least one 460Trp allele of the $\alpha$-adducin Gly460Trp polymorphism showed a greater rise in blood pressure after saline infusion than those with the wild-type gene ${ }^{7-9}$.

Normally, both an acute and a chronic sodium load lower active plasma renin concentration (APRC) and aldosterone levels while increasing atrial natriuretic peptide (ANP) concentrations ${ }^{10,11}$. Not much is known, however, about the association between the $\alpha$-adducin Gly460Trp polymorphism and the time course of renin, aldosterone and ANP during sodium loading. Previous work from our group suggests that both on a low and a high sodium diet, ANP levels are higher in the Trp460Trp genotype group as compared to patients carrying the 460 Gly allele $^{12}$. This could be a mechanism counteracting the tendency of Trp460Trp patients to retain more sodium ${ }^{9}$.

In the present study, we assessed the responses of blood pressure, and neurohormones to dietary sodium loading in relation to the variants of the $\alpha$-adducin Gly460Trp polymorphism. We hypothesized that patients with the Trp460Trp genotype tend to be somewhat overloaded than the others and that this would lead to a greater rise in pressure and ANP and a greater fall in APRC and aldosterone in these subjects.

\section{Methods}

\section{Study population}

Forty-eight patients with hypertension attending the outpatient clinic of the University Hospital Maastricht and 50 normotensive subjects were enrolled in this study. Hypertension was defined as a systolic blood pressure (SBP) of at least $140 \mathrm{mmHg}$ and/or a diastolic blood pressure (DBP) of at least $90 \mathrm{mmHg}$ in subjects without treatment. Other inclusion criteria were: age between 30 and 75 years, absence of secondary causes of hypertension or significant medical illness, including diabetes mellitus and renal impairment (serum creatinine $\geq 120 \mu \mathrm{mo} / \mathrm{l})$. Antihypertensive treatment, if any, was withdrawn three weeks prior to the study. Normotensive subjects were either spouses of 
the patients selected for this study or volunteers. They qualified for the study when they had a SBP below $130 \mathrm{mmHg}$ and a DBP less than $90 \mathrm{mmHg}$ and were free from cardiovascular disease, renal impairment (serum creatinine $\geq 120 \mu \mathrm{mol} / \mathrm{l})$ or diabetes mellitus. The Medical Ethical Committee of the University Hospital Maastricht approved the study protocol and we obtained informed consent in writing from each participant.

\section{Dietary sodium protocol}

This protocol consisted of a low sodium diet $\left(55 \mathrm{mmol} \mathrm{Na}{ }^{+}\right.$per day) and a high sodium diet (220 mmol Na${ }^{+}$per day), each for a one-week period and given in randomized order. Compliance with the diet was checked on the last two days of each dietary period by use of 24-hour urine collections. On the morning of each study day and after 30 minutes of rest, we measured SBP, DBP, mean arterial pressure (MAP) and heart rate (HR) in the supine position with an automatic device. These values were recorded at 10 minute intervals over a period of one hour. Also, fasting blood samples were taken for determination of APRC, aldosterone and ANP.

\section{Assay methods and genetic analysis}

APRC, aldosterone and ANP levels were assayed as mentioned earlier ${ }^{13}$. DNA was extracted from whole blood using the Wizard Genomic DNA Purification Kit (Promega, Leiden, the Netherlands). The $\alpha$-adducin Gly460Trp polymorphism was detected by mutagenically separated $P C R^{14,15}$, as described previously ${ }^{16}$.

\section{Statistical analysis}

For the calculation of allele frequencies to test for Hardy-Weinberg equilibrium we used $\chi^{2}$ analysis comparing expected against observed frequencies. The $\chi^{2}$ test was also used to test the frequencies of the $\alpha$-adducin Gly460Trp polymorphism and gender between the hypertensives and the normotensives. To check whether correction for the order of the sodium diets (period effect) was needed, we applied regression analysis. Linear regression analysis was also done to test for differences in clinical characteristics, urinary sodium excretion, blood pressure, and neurohormones after adjusting for the order of the sodium diets. We performed analysis of covariance (ANCOVA) to detect differences between the three genotype groups with respect to the relationship between changes in urinary sodium excretion and changes in blood pressure or neurohormones. All analyses were carried out with SPSS 11.5 software. A p-value of less than 0.05 was considered statistically significant. Data are reported as means with $95 \%$ confidence intervals $(\mathrm{Cl})$. 


\section{Results}

All participants completed the measurements and were available for analysis. The total group consisted of 98 subjects, of whom 45 carried the Gly460Gly genotype (46\%), while 43 were Gly460Trp carriers (44\%) and 10 had the less common Trp460Trp genotype (10\%). The genotype distribution of the $\alpha$-adducin polymorphism in the hypertensives as well as in the normotensives did not deviate significantly from Hardy-Weinberg's expectation $\left(\chi^{2}=0.149\right.$, $p=0.928$ and $\chi^{2}=0.417, p=0.812$ respectively). Also, no difference in genotype or allele frequencies of the $\alpha$-adducin Gly460Trp polymorphism was detected between hypertensives and normotensives $\left(\chi^{2}=2.1, p=0.343\right)$. Although blood pressure (by definition) and neurohormones differed to some extent between hypertensives and normotensives, these variables showed a remarkably similar pattern in response to dietary sodium loading in the two groups of subjects. Therefore, these two groups were combined for analyses. Characteristics of all subjects by genotype group of $\alpha$-adducin are presented in Table 8.1.

Table 8.1 Clinical characteristics by genotype group of $\alpha$-adducin in all subjects.

\begin{tabular}{|c|c|c|c|}
\hline & $\begin{array}{c}\text { Gly460Gly } \\
\qquad N=44\end{array}$ & $\begin{array}{l}\text { Gly460Trp } \\
\qquad \mathrm{N}=42\end{array}$ & $\begin{array}{c}\text { Trp460Trp } \\
\mathrm{N}=10\end{array}$ \\
\hline Age, years & $55(52-57)$ & $55(52-57)$ & $54(49-59)$ \\
\hline Gender, $\mathrm{m} / \mathrm{f}$ (\% male) & $19 / 26(42 \%)$ & $25 / 18(58 \%)$ & $2 / 8(20 \%)$ \\
\hline \multicolumn{4}{|l|}{ Low sodium diet } \\
\hline $\mathrm{BMl}, \mathrm{kg} / \mathrm{m}^{2}$ & $27.1(26.0-28.2)$ & $25.8(24.6-26.9)$ & $28.0(25.7-30.4)$ \\
\hline $\mathrm{SBP}, \mathrm{mmHg}$ & $138(129-146)$ & $137(128-145)$ & $151(133-169)$ \\
\hline $\mathrm{DBP}, \mathrm{mmHg}$ & $82(78-86)$ & $82(78-86)$ & $85(77-94)$ \\
\hline MAP, $\mathrm{mmHg}$ & $103(97-109)$ & $103(97-109)$ & $113(100-125)$ \\
\hline Heart rate, bpm & $61(58-64)$ & $60(57-63)$ & $63(57-69)$ \\
\hline APRC, $\mu U / \mathrm{ml}$ & $14.1(11.1-17.1)$ & $14.2(11.1-17.3)$ & $13.9(7.7-20.1)$ \\
\hline Aldosterone, pmol/l & $157(131-182)$ & $130(104-156)$ & $113(58-168)$ \\
\hline ANP, $\mathrm{pg} / \mathrm{ml}$ & $91.8(80.0-103.6)$ & $96.3(84.3-108.3)$ & $106.9(80.9-132.9)$ \\
\hline$U_{\mathrm{Na}} V_{1} \mathrm{mmol} / 24 \mathrm{~h}$ & $68(54-81)$ & $79(65-92)$ & $97(70-125)$ \\
\hline \multicolumn{4}{|l|}{ High sodium diet } \\
\hline$B M I, \mathrm{~kg} / \mathrm{m}^{2}$ & $27.3(26.2-28.5)$ & $26.0(24.8-27.1)$ & $28.0(25.7-30.4)$ \\
\hline $\mathrm{SBP}, \mathrm{mmHg}$ & $144(135-152)$ & $141(133-150)$ & $150(132-168)$ \\
\hline DBP, $\mathrm{mmHg}$ & $83(79-87)$ & $84(80-88)$ & $81(73-90)$ \\
\hline MAP, mmHg & $106(100-112)$ & $106(101-112)$ & $109(97-121)$ \\
\hline Heart rate, bpm & $59(57-62)$ & $59(56-62)$ & $62(56-68)$ \\
\hline APRC, $\mu \mathrm{U} / \mathrm{ml}$ & $11.2(9.2-13.2)$ & $8.9(6.8-11.0)$ & $11.3(6.9-15.8)$ \\
\hline Aldosterone, $\mathrm{pmol} / /$ & $107(88-127)$ & $81(62-101)$ & $98(56-140)$ \\
\hline ANP, $\mathrm{pg} / \mathrm{ml}$ & $107.9(96.1-119.6)$ & $100.5(88.6-112.5)$ & $104.9(77.8-132.0)$ \\
\hline $\mathrm{U}_{\mathrm{Na}} \mathrm{V}, \mathrm{mmol} / 24 \mathrm{~h}$ & $183(164-201)$ & $179(161-197)$ & $162(125-199)$ \\
\hline
\end{tabular}

Data are presented as means with $95 \%$ confidence intervals. BMI, body mass index; SBP, systolic blood pressure; DBP, diastolic blood pressure; MAP, mean arterial pressure; bpm, beats per minute; $A P R C$, active plasma renin concentration; $A N P$, atrial natriuretic peptide; $U_{N a} V, 24-$ hour urinary sodium excretion. The analyses are adjusted for the order of the sodium diets 
There were no differences in clinical characteristics between the two genotype groups after the low and the high sodium diet. Although not reaching statistical significance, 24-hour urinary sodium excretion tended to be greater in the Trp460Trp group as compared to the Gly460Gly group after the low sodium diet $(p=0.061)$ while aldosterone tended to be lower in the Gly460Trp group as compared to the Gly460Gly group after the high sodium diet $(p=0.064)$.

Using regression analysis with the order of the sodium diets as an independent factor, the changes in SBP and MAP were greater when subjects changed from the high to the low sodium diet as compared to the change from the low to the high sodium diet: $7.4(95 \% \mathrm{Cl}: 4.5-10.4)$ vs. $2.2(-0.9-5.2) \mathrm{mmHg}(p=0.016)$ for SBP and $5.5(3.4-7.6)$ vs. $0.8(-1.3-3.0) \mathrm{mmHg}(p=0.003)$ for MAP. Therefore, analyses for the mean changes in blood pressure, neurohormones, and 24-hour urinary sodium excretion per genotype group of $\alpha$-adducin were adjusted for the order of the sodium diets, by entering the period effect (low to high sodium diet and high to low sodium diet) into the linear regression model (Tables 8.2). With this adjustment the change in DBP appeared to be significantly smaller in subjects with the Trp460Trp genotype as compared to those with the Gly460Gly genotype ( $\triangle \mathrm{DBP}-3.9 \mathrm{mmHg}(95 \% \mathrm{Cl}:-7.9-0.2)$ vs. $2.6 \mathrm{mmHg}(0.6-4.5) ; p=0.005)$. Differences in the changes in SBP and MAP between these genotype groups were on the border of statistical significance: $\triangle$ SBP $-1.0 \mathrm{mmHg}(95 \% \mathrm{Cl}:-7.6-5.5)$ vs. $6.1 \mathrm{mmHg}(3.0-9.2 ; \mathrm{p}=0.052)$ and $\triangle$ MAP $-1.1 \mathrm{mmHg}(-6.0-3.7)$ vs. $4.0 \mathrm{mmHg}(1.8-6.2 ; p=0.058)$ when the Trp460Trp group is contrasted with the Gly460Gly group. There was no difference in the behavior of heart rate between the three genotype groups and the same was true for the changes in neurohormones (Table 8.3). Changes in urinary sodium excretion, when going from one to the other diet, were greater in subjects with the Gly460Gly genotype as compared to subjects homozygous for the 460Trp allele ( $p=0.041$; Table 8.3).

Because there was a large splay in sodium excretion after the low sodium diet as well as after the high sodium diet, we plotted the changes in 24-hour urinary sodium excretion against changes in blood pressure, and neurohormonal values. The results of these analyses are shown in Figures 8.1 and 8.2. The regression slopes for SBP were not different between the three genotype groups, indicating that SPB responded similarly to alterations in sodium intake in the three groups. The regression slopes for DBP, on the other hand, differed significantly between the Trp460Trp genotype and the Gly460Gly group (ANCOVA, interaction $p=0.006$ ). While the regression slopes do not differ from zero in the Gly460Gly and the Gly460Trp group, it does so in the Trp460Trp group. In other words, in the latter group DBP rises with increased sodium intake while it does not in the other two groups. As far as the hormonal changes are concerned, the three genotype groups had comparable regression 
slopes for APRC, meaning that there was equal suppression of renin in these groups. Although the same was true for aldosterone levels, there was a tendency towards greater suppression in the Trp460Trp group. For ANP, on the other hand, we found a clear interaction between the change in 24-hour urinary sodium excretion and the $\alpha$-adducin polymorphism, in the sense that the regression slope for individuals with the Trp460Trp genotype was steeper compared to those in the Gly460Gly group (ANCOVA, interaction $p=0.027$ ) and the Gly460Trp group (ANCOVA, interaction $p=0.013$ ). Thus, for any given increase in urinary sodium excretion, ANP rose more profoundly in the Trp460Trp group than in the other groups.

Table 8.2 Linear regression analyses: changes in blood pressure in relation to the $\alpha$-adducin Gly460Trp polymorphism.

\begin{tabular}{|c|c|c|}
\hline Determinants in the model & $\begin{array}{c}\text { Univariate analysis } \\
\text { Unstandardized } \beta(95 \% \mathrm{Cl})\end{array}$ & $\begin{array}{c}\text { Multivariate analysis } \\
\text { Unstandardized } \beta(95 \% \mathrm{Cl}\end{array}$ \\
\hline \multicolumn{3}{|l|}{$\triangle S B P$} \\
\hline Intercept & $4.8(2.7-6.9)^{b}$ & $6.1(3.0-9.2)^{b}$ \\
\hline Period effect & $2.6(0.5-4.8)^{b}$ & $2.6(0.5-4.7)^{b}$ \\
\hline ADD1 Gly460Trpa & & $-1.3(-5.8-3.1)$ \\
\hline ADD1 Trp460Trp & & $-7.2(-14.4-0.5)$ \\
\hline \multicolumn{3}{|l|}{$\triangle D B P$} \\
\hline Intercept & $1.8(0.4-3.1)^{b}$ & $2.6(0.6-4.5)^{b}$ \\
\hline Period effect & $1.3(-0.7-2.6)$ & $1.2(-0.6-2.6)$ \\
\hline ADD1 Gly460Trpa & & $-0.3(-3.1-2.4)$ \\
\hline ADD1 Trp460Trp ${ }^{a}$ & & $-6.4(-10.9-(-2.0))^{b}$ \\
\hline \multicolumn{3}{|l|}{$\triangle M A P$} \\
\hline Intercept & $3.1(1.6-4.7)^{b}$ & $4.0(1.8-6.2)^{b}$ \\
\hline Period effect & $2.3(0.8-3.8)^{b}$ & $2.3(0.8-3.8)^{b}$ \\
\hline ADD1 Gly460Trp ${ }^{a}$ & & $-0.9(-4.1-2.2)$ \\
\hline ADD1 Trp460Trpa & & $-5.2(-10.5-0.2)$ \\
\hline
\end{tabular}

Table 8.3 Changes in neurohormones and urinary sodium excretion per genotype group.

$\begin{array}{lccc} & \text { Gly460Gly } & \text { Gly460Trp } & \text { Trp460Trp } \\ \triangle \text { APRC, } \mu \mathrm{U} / \mathrm{ml} & 4.2(1.9-6.4) & 4.3(2.0-6.6) & 2.9(-2.0-7.8) \\ \Delta \text { aldosterone, pmol/l } & 55(31-78) & 40(16-64) & 35(-19-89) \\ \Delta \text { ANP, pg/ml } & 15.1(5.5-24.7) & 10.9(1.1-20.7) & 20.8(-1.4-42.9) \\ \Delta \mathrm{U}_{\mathrm{Na}} \mathrm{V}, \mathrm{mmol} / 24 \mathrm{~h} & 113(93-134) & 100(80-120) & 65(23-106)^{\mathrm{a}}\end{array}$

Data are presented as means with $95 \%$ confidence intervals. APRC, active plasma renin concentration; $A N P$, atrial natriuretic peptide; $U_{\mathrm{Na}} \mathrm{V}, 24$-hour urinary sodium excretion. The analyses are adjusted for the order of the sodium diets. ${ }^{a} p<0.05$ compared with Gly $460 \mathrm{Gly}$ 

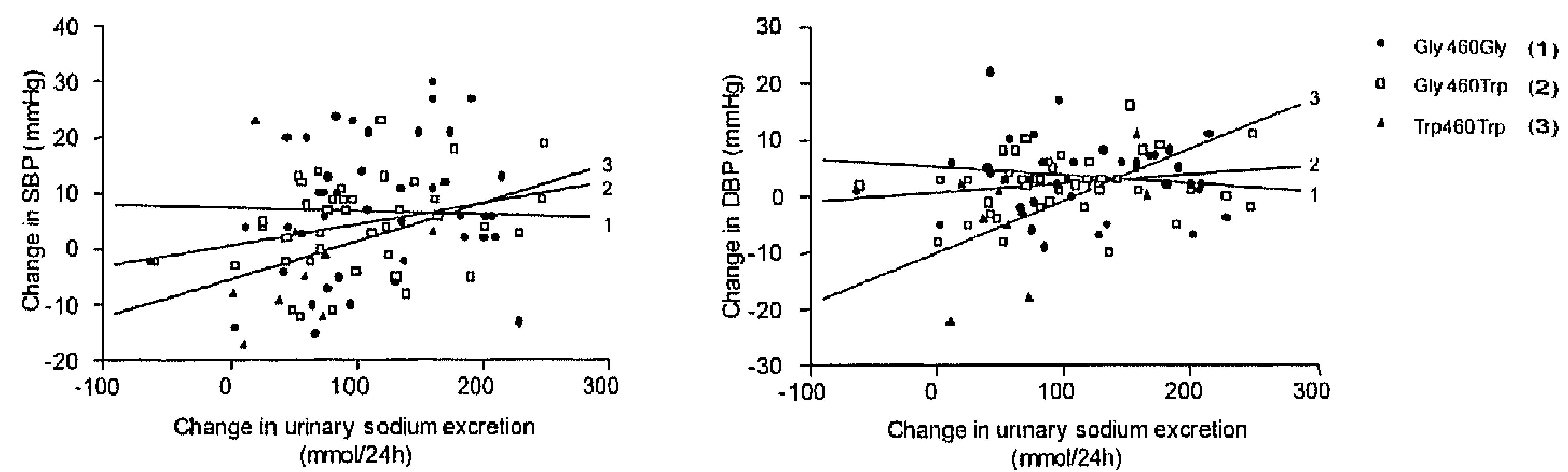

Figure 8.1 Relationship between changes in blood pressure and changes in urinary sodium by genotype group of the $\alpha$-adducin Gly460Trp polymorphism after dietary sodium loading. For DBP the regression slope of the Trp460Trp group was different from the Gly460Gly group (ANCOVA, $p=0.006$ ).
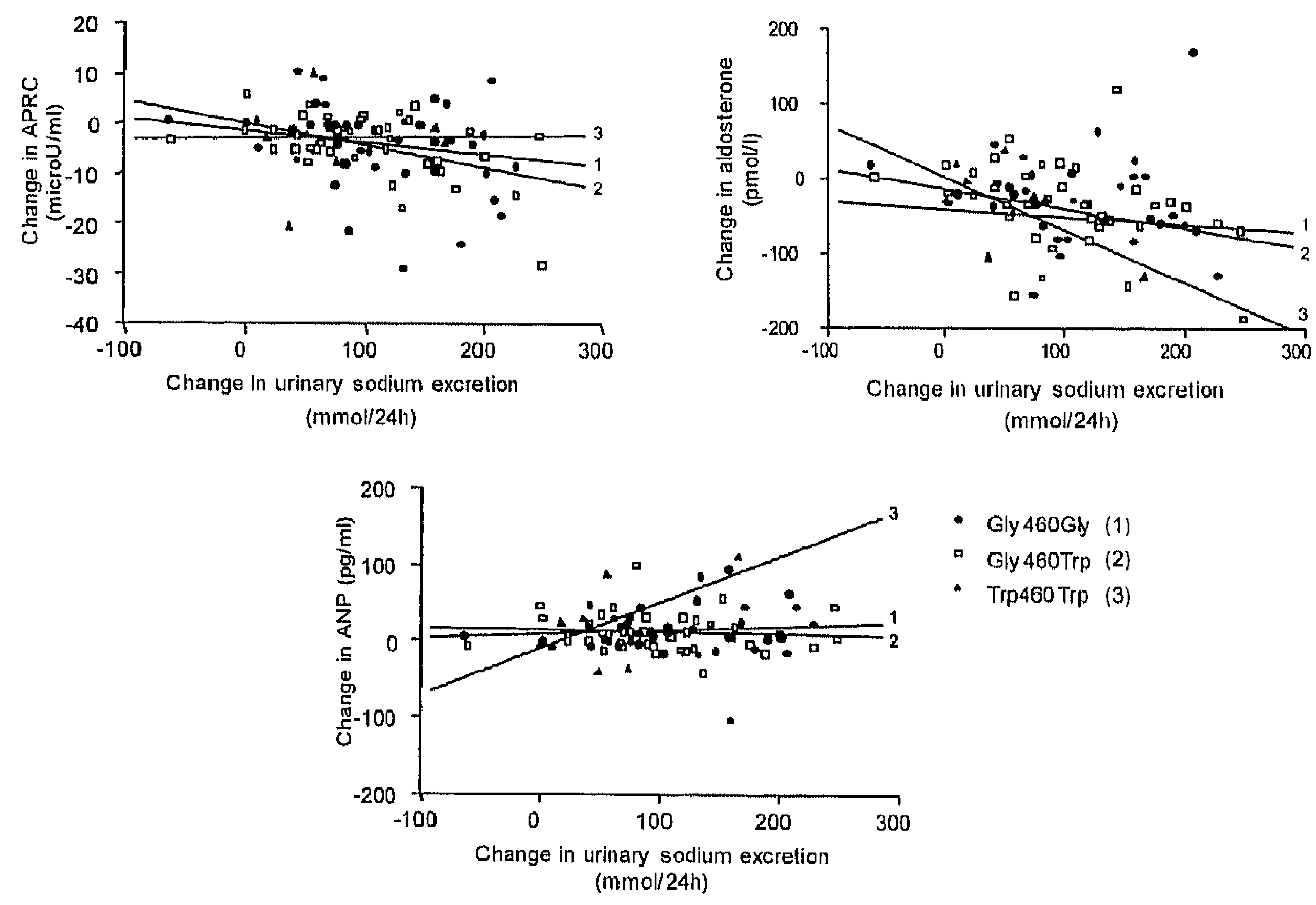

Figure 8.2 Relationship between changes in neurohormones and changes in urinary sodium by genotype group of the $\alpha$-adducin Gly460Trp polymorphism after dietary sodium loading. For ANP the regression slope of the Trp460Trp genotype was different from the Gly460Gly group (ANCOVA, $p=0.027$ ) and the Gly460Trp group (ANCOVA. $p=0.013$ ). 


\section{Discussion}

The present study shows that the responses of blood pressure and neurohormones to one week of sodium loading differs between subjects with different variants of the $\alpha$-adducin Gly460Trp polymorphism. In this respect, it is noteworthy that despite their higher blood pressure, hypertensives behaved similarly as the normotensives. This allowed us to analyze the data from the normotensives and the hypertensives together. As a corollary, our conclusions are valid for a broad range of blood pressure values.

We noticed that the sequence of the diets was of importance for the observed effects of the diet on blood pressure. While this forced us to adapt our statistical analysis, the same fact also illustrates that physiological responses to changes in dietary sodium intake may be dependent on the prevailing salt consumption. As far as the influence of the $\alpha$-adducin genotype is concerned, we found that 460 Gly allele carriers experienced a rise in blood pressure with sodium loading, while in subjects with the Trp460Trp genotype blood pressure did not change or even fell. However, only the difference in DBP responses was statistically significant between these two groups. Moreover, the fact that, on average, DBP fell in the Trp460Trp group is a bit misleading when one considers the magnitude of the changes in urinary sodium excretion. Indeed, when we plotted the alterations in DBP against the changes in urinary sodium output, we found a positive relationship (from a change in sodium excretion greater than $120 \mathrm{mmol} /$ day).

During salt loading neural and endocrine systems show adaptive responses to maintain homeostasis of body fluid volumes and blood pressure. These adaptive responses include suppression of the renin-angiotensin-aldosterone system $^{17.18}$, and stimulation of natriuretic peptides [19]. In our study, changes in neurohormones did not appear to be different between the three genotype groups when only group means or medians were considered. However, when related to the changes in 24-hour urinary sodium excretion we found a potentiated rise in ANP with increasing sodium intake in subjects with the Trp460Trp genotype. This suggests that these individuals were relatively volume overloaded or had at least a greater effective circulating volume than the others. If this is true (but we do not have other supporting evidence), then the enhanced stimulation of ANP in Trp460Trp subjects could be important in counteracting a salt-induced elevation of blood pressure.

In the total group, the difference in 24-hour urinary sodium excretion between the two dietary periods is less (102 mmol/day) than the expected change of $165 \mathrm{mmol} / \mathrm{day}$. Subjects with the Trp460Trp genotype had a significant lower 24 -hour sodium excretion than Gly460Gly homozygotes. When we assume that these subjects were in dietary balance, the Trp460Trp genotype could be associated with lower sodium intake. In experimental animal models of volume- 
expanded hypertension, lesions inflicted to brain areas regulating thirst, vasopressin secretion, and sodium homeostasis prevent the increase in blood pressure $^{20}$. It is possible that volume-expansion, which may be associated with a mutated $\alpha$-adducin gene $e^{21,22}$, also induces changes in salt appetite.

Since the Trp460Trp genotype is rather uncommon, all subjects carrying the 460Trp allele are usually taken together in analyses. However, we considered the three genotypes separately to obtain more extensive information about the different variants of the $\alpha$-adducin gene polymorphism ${ }^{23}$. As a result, the number of subjects homozygous for the 460Trp allele is relatively small, which is a limitation of our study.

In conclusion, Trp460Trp subjects show a greater rise in ANP following a dietary sodium load possibly as a homeostatic mechanism to prevent an excessive rise in blood pressure. 


\section{References}

1. Luft FC, Weinberger $\mathrm{MH}$. Heterogeneous responses to changes in dietary salt intake: the salt-sensitivity paradigm. Am J Clin Nutr 1997;65:612S-617S.

2. Overlack A, Ruppert $M$, Kolloch R, Gobel B, Kraft K, Diehl J, Schmitt W, Stumpe KO. Divergent hemodynamic and hormonal responses to varying salt intake in normotensive subjects. Hypertension 1993; 22:331-338.

3. Weinberger MH. Salt sensitive human hypertension. Endocr Res 1991;17:43-51.

4. Luft FC, Miller JZ, Weinberger MH, Christian JC, Skrabal F. Genetic influences on the response to dietary salt reduction, acute salt loading, or salt depletion in humans. J Cardiovasc Pharmacol 1988;12 Suppl 3:S49-55.

5. Sullivan JM. Salt sensitivity. Definition, conception, methodology, and long-term issues. Hypertension 1991;17:161-68.

6. Beeks $E$, Kessels $A G$, Kroon AA, van der Klauw MM, de Leeuw PW. Genetic predisposition to salt-sensitivity: a systematic review. J Hypertens 2004;22:1243-1249.

7. Barlassina C, Schork NJ, Manunta P, Citterio L, Sciarrone M, Lanella G, Bianchi G, Cusi D. Synergistic effect of alpha-adducin and ACE genes causes blood pressure changes with body sodium and volume expansion. Kidney Int 2000;57:1083-1090.

8. Cusi D, Barlassina C, Azzani T, Casari G, Citterio L, Devoto M, Glorioso N, Lanzani C, Manunta P, Righetti M, Rivera R, Stella P, Troffa C, Zagato L, Bianchi G. Polymorphisms of alpha-adducin and salt sensitivity in patients with essential hypertension. Lancet 1997;349: 1353-1357.

9. Manunta $P$, Cusi $D$, Barlassina $C$, Righetti $M$, Lanzani C, D'Amico M, Buzzi L, Citterio L, Stella $P$, Rivera $R$, Bianchi $G$. Alpha-adducin polymorphisms and renal sodium handling in essential hypertensive patients. Kidney Int 1998;53:1471-1478.

10. Ishimitsu $T$, Minami J, Nishikimi $T$, Kawano $Y$, Takishita $S$, Kangawa $K$, Matsuo $H$, Matsuoka $H$. Responses of natriuretic peptides to acute and chronic salt loading in normotensive and hypertensive subjects. Hypertens Res 1998;21:15-22.

11. Lavrijssen $A T$, Kroon AA, Fuss-Lejeune $M$, Schiffers $P M$, de Leeuw PW. Renal haemodynamics and sodium excretory capacity during urapidil treatment in patients with essential hypertension. J Hypertens 2000;18:963-969.

12. Beeks E, van der Klauw MM, Kroon AA, Spiering W, Fuss-Lejeune MJ, de Leeuw PW. Alphaadducin Gly460Trp polymorphism and renal hemodynamics in essential hypertension. Hypertension 2004;44:419-423.

13. Spiering $W$, Kroon AA, Fuss-Lejeune MM, Daemen MJ, de LeeuW PW. Angiotensin If sensitivity is associated with the angiotensin II type 1 receptor $A(1166) C$ polymorphism in essential hypertensives on a high sodium diet. Hypertension 2000;36:411-416.

14. Kato N, Sugiyama T, Nabika T, Morita H, Kurihara H, Yazaki Y, Yamori Y. Lack of association between the $\alpha$-adducin locus and essential hypertension in the Japanese population. Hypertension 1998;31:730-733.

15. Rust $S$, Funke H, Assmann G. Mutagenically separated PCR (MS-PCR): a highly specific one step procedure for easy mutation detection. Nucleic Acids Res 1993;21:3623-3629.

16. Beeks $E$, Janssen RG, Kroon AA, Keulen ET, Geurts JM, de Leeuw PW, de Bruin TW. Association between the alpha-adducin Gly460Trp polymorphism and systolic blood pressure in familial combined hyperlipidemia. Am J Hypertens 2001;14:1185-1190.

17. Kawasaki T, Delea CS, Bartter FC, Smith H. The effect of high-sodium and low-sodium intakes on blood pressure and other related variables in human subjects with idiopathic hypertension. Am J Med 1978;64:193-198.

18. Fujita $T$, Henry WL, Bartter FC, Lake CR, Delea CS. Factors influencing blood pressure in salt-sensitive patients with hypertension. Am J Med 1980;69:334-344.

19. Kohno M, Yasunari K, Murakawa K, Kanayama Y, Matsuura T, Takeda T. Effects of highsodium and low-sodium intake on circulating atrial natriuretic peptides in salt-sensitive patients with systemic hypertension. Am J Cardiol 1987;59:1212-1213. 
Chapter 8

20. Brody MJ, Fink GD, Buggy J, Haywood JR, Gordon FJ, Johnson AK. The role of the anteroventral third ventricle (AV3V) region in experimental hypertension. Circ Res 1978;43 (Suppl 1):3-13.

21. Manunta $P$, Cusi $D$, Barlassina $C$, Righetti $M$, Lanzani $C$, D'Amico $M$, Buzzi L, Citterio L, Stella $\mathrm{P}$, Rivera R, Bianchi $G$. Alpha-adducin polymorphisms and renal sodium handling in essential hypertensive patients. Kidney Int 1998;53:1471-1478.

22. Manunta $P$, Burnier M, D'Amico $M$, Buzzi L, Maillard $M$, Barlassina $C$, Lanella G, Cusi $D$, Bianchi G. Adducin polymorphism affects renal proximal tubule reabsorption in hypertension. Hypertension 1999; 33:694-697.

23. Beeks $E$, Van Der Klauw MM, Kroon AA, Spiering W, Fuss-Lejeune MJ, De Leeuw PW. Alpha-adducin Gly460Trp polymorphism and renal hemodynamics in essential hypertension. Hypertension 2004;44:419-423. 


\section{Chapter 9}

General discussion

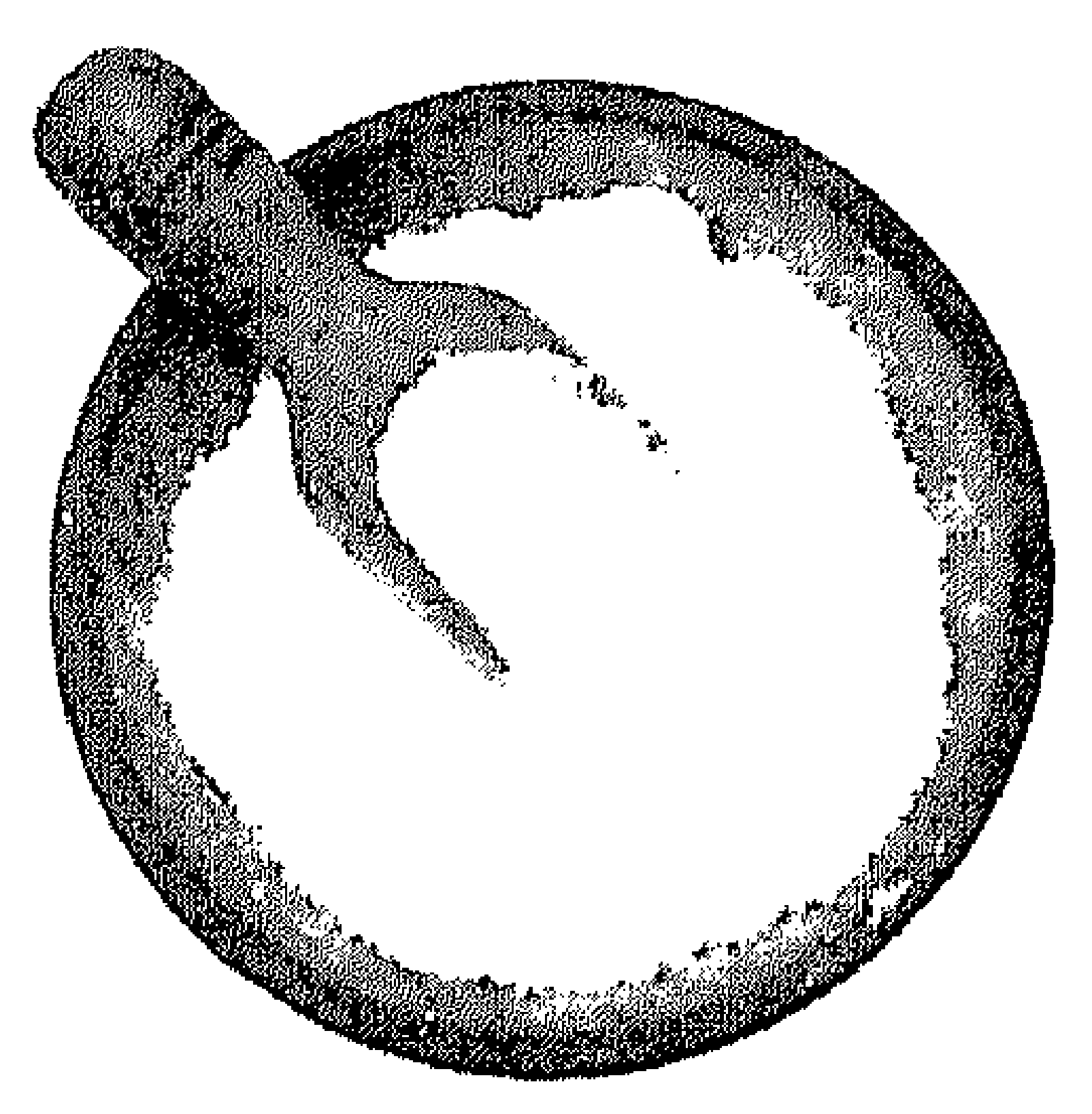




\section{General discussion}

\section{The role of the kidney in hypertension}

The current paradigm on the pathogenesis of hypertension dictates that an elevated blood pressure cannot persist unless there is some renal abmormatiny Obviously, in cases of renal or renovascular hypertension there 㷎站te doubt that renal mechanisms are primarily responsible for a rise in blood pressiure But also in essential hypertension the role of the kidney as a prme mover cannot be negated. Probably, this holds true for salt-sensitive hypertension in particular. It is not surprising, therefore, that the kidney has been the sutyect of many studies on the pathophysiology of hypertension. For mary decades renal hemodynamics, i.e. renal plasma flow (RPF) and glomerular fitration tate (GFR), were thought to be of major importance from the point of vew that (relative) renal ischemia would initiate a series of events ultmately causing hypertension. Indeed, it was clear from a very early stage that in uncomplicated hypertension RPF is usually reduced while GFR is maintained or at most. slightly reduced'. Several cross-sectional studies have shown that RPF falts with age in both normotensives and hypertensives but at a faster pace in the latter ${ }^{2.3}$. These observations certainly lend support for the hypothesis that some degree of renal underperfusion is germane for high blood pressure to occur or to be maintained. However, cross-sectional studies may be biased as far as selection of patients is concerned. In our laboratory, we were lucky enough to be able to study renal hemodynamics longitudinally, over a time span of nearly 25 years. By sheer coincidence. we did not find any difference in blood pressure after this follow-up period. Nevertheless. RPF and GFR had fallen by $25 \%$ and $15 \%$ respectively while renal vascular resistance (RVR) had increased. Regression analyses showed that older age and a higher RPF at baseline were associated with a greater fall in RPF over tume. Like renal flow. the fall in GFR was determined mainly by age and baseline GFR. When the fall in RPF of our hypertensive group is compared to the fall in RPF in a normotensive group (longitudinal study design) ${ }^{4}$, the fall in RPF per year seems to be similar in these two groups. In other words, in hypertensive patients who apparently have been adequately treated for a long time, renal perfusion stith falls progressively. Given the stability of blood pressure over time, the present data allow us to conclude that the age-related decline in renal perfusion is probably related to an increase in RVR with age. The latter may result from structural and/or functional alterations in the renal vascular bed Our results are compatible with Folkow's hypothesis ${ }^{6}$ that structural changes in resistance vessels will lead to progressive deterioration of regional blood flow. Eventuatly. such structural alterations may lead to nephrosclerosis. 
Chapter 9

Whilst reductions in RPF and GFR in itself may not be sufficient to raise blood pressure. these changes could alter renal function in such a way that hypertension will ensue. In this respect, one is inclined to think of either the renin-angiotensin-aldosterone system (RAAS) or of intrarenal regulation of sodium balance as potential mediators. Our longitudinal study revealed that both renin and aldosterone significantly fall with age and that these changes were independent from alterations in renal blood flow or renal vascular resistance. Although we were unable to detect why renin and aldosterone are progressively suppressed, a challenging hypothesis is that this is a compensatory mechanism to counteract a greater sodium-dependency of blood pressure. Unfortunately, the patients who participated in our follow-up study had had no extensive assessment of volume status at baseline and, therefore, we refrained from additional studies at this time. Nevertheless, we may conclude that both renal hemodynamics and sodium regulatory mechanisms are a worthwhile target in studies on the pathophysiology of essential hypertension. In view of the recent interest in genetic polymorphisms underlying variations in many physiological functions, a short overview of the potential impact of such polymorphisms is in order.

\section{Genetic polymorphisms and renal function}

Many genetic polymorphisms have been related to impaired renal function. Regarding the polymorphisms of the renin-angiotensin-aldosterone system, there are conflicting data with respect to the angiotensin II type 1 receptor polymorphism (AT1R A1166C) and the angiotensin converting enzyme polymorphism (ACE I/D). A study performed by our research group showed that the AT1R $C$ allele was independently associated with reduced renal plasma flow and glomerular filtration rate (Spiering, thesis 2004). In line with these results, Miller et al. showed that the combined AC/CC genotype group had a lower RPF and GFR compared to AA subjects'. However, this was not confirmed by another study ${ }^{8}$. As far as the ACE I/D polymorphism is concerned, neither of the three genotypes was associated with impaired renal function $^{9.10}$ and the same is true with respect to the aldosterone synthase (CYP11B2 C-344T) polymorphism ${ }^{10}$. However, while none of these polymorphisms may be able to affect renal function by themselves (e.g. because their effect is compensated for by other mechanisms), they could do so when they occur in specific combinations or in the presence of other risk factors.

\section{Genetic polymorphisms and salt sensitivity}

Although many studies have been performed on the association between genetic polymorphisms and hypertension per se, far less is known about such 
associations with the degree of sodium sensitivity of blood pressure. Polymorphisms in genes related to cellular sodium transport ( $\alpha$-adducin, $G$ protein $\beta 3$ subunit (GNB3) and epithelial $\mathrm{Na}^{+}$channel), the renin-angiotensinaldosterone system (ACE, angiotensinogen, AT1R and aldosterone synthase CYP11B2) or steroid hormones like 11 $\beta$-hydroxysteroid dehydrogenase type 2 are thought to be of prime interest in salt-sensitive hypertension. A difficulty in summarizing the literature on this subject is the heterogeneity in sodium sensitivity testing, and the different definitions of sodium sensitivity. In an attempt to clarify this issue we conducted a systematic review on the association between genetic polymorphisms and salt sensitivity of blood pressure. Contrary to our expectations, the variants of the AT1R gene and the $-344 \mathrm{C} / \mathrm{T}$ variant of the aldosterone synthase gene appear not to be associated with a sodium-sensitive phenotype. Conflicting results have been found with respect to the GNB3 C825T polymorphism, the ACE I/D polymorphism, the angiotensinogen M235T polymorphism, and a polymorphism in the $11 \beta$-hydroxysteroid dehydrogenase type 2 gene. We found that of all polymorphisms studied, the 460Trp variant of the $\alpha$-adducin polymorphism is probably the only one which is most consistently related to a sodium-sensitive form of hypertension. After sodium loading (dietary or intravenous infusion, with or without furosemide administration), the response of blood pressure to
sodium seems to be the greatest in subjects carrying the 460Trp allele ${ }^{11-14}$. In addition, when hypertensive patients are treated with diuretics, subjects with the 460Trp allele show the largest fall in blood pressure ${ }^{15,16}$. In view of the lack of standardization in salt sensitivity testing, however, firm conclusions cannot be drawn at this moment. Therefore, it is mandatory that uniformity in study design will be developed for these type of studies.

One should bear in mind, that most data on the $\alpha$-adducin polymorphism and blood pressure have been generated by the research group of Bianchi and coworkers in Milan. Others could not always replicate the association between the mutated gene and (volume-dependent) hypertension. One explanation may be that the mutation itself is not sufficient to produce a sodium-sensitive form of hypertension and that a second abnormality is necessary to allow the hemodynamic changes to develop. With this in mind, we studied whether the $\alpha$-adducin polymorphism would have any effect on blood pressure in patients with familial combined hyperlipidemia, a condition which is associated with a tendency to sodium sensitivity.

The $\alpha$-adducin polymorphism and familial combined hyperlipidemia (FCHL)

About five years ago, Allayee and coworkers described a genome scan which identified a locus that contributed to systolic blood pressure (SBP) in families 
with $\mathrm{FCHL}^{17}$. The quantitative trait locus was found on chromosome 4 (LOD score of 3.9), which contains the $\alpha$-adducin gene. Therefore, we set up a study in which we investigated the effect of the 460Trp allele of the $\alpha$-adducin Gly460Trp polymorphism on SBP in a group of patients with FCHL. The u-adducin Gly460Trp polymorphism showed a significant association with FCHL, with the number of subjects carrying a 460Trp allele being significantly higher in patients compared to controls. Also, the 460Trp allele of the $\alpha$-adducin polymorphism was associated with a higher SBP in patients with FCHL who were without antihypertensive therapy, but not in normal subjects. In our FCHL patients we did not find a difference in (total) cholesterol-levels between the Gly460Gly and 460Trp genotype groups, while another study showed that the increase in LDL-cholesterol was associated with the Gly460Trp genotype of the $\alpha$-adducin polymorphism ${ }^{18}$.

The possible interaction between FCHL, the $\alpha$-adducin polymorphism and blood pressure could be related to obesity, insulin resistance ${ }^{19}$ and salt sensitivity $^{20}$. Salt-sensitive essential hypertensives are relatively insulin resistant as compared to salt-resistant hypertensives, independently of confounding factors such as age, obesity and glucose tolerance. Furthermore, there is a significant correlation between salt-induced changes in blood pressure and fasting insulin levels, suggesting a relationship between hyperinsulinemia and salt sensitivity ${ }^{21}$. Hyperinsulinemia could be a key background feature to explain the expression of hypertension in FCHL and explain the observed association. Also, FCHL patients have impaired vascular function $^{22}$. In hypercholesterolemia and hypertension, impaired endothelium dependent vasodilation has been documented ${ }^{23}$. This could contribute to blood pressure elevation when sodium intake is increased ${ }^{24}$. Contrary to this, other studies suggest that patients with hypercholesterolemia who have impaired endothelial dependent relaxation remain normotensive $e^{25}$. Therefore, endothelial dysfunction which may manifest itself in decreased nitric oxide availability does not necessarily result in systemic hypertension by itself, but it may enhance the individual's sensitivity to the hypertensinogenic effect of dietary sodium ${ }^{26}$. In this theory, endothelial dysfunction could mediate, in part, the expression of higher SBP and hypertension, especially in FCHL. Since we did not measure sodium sensitivity in this part of our studies, it remains elusive whether the mutated gene had any effect on the response to sodium in this population.

\section{The $\alpha$-adducin Gly460Trp polymorphism in essential hypertension}

Turning back to essential hypertension, we may now consider the possibility that the $\alpha$-adducin polymorphism in itself does not necessarily lead to (saltsensitive) hypertension but that it is a risk factor which becomes important in the presence of another abnormality. This may be FCHL as described above 
but it could also be an alteration in the pathophysiological make-up of the patient. It could even be that the genetic abnormality induces a change in renal function in such a way that the kidney becomes the major driver of the increase in blood pressure. Therefore, we focused our further studies on the relationship between the $\alpha$-adducin polymorphism and kidney function. As a first step, we assessed the impact of the 460Trp allele of the $\alpha$-adducin gene on renal hemodynamics and glomerular filtration in hypertensive patients during different sodium diets. Results of this study showed that the Trp460Trp variant is significantly associated with impaired renal hemodynamics and glomerular filtration. On a low sodium diet, effective renal plasma flow (ERPF) and GFR were lower in patients homozygous for the 460Trp allele compared with patients with the Gly460Gly genotype. Regression analysis showed that apart from the known determinants of renal hemodynamics like age and mean arterial pressure, the Trp460Trp genotype is an independent factor determining ERPF. Besides age, the Trp460Trp genotype is also an independent factor determining GFR. Even though a tiny impairment in renal hemodynamics may not be sufficient to explain (salt-sensitive) hypertension (see above), these observations could mean that the 460Trp allele of the $\alpha$-adducin Gly460Trp polymorphism is able to 'sensitize' the cardiovascular system by its vascular effect on the kidney. Under those circumstances, perhaps a minor additional abnormality is enough to set into motion the mechanisms which will ultimately produce hypertension.

The $\alpha$-adducin protein stimulates cellular sodium transport in the renal tubules. Thus, except for modifying blood pressure through an effect on renal hemodynamics, the 460Trp variant of the $\alpha$-adducin gene may increase blood pressure through stimulation of sodium reabsorption in the kidney and chronic expansion of the circulating fluid volume $e^{12,15,27}$. This may not only influence large muscular arteries ${ }^{28}$, but also directly or indirectly lead to changes in renal glomerular or tubular structure and function.

Following an increase in dietary sodium, several mechanism are activated to limit renal retention of sodium. These include stimulation of natriuretic peptides and suppression of the RAAS. Conversely, the RAAS is stimulated and natriuretic peptides suppressed when the body faces a reduction in sodium load. Interestingly, atrial natriuretic peptide (ANP) levels were significantly higher in the Trp460Trp group as compared to the others on both a low and a normal-to-high sodium intake. These elevated levels of ANP in the Trp460Trp genotype group could point to a mechanism counteracting the tendency to retain more sodium. In that regard, the increase in ANP could be viewed upon as a compensatory mechanism to increase postglomerular resistance and hydrostatic pressure in the glomerular capillaries ${ }^{29}$. If this supposition is correct, it would mean that patients with the Trp460Trp genotype are in a constant state 
of volume overload. This makes it even more interesting to evaluate how these patients deal with acute or chronic sodium loading. However, if one considers studying the pathophysiological significance of sodium loading and its bearing on the degree of sodium sensitivity of blood pressure, the first question which arises is what protocol should be used. Because it is difficult enough to find an answer to this question we decided to perform a separate study in which we compared two different protocols of sodium challenge.

\section{Comparison of sodium loading protocols}

Many different forms of sodium sensitivity protocols exist. These can be divided in two main groups, dietary sodium intervention and intravenous saline infusion protocols. The sodium sensitivity protocol of Weinberger has been widely used to assess sodium sensitivity ${ }^{30}$. This protocol uses an isotonic $(0.9 \%)$ saline infusion of 2 I over 4 hours and furosemide administration (orally, $3 \times 40 \mathrm{mg}$ ) the day after the infusion. Some investigators have adapted the Weinberger protocol $^{12,31}$ but there is no consensus as to what is the best one. To assess the effects of an acute intravenous sodium load, we chose to infuse a hypertonic saline solution ( $300 \mathrm{ml}$ in 30 minutes) because with this procedure more of the administered volume will remain within the intravascular space, thereby creating a strong hemodynamic stimulus within a short period of time. This is certainly different from infusion with an isotonic saline solution where a large part of the volume will rapidly 'leak' into the interstitium.

Although there is some controversy about the effect of a reduction in sodium intake on blood pressure, there is substantial evidence that, on average, sodium reduction leads to a fall in blood pressure ${ }^{32,33}$. Also with respect to dietary sodium challenges, protocols differ widely in the literature and there is no consensus about the optimal approach. In our studies, we decided to evaluate the responses to dietary sodium by alternating a low sodium diet of $55 \mathrm{mmol} \mathrm{Na} /$ day with a high sodium diet of $220 \mathrm{mmol} \mathrm{Na}^{+} /$day, each given for a one-week period and in randomized order. Previous studies have shown that heterogeneity in outcome exists when saline infusion with furosemide administration is compared with dietary sodium loading ${ }^{34-37}$. When we compared the effects of a hypertonic saline infusion protocol and dietary sodium intervention we found that although the mean difference in SBP of the two sodium loading tests is close to zero, there was considerable lack of agreement between these two tests due to wide variations in the results. This finding together with the observation that neurohormonal changes differ between the two techniques, illustrates that the two methods of sodium loading do not elicit similar responses. Differences in regulatory systems involved in the blood pressure response between the rapid saline infusion and the more physiologic dietary intervention could be responsible for these discrepancies. 
For this reason, we decided to use both the acute and the chronic sodium challenge to evaluate the impact of the $\alpha$-adducin Gly460Trp polymorphism on the pathophysiological adaptation to such stimuli.

\section{The $\alpha$-adducin Gly460Trp polymorphism and the response to sodium loading}

To test whether the 460Trp variant of $\alpha$-adducin plays a role in sodium handling, we subjected a group of hypertensive patients and normotensive controls to two sodium loading tests. First, we evaluated the responses to two sodium diets (a low sodium diet of $55 \mathrm{mmol} \mathrm{Na}^{+} /$day and a high sodium diet of $220 \mathrm{mmol} \mathrm{Na}^{+} /$day, in randomized order) in relation to the $\alpha$-adducin Gly460Trp polymorphism. The responses of SBP and neurohormones were similar for the three genotype groups of $\alpha$-adducin. However, subjects with the Trp460Trp genotype showed a decrease of diastolic blood pressure (DBP) with increased sodium intake as compared to subjects carrying the $460 \mathrm{Gly}$ allele. This is remarkable because we expected to find a rise in blood pressure in patients with the mutated allele. Because the change in blood pressure after a change in sodium (dietary or infusion) is usually given in MAP, we cannot compare the finding regarding DBP with other studies. From a pathophysiological point of view it is important to note that Trp460Trp subjects showed a greater rise in ANP (a salt-losing hormone) as compared to the 460Gly allele carriers, possibly because these subjects are already more volume overloaded than the others.

After hypertonic saline infusion, changes in SBP and DBP were not different between the three genotype groups of $\alpha$-adducin. All three groups showed an increase in SBP. Like the dietary sodium loading test, DBP seemed to fall after infusion in the Trp460Trp group, but this was not significantly different from subjects with the Gly460Gly and Gly460Trp genotype. The rise in ANP and natriuresis was greater in subjects with the Trp460Trp genotype than in the $460 \mathrm{Gly}$ allele carriers after saline infusion. The enhanced stimulation of ANP and natriuresis in Trp460Trp subjects after this more drastic increase in salt load and after the more chronic dietary sodium loading could be a necessary compensatory mechanism to excrete the excess of sodium in an attempt to normalize blood pressure.

It is important to note that our studies included intermediate phenotypes, such as changes in renal hemodynamics, neurohormones and natriuresis, and in this respect differed from many others which focused on more distal endpoints like blood pressure ${ }^{38,39}$ or hypertension ${ }^{40,41}$. By taking intermediate phenotypes, we thought to be better able to tell which mechanisms are involved in the relation between the $\alpha$-adducin gene and sodium-dependent changes in blood 
pressure. Another issue which is frequently overlooked concerns the question whether there exists an allele-dose effect. Due to the fact that patients homozygous for the 460Trp allele are rare in most Caucasian populations, the Gly460Trp and Trp460Trp genotypes are usually combined to find an effect of this polymorphism on outcome parameters like blood pressure. This implicitly suggests that the 460Trp allele is dominant. However, we failed to find differences in blood pressure responses between patients heterogeneous for the 460Trp allele and patients carrying both mutated alleles. But when the association between renal hemodynamics and the $\alpha$-adducin Gly460Trp polymorphism was investigated, we found that patients homozygous for the 460Trp allele are actually different from patients carrying the Gly460Trp genotype. Thus, the $460 \mathrm{Gly}$ allele seems to be the dominant one regarding renal hemodynamics. This could be an explanation why some studies failed to show an association between genetic polymorphisms and certain outcome measures.

\section{Clinical implications and future research}

Eventually, the clinical impact of genetic variants like the $\alpha$-adducin Gly460Trp polymorphism either alone or in combination with other relevant polymorphisms is determined by their potential to guide treatment decisions. A few studies have addressed the effect of the 460Trp allele of the $\alpha$-adducin polymorphism on blood pressure decline after diuretic treatment ${ }^{12,15,16,42}$. For instance, thiazide diuretics inhibit the apical $\mathrm{NaCl}$ cotransporter found mainly in the early distal tubule. The level of blood pressure achieved during thiazide therapy is the net effect of the antihypertensive action of the drug on the one hand and the activation of several physiological counter-regulatory mechanisms which tend to stabilize blood pressure and extracellular volume on the other. The major effect of diuretics appears to be due to direct vasodilation and/or reduced peripheral resistance secondary to diuresis and natriuresis ${ }^{43,44}$. Because the $460 T r p$ allele of the $\alpha$-adducin gene is associated with renal sodium retention and a salt-sensitive form of hypertension, patients carrying this variant could potentially benefit from diuretic therapy. Indeed, there is data to show that the decrease in mean arterial pressure after two months of treatment with hydrochlorothiazide (HCT) is greater in patients carrying the 460Trp allele as compared with patients homozygous for the $460 \mathrm{Gly}$ allele ${ }^{12,15,16}$. In contrast with these findings reported in Italian subjects, there was no association between the 460Trp allele and the magnitude of the blood pressure response to HCT in a sample of African-Americans and non-Hispanic white Americans of European descent $t^{42}$. Regarding the effect of the $\alpha$-adducin gene on target organs, such as the heart or brain, diuretic therapy was associated with a lower 
risk of combined myocardial infarction and stroke than other antihypertensive therapies in carriers of the 460Trp allele ${ }^{45}$.

Although further prospective studies are necessary to firmly establish whether or not diuretic therapy is to be preferred in patients with the mutated $\alpha$-adducin gene, these initial data certainly form a promising basis.

Ouabain and adducin enhance the Na-K pump function and play an important role in sodium homeostasis and blood pressure regulation in both humans and rats $^{46-48}$. Ouabain is a high-affinity, reversible, and specific inhibitor of the sodium pump, with ionotropic and vasopressor activity ${ }^{49,50}$. It is not yet clear which mechanism is involved in the pressor effect of ouabain, but according to Blaustein's hypothesis, both a renal defect in sodium handling and a high level of ouabain must be present to induce a rise in peripheral vascular resistance and blood pressure ${ }^{51}$. The 460Trp allele of the $\alpha$-adducin gene is associated with enhanced renal tubular sodium reabsorption and a salt-sensitive rise in blood pressure, and carriers of the 460Trp allele of the $\alpha$-adducin gene have higher plasma ouabain levels than Gly460Gly homozygotes ${ }^{52}$.

A digitoxigenin derivate, PST2238, is a new antihypertensive agent able to selectively antagonize both the endogenous ouabain (EO) and adducin pressor effects. It can displace ouabain from Na-K ATPase in vitro, does not have an effect on receptors involved in blood pressure and hormonal regulation, antagonizes the pressor effect of ouabain in vivo and normalizes ouabaindependent hyperactivation of the Na-K pump both in cultured cells and in vivo $^{48}$. In rats, PST2238 reduced the development of hypertension and normalized renal Na-K ATPase activity and expression in Milan Hypertensive Strain (MHS) rats when given orally at very low doses ${ }^{53}$. In hypertensive patients, PST2238 given for 3 months at $0.5 \mathrm{mg} /$ day, significantly reduced blood pressure in subjects with moderate salt intake, implying that it may be selectively effective in conditions where EO plays a pressor role. The polymorphisms of genes coding for adducin and enzymes involved in EO synthesis seem to influence PST2238 efficacy ${ }^{54}$. Although the pressor effect of adducin is not so clear in our Dutch hypertensive population as compared to the Italian subjects, it is possible that these patients could benefit from treatment with this new antihypertensive agent PST2238.

The long-term goal of research in the area of pharmacogenomics is to help clinicians to individualize treatment in their patients and to select drug therapies that maximizes effectiveness. If the $\alpha$-adducin $460 \operatorname{Trp}$ variant is, indeed, able to identify a subset of hypertensive patients who are particularly likely to benefit from diuretic therapy or other antihypertensive agents like PST2238, it is reasonable to evaluate whether screening hypertensive patients for selected genetic polymorphisms is indicated. Furthermore, it will be interesting to find 
Chapter 9

out if patients with the Trp460Trp genotype group respond differently to treatment with 'non-diuretic' agents such as ACE inhibitors or other antihypertensive drugs capable of lowering renal vascular resistance than patients with the Gly460Gly genotype. Since only a few studies have been performed in this field so far, other studies are urgently needed to either confirm or dismiss the importance of the $\alpha$-adducin gene and its variants. 


\section{References}

1. Birkenhäger $\mathrm{WH}$, Schalekamp MADH. Control mechanisms in essential hypertension. Amsterdam: Elsevier Scientific Publishing Company 1976.

2. London GM, Safar ME, Sassard JE, Levenson JA, Simon AC. Renal and systemic hemodynamics in sustained essential hypertension. Hypertension 1984; 6:743-754.

3. Schmieder RE, Schachinger $H$, Messerli FH. Accelerated decline in renal perfusion with aging in essential hypertension. Hypertension 1994; 23:351-357.

4. Siewert-Delle A, Ljungman $S$, Hartford $M$, Wikstrand J. Effect of 14 years of antihypertensive treatment on renal function and urinary albumin excretion in primary hypertension. $A m J$ Hypertens 1996; 9:841-849.

5. Epstein M. Aging and the kidney. J Am Soc Nephrol 1996; 7:1106-1122.

6. Folkow B. The debate on the amplifier hypothesis' - some comments. J Hypertens 2000: 18:375-378.

7. Miller JA, Thai $K$, Scholey JW. Angiotensin II type 1 receptor gene polymorphism predicts response to losartan and angiotensin II. Kidney Int 1999; 56:2173-2180.

8. Hilgers KF, Langenfeld MR, Schlaich M, Veelken R, Schmieder RE. 1166 AVC polymorphism of the angiotensin II type 1 receptor gene and the response to short-term infusion of angiotensin II. Circulation 1999; 100:1394-1399.

9. Fernández-Llama P, Poch E, Oriola J, Botey A, Coll E, Darnell A, Rivera F, Revert L. Angiotensin converting enzyme gene I/D polymorphism in essential hypertension and nephroangiosclerosis. Kidney Int 1998; 53:1743-1747.

10. Wang JG, Staessen JA, Tizzoni L, Brand E, Birkenhager WH, Fagard R, Herrmann SM, Bianchi G. Renal function in relation to three candidate genes. Am J Kidney Dis 2001; 38:1158-1168.

11. Barlassina C, Schork NJ, Manunta P, Citterio L, Sciarrone M, Lanella G, Bianchi G, Cusi D. Synergistic effect of alpha-adducin and ACE genes causes blood pressure changes with body sodium and volume expansion. Kidney Int 2000; 57:1083-1090.

12. Cusi D, Barlassina $C$, Azzani $T$, Casari $G$, Citterio $L$, Devoto $M$, Glorioso $N$, Lanzani $C$, Manunta P, Righetti M, Rivera R, Stella P, Troffa C, Zagato L, Bianchi G. Polymorphisms of alpha-adducin and salt sensitivity in patients with essential hypertension. Lancet 1997: 349:1353-1357.

13. Grant FD, Romero JR, Jeunemaitre $X$, Hunt SC, Hopkins PN, Hollenberg NH, Williams GH. Low-renin hypertension, altered sodium homeostasis, and an alpha-adducin polymorphism. Hypertension 2002; 39:191-196.

14. Manunta $P$, Cusi $D$, Barlassina $C$, Righetti $M$, Lanzani $C$, D'Amico $M$, Buzzi L, Citterio L. Stella $P$, Rivera R, Bianchi $G$. Alpha-adducin polymorphisms and renal sodium handling in essential hypertensive patients. Kidney Int 1998; 53:1471-1478.

15. Glorioso N, Manunta P, Filigheddu F, Troffa C, Stella P, Barlassina C, Lombardi C, Soro A, Dettori F, Parpaglia PP, Alibrandi MT, Cusi D, Bianchi G. The role of alpha-adducin polymorphism in blood pressure and sodium handling regulation may not be excluded by a negative association study. Hypertension 1999; 34:649-654

16. Sciarrone MT, Stella $P$, Barlassina $C$, Manunta $P$, Lanzani $C$, Bianchi G, Cusi D. ACE and alpha-adducin polymorphism as markers of individual response to diuretic therapy Hypertension 2003; 41:398-403.

17. Allayee $H$, de Bruin TW, Michelle Dominguez K, Cheng LS, Ipp E, Cantor RM, Krass KL, Keulen ET, Aouizerat BE, Lusis AJ, Rotter JI. Genome scan for blood pressure in Dutch dyslipidemic families reveals linkage to a locus on chromosome 4p. Hypertension 2001; 38:773-778.

18. Castejon AM, Alfieri AB, Hoffmann IS, Rathinaveiu A, Cubeddu LX. Alpha-adducin polymorphism, salt sensitivity, nitric oxide excretion, and cardiovascular risk factors in normotensive Hispanics. Am J Hypertens 2003; 16:1018-1024. 
19 Meigs JB. D'Agostino RB. Sr., Wilson PW, Cupples LA. Nathan DM, Singer DE. Risk variable clustering in the insulin resistance syndrome. The Framingham Offspring Study. Diabetes 1997: 46:1594-1600.

20. Rocchini AP, Key J, Bondie D. Chico R. Moorehead C. Katch V, Martin M. The effect of weight loss on the sensitivity of blood pressure to sodium in obese adolescents. $N$ Engl J Med 1989; 321:580-585.

21 Sharma AM. Schorr U. Salt sensitivity and insulin resistance: Is there a link? Blood Press Supp/1996; 1:59.63.

22 Stroes $E$, de Bruin T, de Valk H. Erkelens W. Banga JD, van Rijn H, Koomans H, Rabelink T. NO activity in familial combined hyperlipidemia: potential role of cholesterol remnants. Cardiovasc Res 1997; 36:445-452.

23. John S. Schmieder RE. Impaired endothelial function in arterial hypertension and hypercholesterolemia: potential mechanisms and differences. J Hypertens 2000; 18:363-374.

24. Miyoshi A. Suzuki H. Fujiwara M. Masai M. Iwasaki T. Impairment of endothelial function in salt-sensitive hypertension in humans. Am J Hypertens 1997; 10:1083-1090.

25 Chowienczyk PJ, Watts GF, Cockcroft JR, Ritter JM. Impaired endothelium-dependent vasodilation of forearm resistance vessels in hypercholesterolaemia. Lancet 1992; 340: 1430-1432.

26 Hayakawa H. Raij L. Relationship between hypercholesterolaemia, endothelial dysfunction and hypertension. J Hypertens 1999; 17:611-619.

27. Staessen JA. Wang JG, Brand E. Barlassina C, Birkenhager WH, Herrmann SM, Fagard R, Tizzoni L. Bianchi $G$. Effects of three candidate genes on prevalence and incidence of hypertension in a Caucasian population. J Hypertens 2001; 19:1349-1358.

28. Balkestein EJ. Wang JG. Struijker-Boudier HA, Barlassina C, Bianchi G, Birkenhager WH, Brand E, Den Hond E, Fagard R. Herrmann SM, Van Bortel LM, Staessen JA. Carotid and femoral intima-media thickness in relation to three candidate genes in a Caucasian population. J Hypertens 2002; 20:1551-1561.

29. Brenner BM. Ballermann BJ, Gunning ME, Zeidel ML. Diverse biological actions of atrial natriuretic peptide. Physiol Rev 1990; 70:665-699.

30. Weinberger MH. Miller JZ, Luft FC, Grim CE. Fineberg NS. Definitions and characteristics of sodium sensitivity and blood pressure resistance. Hypertension 1986; 8:I1127-134.

31. Kato N, Kanda T, Sagara M, Bos A, Moriguchi EH, Moriguchi Y, Yamori Y. Proposition of a feasible protocol to evaluate salt sensitivity in a population-based setting. Hypertens Res 2002; 25:801-809

32. Stamler J. The INTERSALT Study: background, methods, findings, and implications. $A m \mathrm{~J}$ Clin Nutr 1997; 65:626S-642S.

33. Vollmer WM, Sacks FM, Ard J, Appel LJ, Bray GA, Simons-Morton DG, Conlin PR, Svetkey LP. Erlinger TP, Moore TJ, Karanja N; DASH-Sodium Trial Collaborative Research Group. Effects of diet and sodium intake on blood pressure: subgroup analysis of the DASH-sodium trial. Ann Intern Med 2001; 135:1019-1028

34. de la Sierra A, Giner V, Bragulat E, Coca A. Lack of correlation between two methods for the assessment of salt sensitivity in essential hypertension. J Hum Hypertens 2002; 16:255-260.

35. Galletti F, Ferrara I, Stinga F, lacone R, Noviello F, Strazzullo P. Evaluation of a rapid protocol for the assessment of salt sensitivity against the blood pressure response to dietary sodium chloride restriction. Am J Hypertens 1997; 10:462-466.

36. Sharma AM, Schorr U, Cetto C, Distler A. Dietary $v$ intravenous salt loading for the assessment of salt sensitivity in normotensive men. Am J Hypertens 1994; 7:1070-1075.

37. Weinberger MH, Stegner JE. Fineberg NS. A comparison of two tests for the assessment of blood pressure responses to sodium. Am J Hypertens 1993; 6:179-184.

38. Ciechanowicz A, Widecka K, Drozd R, Adler G, Cyrylowski L, Czekalski S. Lack of association between Gly460Trp polymorphism of alpha-adducin gene and salt sensitivity of blood pressure in Polish hypertensives. Kidney Blood Press Res 2001; 24:201-206.

39. Kato N, Sugiyama T, Nabika T, Morita H, Kurihara H, Yazaki Y, Yamori Y. Lack of association between the $x$-adducin locus and essential hypertension in the Japanese population. Hypertension 1998; 31:730-733 
40. Melander O, Bengtsson K, Orho-Melander M, Lindblad U, Forsblom C, Rastam L, Groop L. Hulthen UL. Role of the Gly460Trp polymorphism of the alpha-adducin gene in primary hypertension in Scandinavians. J Hum Hypertens 2000; 14:43-46.

41. Wang WYS, Adams DJ, Glenn CL, Morris BJ. The Gly460Trp variant of $u$-adducin is not associated with hypertension in white Anglo-Australians. Am J Hypertens 1999; 12:632-636

42. Turner ST, Chapman AB, Schwartz GL, Boerwinkle E. Effects of endothelial nitric oxide synthase, alpha-adducin, and other candidate gene polymorphisms on blood pressure response to hydrochlorothiazide. Am J Hypertens 2003; 16:834-839.

43. Lant A. Diuretics. Clinical pharmacology and therapeutic use (Part II). Drugs 1985;29 162-188.

44. Man in 't Veld AJ, Van der Meiracker AH. Effects of antihypertensive drugs on cardiovascular hemodynamics. In: Laragh JH, Brenner BM. Hypertension: Pathophysiology, Diagnosis and Management. New York: Raven Press, Ltd; 1995:2753-2763.

45. Psaty BM, Smith NL, Heckbert SR, Vos HL, Lemaitre RN, Reiner AP, Siscovick DS, Bis J. Lumley $T$, Longstreth $W T J r$, Rosendaal FR. Diuretic therapy, the alpha-adducin gene variant. and the risk of myocardial infarction or stroke in persons with treated hypertension. Jama 2002; 287:1680-1689.

46. Aperia A. Regulation of sodium/potassium ATPase activity: impact on salt balance and vascular contractility. Curr Hypertens Rep 2001; 3:165-171.

47. Ferrandi M, Salardi S, Tripodi G, Barassi P, Rivera R, Manunta P, Goldshleger R, Ferrari $P$. Bianchi $\mathrm{G}$, Karlish SJ. Evidence for an interaction between adducin and $\mathrm{Na}(+)-\mathrm{K}(+)-\mathrm{ATP}$ ase relation to genetic hypertension. Am J Physiol 1999; 277:H1338-1349.

48. Ferrari $P$, Torielli $L$, Ferrandi $M$, Padoani $G$, Duzzi L, Florio M, Conti F, Melloni $P$, Vesci L, Corsico N, Bianchi G. PST2238: a new antihypertensive compound that antagonizes the long-term pressor effect of ouabain. J Pharmacol Exp Ther 1998; 285:83-94.

49. Bova S, Blaustein MP, Ludens JH, Harris DW, DuCharme DW, Hamlyn JM. Effects of an endogenous ouabainlike compound on heart and aorta. Hypertension 1991; 17:944-950.

50. Hamlyn JM, Blaustein MP, Bova S, DuCharme DW, Harris DW, Mandel F, et al. Identification and characterization of a ouabain-like compound from human plasma. Proc Natl Acad Sci U $S$ A 1991; 88:6259-6263.

51. Blaustein MP. Sodium ions, calcium lons, blood pressure regulation, and hypertension: a reassessment and a hypothesis. Am J Physiol 1977; 232:C165-173.

52. Wang JG, Staessen JA, Messaggio E, Nawrot T, Fagard R, Hamlyn JM, Bianchi G, Manunta $P$. Salt, endogenous ouabain and blood pressure interactions in the general population. $J$ Hypertens 2003; 21:1475-1481.

53. Ferrari $P$, Ferrandi $M$, Tripodi $G$, Torielli L, Padoani G, Minotti E, Melloni P, Bianchi G. PST 2238: a new antihypertensive compound that modulates Na,K-ATPase in genetic hypertension. J Pharmacol Exp Ther 1999; 288:1074-1083.

54. Ferrari $P$, Ferrandi M, Zanna $C$, Valentini G, Bianchi $G$, Lanzani $C$, et al. PST 2238, a new antihypertensive agent that selectively antagonizes the pressor effect of endogenous ouabain and adducin. Hypertension 2004; 44:570. 
0 
This thesis describes the relationship between the 460Trp allele of the a-adducin polymorphism and factors related to sodium-sensitive hypertension. Besides blood pressure, the effects of variants of the $\alpha$-adducin Gly460Trp polymorphism on renal hemodynamics, the renin-angiotensin system and atrial natriuretic peptide have been assessed. Furthermore, long-term changes in renal hemodynamics were determined, and two sodium sensitivity tests were compared.

Chapter 2 provides a systematic review on the relationships between genetic polymorphisms and salt sensitivity of blood pressure. Twenty-three studies fulfilled the inclusion criteria, and were used for this review. Because the selected studies showed substantial heterogeneity in method of salt sensitivity testing, it was not possible to pool the data. To avoid the lack of standardization in salt sensitivity testing, uniformity in study design in this type of studies should be propagated. Considering the $\alpha$-adducin polymorphism, the 460Trp variant is likely to be associated with a sodium-sensitive form of hypertension, while on the other hand the polymorphisms of the angiotensin II type 1 receptor gene and the $-344 \mathrm{C} / \mathrm{T}$ variant of the aldosterone synthase gene are not associated with such a phenotype.

The long-term changes in renal hemodynamics, glomerular filtration and neurohormones in patients with essential hypertension are described in chapter 3 . In this study, patients with uncomplicated essential hypertension were examined 24 years after their first investigation in the period 1971-1981. Blood pressure, renal hemodynamics and neurohormones had been measured at baseline and were assessed again at the follow-up visit under identical circumstances. This study indicates that in uncomplicated hypertension that has been adequately treated; untreated blood pressure may remain remarkably stable over a prolonged period of time, despite a significant decline in renal function. Furthermore, the renin system is suppressed with aging, irrespective of hemodynamic factors.

The association between the 460Trp variant of the $\alpha$-adducin Gly460Trp polymorphism and blood pressure in patients with familial combined hyperlipidemia (FCHL) features in chapter 4 . A previous study has shown that in a genome scan for $\mathrm{FCHL}$, a locus contributing to systolic blood pressure (SBP) was identified on chromosome 4, containing the $\alpha$-adducin gene. Seventy-nine patients with FCHL and 121 controls were included. The $\alpha$-adducin Gly460Trp polymorphism showed a significant association with FCHL and the number of subjects carrying a 460Trp allele was significantly higher in $\mathrm{FCHL}$ patients compared with controls. In $\mathrm{FCHL}$ patients carrying at 
least one 460Trp allele, SBP was significantly higher compared with patients homozygous for the 460 Gly allele.

Despite the fact that several studies have described an association between the 460Trp allele of the $\alpha$-adducin polymorphism and blood pressure, it is unknown whether the 460Trp allele has any effect on renal function. As the kidney plays an important role in blood pressure regulation, the effect of the $460 T r p$ allele on renal hemodynamics was investigated in chapter 5 . After a low sodium diet of $55 \mathrm{mmol}$ sodium per day, effective renal plasma flow (ERPF) and glomerular filtration rate (GFR) were lower in patients homozygous for the 460Trp allele as compared to patients with the Gly460Gly genotype. Levels of atrial natriuretic peptide (ANP) were significantly higher in patients with the Trp460Trp genotype as compared to patients with the Gly460Gly genotype. This study showed that the Trp460Trp genotype is associated with a reduced ERPF and a reduced GFR as compared to the wild-type variant.

In chapter 6, blood pressure and neurohormonal responses to two types of sodium loading tests were compared. These two tests comprised of a hypertonic saline infusion and dietary sodium intervention and were performed in both hypertensive and normotensive subjects. In the whole group, the two tests show no agreement due to large variations in blood pressure responses even though only a small mean difference in systolic blood pressure between the two types of sodium loading was found. After dietary sodium loading, changes in diastolic pressure in hypertensives were opposite to those after saline infusion. The decrease in active renin (APRC) and aldosterone were larger after the acute saline infusion than after dietary sodium loading. In general, normotensives showed greater responses in blood pressure and neurohormones than hypertensives, whereas saline infusion induced a more substantial suppression of the renin-angiotensin system. These differences should be taken into account when testing for salt sensitivity among different groups. Although about the same amount of sodium is given to the subjects in each protocol, the responses of blood pressure are different between these two methods. Different regulatory mechanisms could be involved in the blood pressure response to rapid salt loading and the more physiologic dietary intervention.

The differences between the three genotype groups of the $\alpha$-adducin Gly460Trp polymorphism to the two methods of sodium loading as described above, were evaluated in chapter 7 and 8 . When the hypertonic saline load is considered (chapter 7), the rise in systolic blood pressure was not different between the three genotype groups of $\alpha$-adducin. The increase in ANP was greater in subjects with the Trp460Trp genotype than in the 460Gly allele 
carriers, while the falls in APRC and aldosterone were similar. One and two hours after infusion, cumulative urinary sodium excretion was higher in subjects with the Trp460Trp genotype as compared to the Gly460Trp group. Therefore, subjects with the Trp460Trp genotype respond to acute saline loading with a faster excretion of sodium (hypernatriuresis), possibly mediated by an excessive rise in ANP.

Following dietary sodium loading (chapter 8), neither the changes in SBP nor those in neurohormones differed between the three genotype groups. Changes in diastolic blood pressure (DBP) after sodium loading were significantly less in subjects with the Trp460Trp compared with subjects with Gly460Gly genotypes. When DBP and ANP were plotted against 24-hour urinary sodium excretion, the regression lines of the Trp460Trp group were different from the Gly460Gly group, indicating that subjects with the Trp460Trp genotype could be more volume overloaded than the others. This could be important in counteracting a salt-induced elevation of blood pressure. 
Samenvatting

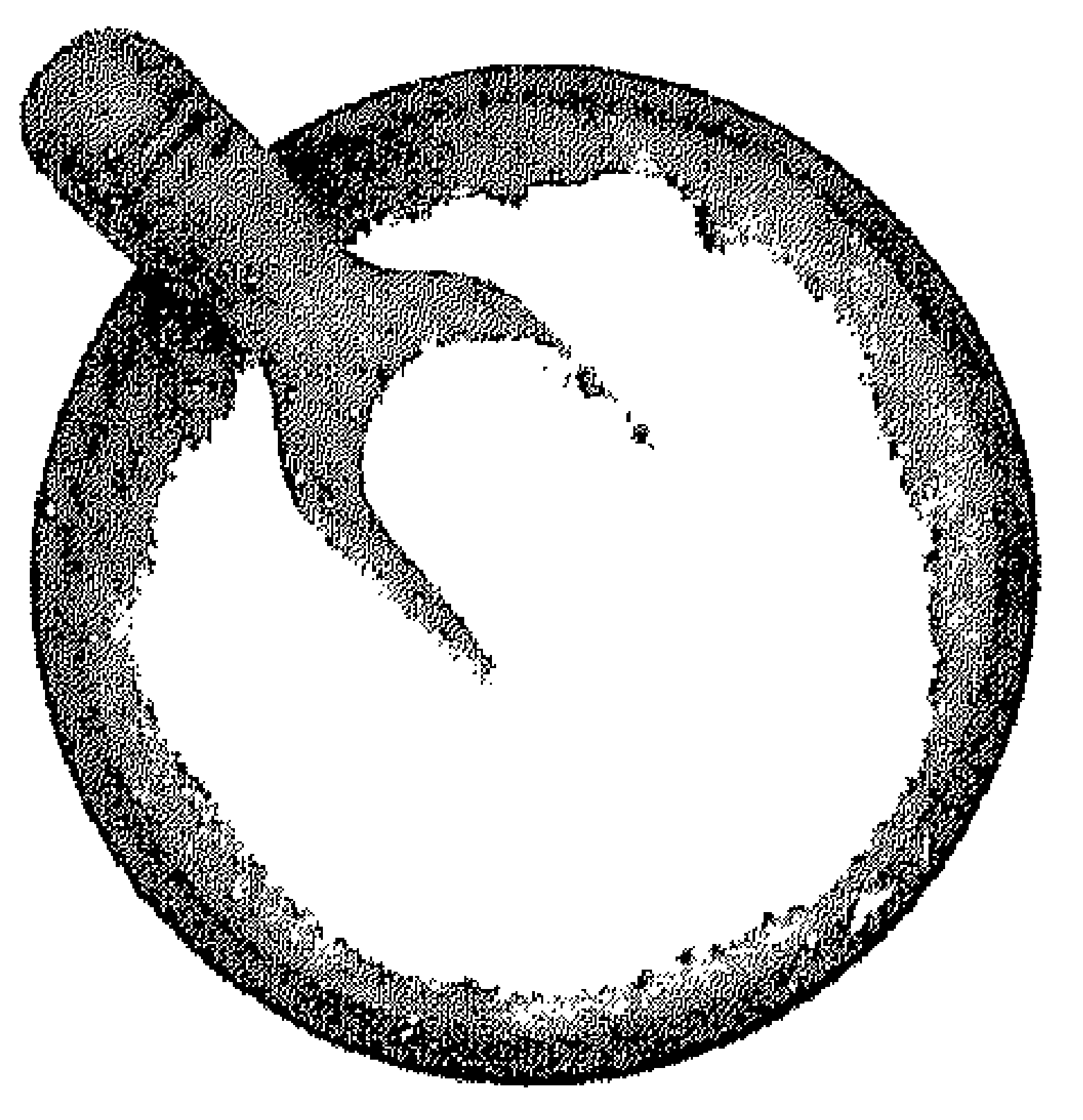


Dit proefschrift beschrijft de relatie tussen het 460Trp allel van het $a$-adducine polymorfisme en factoren die gerelateerd zijn aan zoutgevoelige hypertensie. Naast bloeddruk werden ook de effecten van varianten van het $a$-adducine polymorfisme op renale hemodynamica, het renine-angiotensine systeem en atriaal natriuretisch peptide bepaald. Verder zijn de lange termijn veranderingen van renale hemodynamica onderzocht, en werden twee testen van zoutgevoeligheid met elkaar vergeleken.

Hoofdstuk 2 bestaat uit een systematisch overzichtsartikel over de relatie tussen genetische polymorfismen en zoutgevoelige hoge bloeddruk. Drieëntwintig studies voldeden aan onze inclusiecriteria. De onderzochte studies verschilden onderling sterk met betrekking tot de methoden voor het testen van zoutgevoeligheid, hierdoor was het niet mogelijk om de gegevens samen te voegen. Uniformiteit in onderzoeksopzet is bij dit type onderzoek gewenst, zodat studies onderling vergeleken kunnen worden. Van het aadducine polymorfisme was de 460Trp variant het meest waarschijnlijk gerelateerd aan een zoutgevoelige vorm van hypertensie. Uit de gegevens van de overige studies bleek dat het polymorfisme van het angiotensine II type 1 receptor gen en de $-344 \mathrm{C} / \mathrm{T}$ variant van het aldosterone synthase gen niet gerelateerd waren met dit fenotype.

De lange termijn veranderingen in renale hemodynamica en neurohormonen worden beschreven in hoofdstuk 3 . In dit onderzoek werden patiënten met ongecompliceerde essentiële hypertensie 24 jaar na een eerste onderzoek (in de periode van 1971 tot 1981) opnieuw bestudeerd. Hierbij werden bloeddruk, renale plasma doorstroming, glomerulaire filtratiesnelheid en neurohormonen bepaald. Dit onderzoek laat zien dat in patiënten met ongecompliceerde hypertensie welke adequaat behandeld is, de onbehandelde bloeddruk beduidend stabiel is over een langere periode, ondanks een significante afname in nierfunctie. Daarnaast blijkt dat het renine systeem op oudere leeftijd onderdrukt is, ongeacht hemodynamische factoren.

De associatie tussen de 460Trp variant van het $\alpha$-adducine Gly460Trp polymorfisme en bloeddruk in patiënten met familiair gecombineerde hyperlipidemie $(\mathrm{FCH})$ is onderzocht in hoofdstuk 4 . Eerdere studies hebben in een genoom scan een locus op chromosoom 4 laten zien welke bijdraagt aan de hoogte van de systolische bloeddruk. Dit locus bevat het $\alpha$-adducine gen. In de huidige studie bleek dat het $\alpha$-adducine Gly460Trp polymorfisme geassocieerd is met $\mathrm{FCH}$, waarbij het aantal personen met het 460Trp allel significant hoger was in patiënten, vergeleken met controlepersonen. In patiënten met $\mathrm{FCH}$ die minimaal één $460 \mathrm{Trp}$ allel bezitten, was de systolische 
bloeddruk significant hoger vergeleken met patiënten die het Gly460Gly genotype bezitten.

Ondanks het feit dat verschillende onderzoekers een associatie hebben beschreven tussen het 460Trp allel van het $\alpha$-adducine polymorfisme en bloeddruk, is het onbekend of het 460Trp allel een effect heeft op de nierfunctie. Aangezien de nieren een belangrijke rol spelen bij de regulatie van de bloeddruk, is het effect van het 460Trp allel op renale hemodynamica onderzocht in hoofdstuk 5. Na een laag zout dieet van $55 \mathrm{mmol}$ natrium per dag, bleken de effectieve renale plasmastroom en de glomerulaire filtratiesnelheid lager te zijn in patiënten die homozygoot waren voor het 460Trp allel dan in degenen met het Gly460Gly genotype. Het atriaal natriuretisch peptide was significant hoger in patiënten met het Trp460Trp genotype, vergeleken met patiënten met het Gly460Gly genotype. Deze studie laat zien dat het Trp460Trp genotype geassocieerd is met een verminderde effectieve renale plasmastroom en afname in glomerulaire filtratiesnelheid, vergeleken met de wild-type variant.

In hoofdstuk 6 worden de reactie van bloeddruk en neurohormonen op twee verschillende typen van zoutbelastingstesten vergeleken. De volgende testen werden gebruikt: een hypertone zoutinfusie en een dieetinterventie. Deze testen werden uitgevoerd in zowel hypertensieve als normotensieve personen. Wanneer de groep als geheel wordt beschouwd, blijken de resultaten van de twee testen niet goed met elkaar overeen te komen, ook al was het gemiddelde verschil in systolische bloeddruk tussen de twee testen gering. $\mathrm{Na}$ zouttoediening via het dieet was de verandering in diastolische bloeddruk tegengesteld aan die na de zoutinfusie. De daling in actief renine en aldosteron waren groter na acute zoutinfusie dan na het dieet. Globaal laten de normotensieven een sterkere reactie in bloeddruk en neurohormonen zien dan hypertensieven, zoutinfusie liet een sterkere suppressie van het renineangiotensine systeem zien. Deze verschillen dienen in overweging te worden genomen wanneer men test op zoutgevoeligheid in verschillende groepen. Ondanks dat ongeveer dezelfde hoeveelheid zout is toegediend bij beide methoden, is toch de reactie van de bloeddruk verschillend. Dit kan veroorzaakt worden doordat verschillende regulatiemechanismen betrokken zijn bij een acute danwel bij een chronische en meer fysiologische zoutbelasting.

In hoofdstuk 7 en 8 worden de verschillen tussen de drie genotype groepen van het $\alpha$-adducine Gly460Trp polymorfisme onderzocht met behulp van de twee bovengenoemde methoden van zoutgevoeligheidstesten. $\mathrm{Na}$ een hypertone zoutinfusie (hoofdstuk 7) verschilt de verandering in systolische 
bloeddruk niet tussen de drie genotypen: alle groepen vertoonden een toename. $\mathrm{Na}$ zoutinfusie steeg het atriaal natriuretisch peptide sterker in personen met het Trp460Trp genotype dan in dragers van het 460Gly allel, terwijl de dalingen in actief renine en aldosteron gelijk waren tussen de drie genotype groepen. Eén en twee uren na infusie was de cumulatieve urinaire natriumuitscheiding groter in personen met het Trp460Trp genotype, vergeleken met de Gly570Trp groep. Personen met het Trp460Trp genotype laten derhalve een vorm van hypernatriurese zien, welke mogelijk veroorzaakt wordt door de sterkere toename in atriaal natriuretisch peptide.

$\mathrm{Na}$ een toename van de hoeveelheid zout in het dieet (hoofdstuk 8) zijn de veranderingen in systolische bloeddruk en neurohormonen niet verschillend tussen de drie genotype groepen. De verandering in diastolische bloeddruk is echter significant geringer in personen met het Trp40Trp genotype vergeleken met het Gly460Gly genotype. Wanneer diastolische bloeddruk of atriaal natriuretisch peptide en 24-uurs zoutexcretie in de urine tegen elkaar uit worden gezet in een grafiek, dan blijken de regressielijnen voor de Trp460Trp groep verschillend te zijn dan die van de Gly460Gly groep. Dit kan impliceren dat personen met het Trp460Trp genotype op voorhand al een groter extracellulair volume hebben dan de anderen. Dat zou een belangrijke rol kunnen spelen in het tegenwerken van een zoutgeïnduceerde verhoging van de bloeddruk. 
Dankwoord

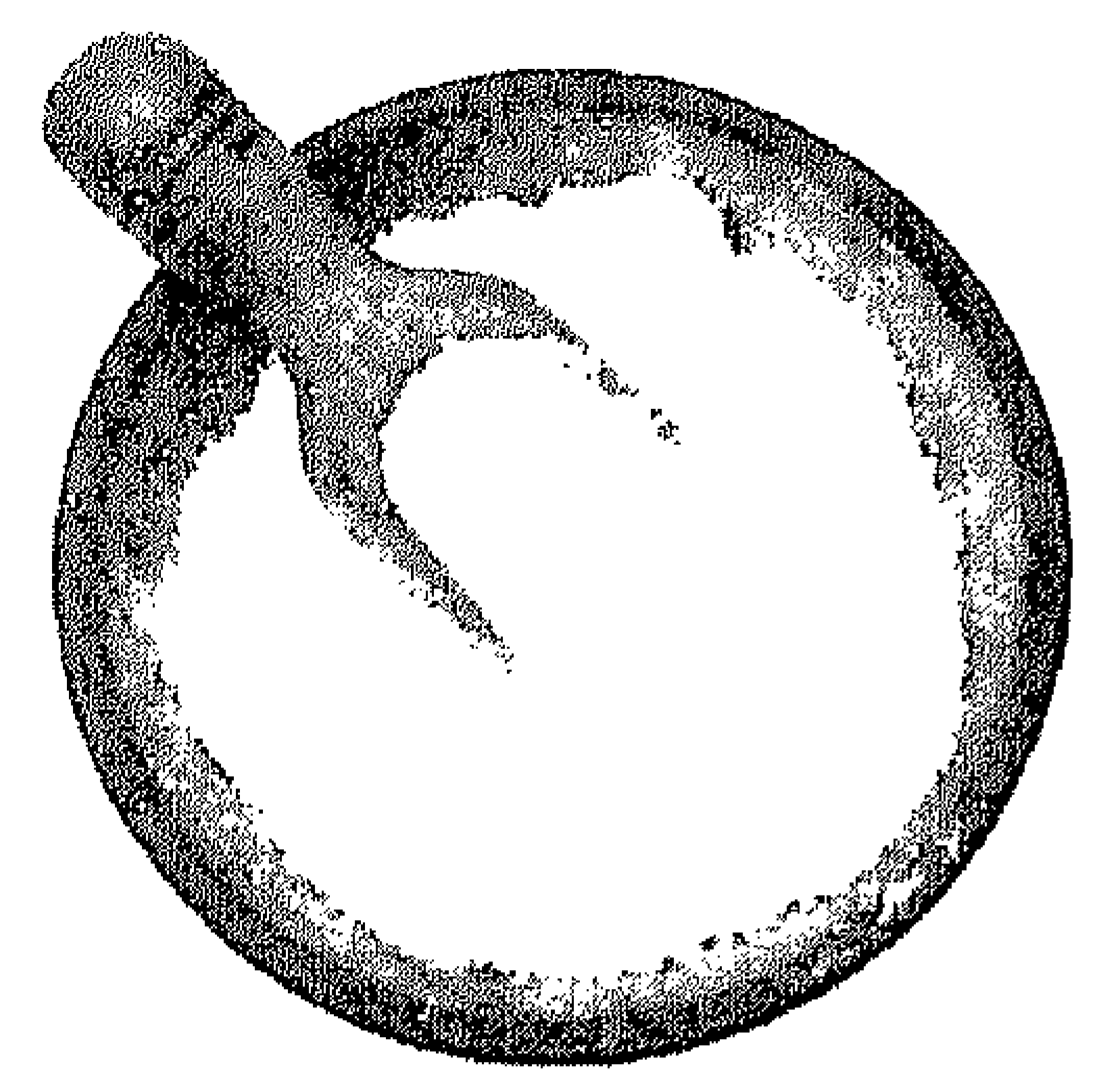


"Hoe schrijf je het dankwoord" heb ik me vaak afgevraagd... Voor mij is dit toch wel één van de lastigste hoofdstukken van het proefschrift, want dit is natuurlijk het meest gelezen hoofdstuk! Eigenlijk hoeft dit helemaal niet zo lastig te zijn. er hoeven geen methoden te worden omschreven en er zijn geen statistische analyses voor nodig. De conclusie ligt voor de hand: "ledereen die op een directe of indirecte manier bij dit werk betrokken is geweest, hartelijk dank!" Om de 'power' van dit dankwoord te vergroten, wil ik graag iedereen apart bedanken.

Allereerst wil ik alle patiënten en gezonde proefpersonen noemen. Er werd veel verwacht tijdens de studies: 3 weken diëten, 3 ochtenden op een bed in het Circulatielab doorbrengen, infusen prikken en bloed afstaan. Ik wil iedereen hierbij hartelijk danken voor hun deelname aan deze onderzoeken en hun bijdrage aan dit proefschrift.

Mijn promotor Prof. dr. P.W. de Leeuw, beste Peter, ik heb veel van je geleerd tijdens het gehele promotietraject. Dankzij jouw inzet en wetenschappelijke kennis heb ik mijn promotieonderzoek op deze wijze kunnen afronden. Enorm bedankt! Natuurlijk dienen de "schrijfweken in de Ardèche" hierbij niet vergeten te worden, deze waren goed om veel hoofdstukken van mijn proefschrift af te schrijven.

Mijn copromotoren Dr. A.A. Kroon en Dr. M.M. van der Klauw. Jullie hebben beiden een belangrijke rol gespeeld, en ik wil jullie hierbij bedanken! Beste Bram, als copromotor ben je altijd aanwezig geweest. In het voortraject heb je een belangrijke rol gespeeld, maar ook in de eindfase door mijn artikelen kritisch te bekijken. Beste Melanie, halverwege mijn promotietraject kwam jij het team versterken, en dat heeft zeker bijgedragen aan dit proefschrift. Naast je wetenschappelijke input heb ik het erg gewaardeerd dat je bij de start van de functietesten ook zelf bij de uitvoer betrokken was.

Het belangrijkste deel van mijn onderzoek speelde zich af op het Circulatielab. Claudia, Monique en Dorien wil ik erg bedanken voor hun hulp bij het praktische gedeelte van de studies, de uitvoer van de nierklaringen en zoutinfusietesten. Als er iets niet ging zoals het moest, dan hoorden jullie me altijd aan en boden jullie hulp! Het Circulatielab was niet alleen belangrijk voor het uitvoeren van de studies, maar ook voor de gezellige sfeer! Kerstdiners, het jaarlijkse dagje uit en de avondjes in de stad werden veelal vanuit het Circulatielab georganiseerd, en waren erg gezellig! Hierbij wil ik de overige collega's van het Circulatielab bedanken: Kim, Ingrid, Wilko, Boy, Léon, Marian, Marieke, Willem, Thomas, Marrigje, Sergio, Heidi, Claudia B, en in de laatste fase Daniëlle, Jolanda en Peggy. Stella, bedankt voor je hulp bij de invoer en het overzetten van de "Rotterdam-data" en voor je 'wijze adviezen', je weet vast wel wat ik bedoel! Roger Rennenberg wil ik bedanken voor het bijspringen bij het aanprikken van de infusen. 
"Hoe lay-out ik een proefschrift" heb ik me gelukkig niet hoeven af te vragen. Beste Tiny, je hebt er een prachtig boekje van gemaakt! Bedankt voor al die (late) uren die je er in gestoken hebt.

De student-assistenten Barbra Backus, Jan-Willem Beijen, Femke Mooij en Claudia Vernooij wil ik bedanken voor hun hulp bij de verschillende projecten, die zich bevonden in verschillende delen van het land, van Maastricht via Achterveld naar Rotterdam!

De afdeling Pathologie onder leiding van Prof. dr. M. Daemen wil ik bedanken voor het beschikbaar stellen van hun lab zodat ik daar de DNA bepalingen kon uitvoeren in de beginfase van het onderzoek. Paul Schiffers, Jet Bost, Michael Geurts en Daniëla Bisschops van het neurohumoraal lab (en CAGT lab) wil ik bedanken voor de bepalingen van de neurohormonen en de DNA bepalingen. De medewerkers van het Klinisch Chemisch Laboratorium. Prof. dr. B. van Kreel. Lou Habets, Lou Donselaar, Simone van Wijngaarden, Mia Meers en Armand Gubbels wil ik bedanken voor de bepalingen van de vele monsters.

Drs. ir. Fons Kessels, ik wil je graag bedanken voor je tijd en de statistische bijdrage aan het review-artikel.

Prof. dr. T. de Bruin en Rob Janssen, toen werkzaam bij het MME laboratorium van de afdeling Interne Geneeskunde, wil ik bedanken voor de prettige samenwerking bij het FCHL-artikel.

Drs. J. Ligthart en zijn team van het Medisch Centrum Rijnmond Zuid (locatie Zuider) in Rotterdam wil ik bedanken voor de hulp bij het regelen van alle praktische zaken, zodat ik in de zomer van 2001 en 2002 de follow-up nierklaringen bij de Rotterdamse populatie kon uitvoeren.

De leden van de beoordelingscommissie, Prof. dr. M. Daemen, Prof. dr. A. de Boer, Prof. dr. M. van Dieijen-Visser en Prof. dr. Y. Pinto wil ik graag bedanken voor het kritisch beoordelen van mijn proefschrift. Prof. dr. G. Bianchi, I would like to thank you for reviewing my thesis and for being present at my thesis defence.

Mijn paranimfen Iris en Kim, ik ben blij dat jullie mijn paranimfen willen zijn! Iris, we leerden elkaar kennen toen ik net was begonnen in Maastricht, en jij als student-assistent begon bij het Circulatielab. Al snel bleek dat we veel dezelfde interesses hadden, en vooral door jouw vriendschap heb ik een enorm leuke tijd in Maastricht gehad; als ik al denk aan de 'beruchte' Hemelvaartsdag in Parijs... Kim, ook door jou heb ik me erg 'thuis' gevoeld in 't zuiden. De congressen bezochten we vaak samen (denk aan Chicago!), en naast het werkgedeelte waren ze één voor één ook erg gezellig.

Lieve papa en mama, bedankt voor jullie steun tijdens alles! Al tijdens de middelbare school periode lieten jullie me vrij in het bepalen wat ik wilde gaan doen, maar wel met de achterliggende gedachte om onafhankelijk te zijn. Dit is voor mij heel belangrijk geweest in alles wat ik heb gedaan, en wat ik nu doe. 
Als laatste wil ik jou bedanken Dik. Door een toevallige ontmoeting (of juist niet?) kwamen we elkaar tegen, nu ruim een jaar geleden. Beiden met promotieperikelen... Al snel hielp je me met de "cover" van mijn boekje! lk waardeer je support enorm in deze hectische periode, en de rust die je altijd uitstraalt. Je weet niet half hoe blij ik hiermee ben. Nog even, en dan kunnen we in de zomer weer heerlijk 'ontstressen'! 
0 
Esther Beeks werd op 14 december 1972 geboren te Winterswijk. In 1992 behaalde zij het VWO diploma aan de Christelijke Scholengemeenschap te Aalten. In datzelfde jaar startte zij met de studie Biomedische Gezondheidswetenschappen aan de Katholieke Universiteit Nijmegen, met als afstudeerrichting Epidemiologie. Na een stage op de afdeling Community Medicine van het Institute of Public Health in Cambridge (UK) en een stage op de afdeling Urologie van het Academisch ziekenhuis Nijmegen werd het doctoraal examen behaald in september 1997. Hierna is zij werkzaam geweest als onderzoeker op de afdeling Research en Ontwikkeling van de St. Maartenskliniek te Nijmegen en op de afdeling Infectieziekten Epidemiologie van het Rijksinstituut voor Volksgezondheid en Milieu. In september 1998 begon zij als assistent in opleiding bij de vakgroep Interne Geneeskunde binnen het Cardiovasculair Research Instituut Maastricht onder leiding van Prof. dr. P.W. de Leeuw. Het onderzoek dat tijdens deze periode is uitgevoerd heeft geleid tot dit proefschrift. Vanaf september 2005 is zij werkzaam als Clinical Research Associate bij de firma sanofi-aventis. 